\title{
SCREENING OF BIOCONTROL ORGANISMS FOR THE MANAGEMENT OF PHYTOPATHOGENIC FUNGI AND FOODBORNE PATHOGENS ON PRODUCE
}

\author{
A Thesis \\ presented to \\ the Faculty of California Polytechnic State University, \\ San Luis Obispo
}

In Partial Fulfillment

of the Requirements for the Degree

Master of Science in Agriculture, with a specialization in Food Science and Nutrition

by

Antoinette de Senna

June 2015 
(C) 2015

Antoinette de Senna

ALL RIGHTS RESERVED 
TITLE:

AUTHOR:

DATE SUBMITTED:

COMMITTEE CHAIR:

COMMITTEE MEMBER:

COMMITTEE MEMBER:
Screening of Biocontrol Organisms for the Management of Phytopathogenic Fungi and Foodborne Pathogens on Produce

Antoinette de Senna

June 2015

Amanda Lathrop, Ph.D.

Assistant Professor of Food Science and Nutrition

Christopher Kitts, Ph.D.

Professor and Department Chair of Biological Sciences

Richard Carpenter, Ph.D.

Chief Technology Officer of BiOWiSH Technologies 


\begin{abstract}
Screening Of Biocontrol Organisms For The Management Of Phytopathogenic Fungi And Foodborne Pathogens On Produce

Antoinette de Senna
\end{abstract}

The multibillion dollar agricultural industry is an important part of the United States economy, and the management of factors that affect crop and human health is imperative to maintaining this economic sector. The fungi Botrytis cinerea, Fusarium pallidoroseum, and Fusarium moniliforme are the causative agents of several plant diseases and can cause significant crop loss both before and after harvest in commodities such as strawberries, lettuce, citrus, and grains. Fungicides are employed to control these phytopathogens, but the use of these chemicals has led to an increase in fungicide resistance and may negatively affect the environment and human health. In addition to plant pathogens, foodborne pathogens also have a substantial impact on the agricultural industry. Foodborne disease outbreaks involving Listeria monocytogenes, Salmonella, and Escherichia coli $\mathrm{O} 157: \mathrm{H} 7$ not only cause considerable economic losses, but can also result in devastating health problems for consumers. The increase in fungicide resistance and number of produce-related foodborne disease outbreaks warrants investigation into additional methods of microbial control for use in the agricultural industry. Many bacterial species, including Lactic Acid Bacteria (LAB) and Bacillus species, produce antifungal and antimicrobial compounds, thus the use of biological control agents preand postharvest could augment current methods of pathogen management. The purpose of this study was to screen 22 bacterial isolates for inhibitory activity against the fungal 
phytopathogens Botrytis cinerea, Fusarium pallidoroseum, and Fusarium moniliforme and the foodborne pathogens Listeria monocytogenes, Salmonella, and Escherichia coli O157:H7 in vitro, then evaluate antimicrobial efficacy of select isolates against the foodborne pathogens on fresh produce.

To evaluate antifungal activity, the bacterial isolates were individually spotinoculated onto Tryptic Soy Agar, Potato Dextrose Agar, or MRS agar, depending on isolate growth requirements and then a plug of fungal-colonized agar was placed onto the center of the isolate-inoculated plate. Plates were incubated at $24^{\circ} \mathrm{C}$ for 10 days; fungal growth was evaluated daily, beginning on Day 3. Nine of the 22 isolates screened inhibited all three fungi; inhibition by these isolates ranged from $51-62 \%$ for B. cinerea, 60-68\% for F. pallidoroseum, and 40-61\% for F. moniliforme. Isolates were also screened for biosurfactant activity using the drop-collapse test. Biosurfactant production was detected in seven of the nine isolates. Bacillus megaterium, Bacillus coagulans, Bacillus thuringiensis BT2 and three Bacillus amyloliquefaciens isolates demonstrated strong biosurfactant activity and suppression of all three fungi, and therefore are recommended for further study.

Antimicrobial activity of the isolates was assessed using two methods: LAB isolates were screened using a seeded-overlay method and all other isolates were evaluated by spot inoculating the isolate on pathogen-seeded TSA. Three LAB isolates and six Bacillus isolates suppressed L. monocytogenes, Salmonella, and E. coli O157:H7 in vitro. Based on the results of the screening, three LAB isolates-Lactobacillus plantarum, Pediococcus acidilactici, and Pediococcus pentosaceus — were selected for further evaluation and use in challenge studies on fresh produce. 
The role of organic acids in pathogen inhibition was evaluated by incubating $L$. monocytogenes, Salmonella, and E. coli O157:H7 cultures in the cell-free supernatant (CFS; pH 3.81-4.27) or the neutralized cell-free supernatant ( $\mathrm{pH}$ adjusted to 6.5 -7.0) of each isolate. When neutralized, the antimicrobial activity of the CFS of the three LAB isolates was greatly diminished, illustrating the role of lactic acid in the inhibition of pathogen growth.

To assess antimicrobial efficacy on Iceberg lettuce, a cocktail of the three LAB isolates (7-8 $\log \mathrm{CFU} / \mathrm{g}$ ) was sprayed onto lettuce spot-inoculated with L. monocytogenes (2-3 $\log \mathrm{CFU} / \mathrm{g}$ ); lettuce was incubated at $10^{\circ} \mathrm{C}$ for $14 \mathrm{~d}$. L. monocytogenes levels were $1.84 \log$ lower on LAB-treated lettuce than on untreated lettuce at the end of incubation. Because the LAB cocktail suppressed the growth of L. monocytogenes on lettuce, testing on fresh produce continued using DF1, which was a powdered product comprised of the three LAB isolates and media components. Because DF1 caused substantial browning of Iceberg lettuce after $2 \mathrm{~d}$, Gala apples were chosen to evaluate the antimicrobial activity of DF1 against L. monocytogenes, Salmonella, and E. coli O157:H7.

The effect of DF1 on L. monocytogenes, Salmonella, and E. coli O157:H7 on Gala apples was determined by spraying a Gala apple spot-inoculated with pathogen (6-7 $\log \mathrm{CFU} / \mathrm{plug}$ ) with approximately $3 \mathrm{~mL}$ of a $20 \% \mathrm{DF} 1$ solution, then incubating at $20^{\circ} \mathrm{C}$ for $5 \mathrm{~d}$. After $5 \mathrm{~d}$ incubation, L. monocytogenes, Salmonella, and E. coli O157:H7 levels on DF1-treated apples were approximately 4, 2, and $2 \log$ higher than the control, respectively. Based on the results of these experiments, DF1 is not the optimal formulation for the biocontrol of foodborne pathogens on fresh produce. 
This study identified several bacterial isolates with potential for use in the biocontrol of plant and foodborne pathogens. Further investigation is required to assess possible use in the agricultural industry, including characterization of bioactive compounds, optimization of biocontrol product formulation, and evaluation of the commercial viability of the biocontrol product. 


\section{ACKNOWLEDGMENTS}

I would like to thank my committee-Dr. Amanda Lathrop, Dr. Christopher Kitts, and Dr. Richard Carpenter - for their support and guidance throughout my graduate school experience. Their involvement has helped me to vastly develop myself and my technical skills in fun and unexpected ways.

I would also like to thank Margot Dittmar, Suyapa Padilla-Antunez, Evan Quigley and Tiffany Taylor for their help in and out of the lab.

I am very grateful for the financial and moral support provided by BiOWiSH Technologies. This project was partially funded by the California State University Agricultural Research Institute (CSU-ARI), for which I am also thankful.

Finally, I would like to thank my family and friends for their support and encouragement throughout this very, very long process. 


\section{TABLE OF CONTENTS}

Page

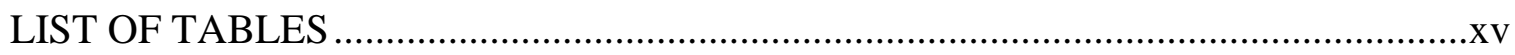

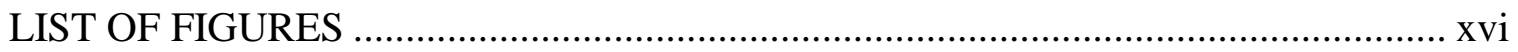

\section{CHAPTER}

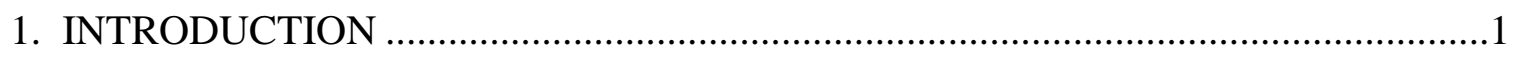

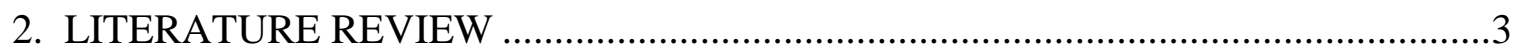

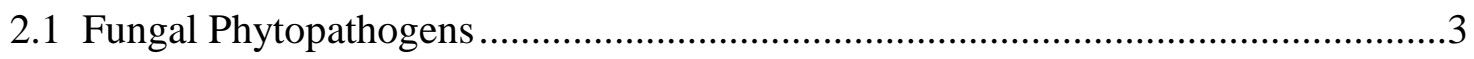

2.1.1 Economic Impact of Fungal Phytopathogens ....................................................

2.1.2 Pre-harvest Control of Phytopathogenic Fungi...................................................

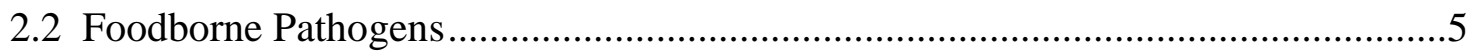

2.2.1 Foodborne Illness Outbreaks in the United States............................................

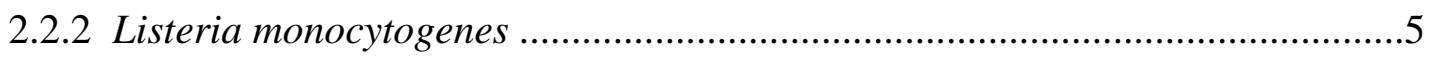

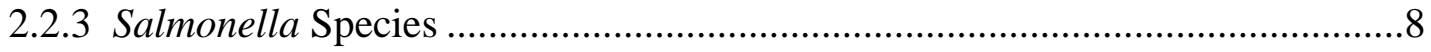

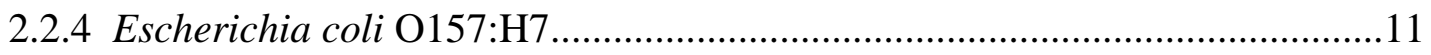

2.3 Postharvest Control of Foodborne Pathogens .........................................................12

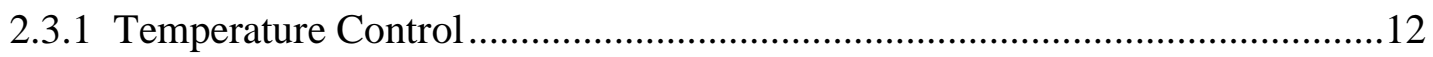

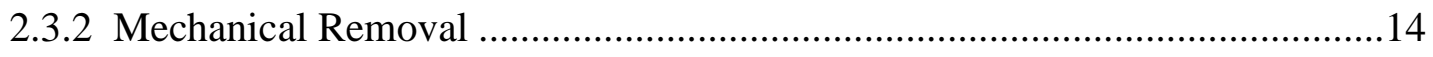

2.3.3 Chlorine

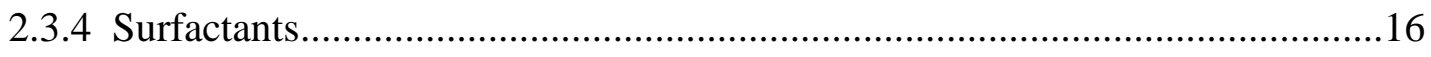

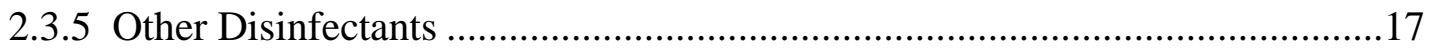

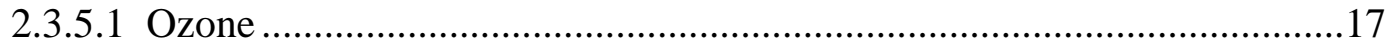

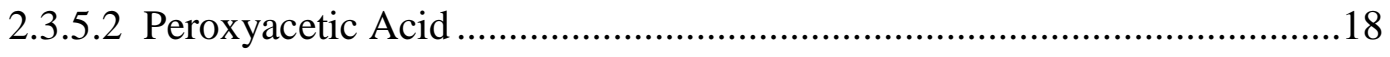

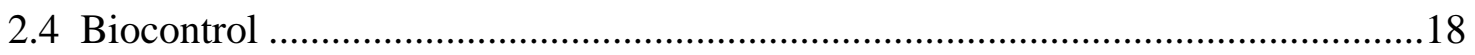

2.4.1 Antifungal and Antimicrobial Modes of Action .............................................18 


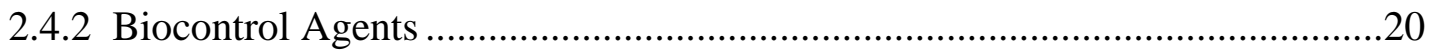

2.4.2.1 Lactic Acid Bacteria ………………………....................................20

2.4.2.1.1 Antifungal Activity on Produce …………..........................................22

2.4.2.1.2 Antimicrobial Activity on Produce ………………..............................23

2.4.2.1.2.1 Lactic Acid Bacteria Isolates on Produce.......................................23

2.4.2.1.2.2 Bacteriocins on Produce ……………………...............................24

2.4.2.2 Bacillus Species .............................................................................26

2.4.2.2.1 Antifungal Activity on Produce .............................................................29

2.4.2.2.2 Antimicrobial Activity on Produce …………………….......................30

2.4.2.3 Other Bioprotective Species ................................................................30

2.4.2.3.1 Serratia plymuthica .............................................................................30

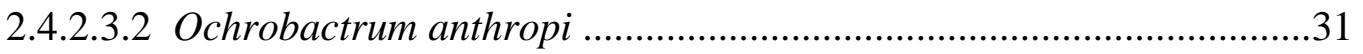

2.4.2.3.3 Oceanobacillus Species.......................................................................

2.5 Commercially Available Biocontrol Products ……………………………............32

2.5.1 Antifungal Biocontrol Products ....................................................................

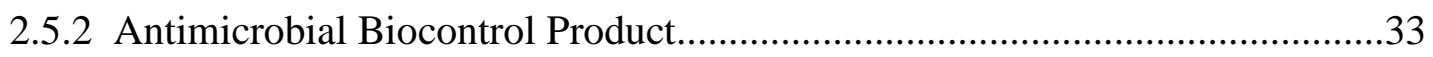

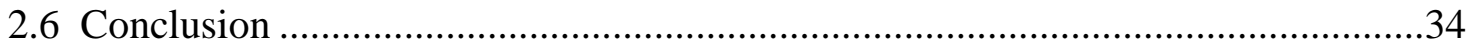

3. ANTIFUNGAL SCREENING OF BIOPROTECTIVE ISOLATES AGAINST

BOTRYTIS CINEREA, FUSARIUM PALLIDOROSEUM, AND FUSARIUM

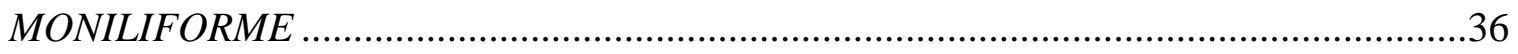

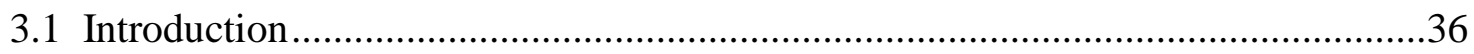

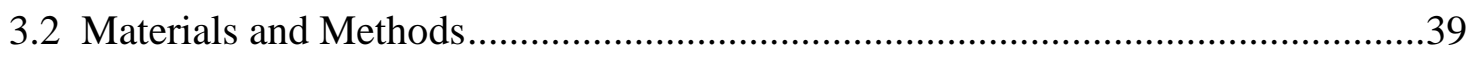

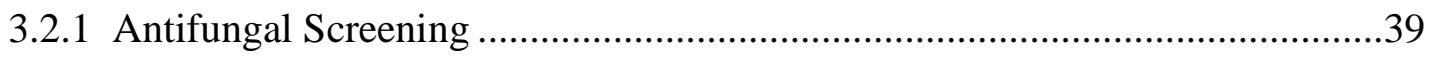

3.2.1.1 Fungal Pathogens ....................................................................................

3.2.1.2 Bioprotective Isolates..............................................................................

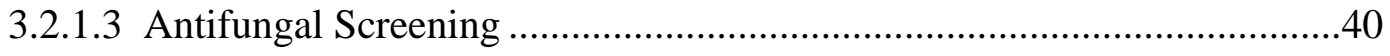




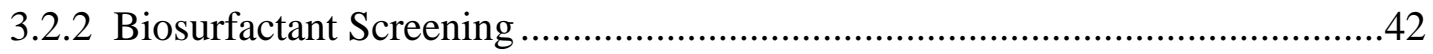

3.2.2.1 Bioprotective Isolates................................................................... 42

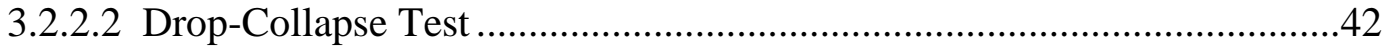

3.2.2.3 Statistical Analysis ......................................................................42

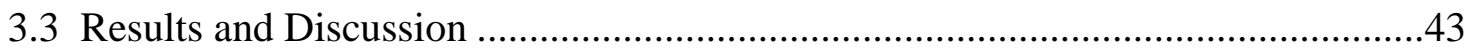

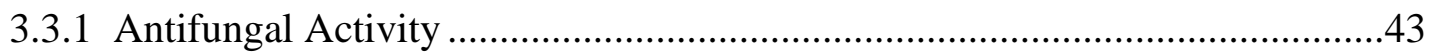

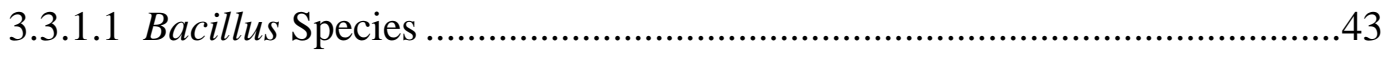

3.3.1.2 Lactic Acid Bacteria ........................................................................45

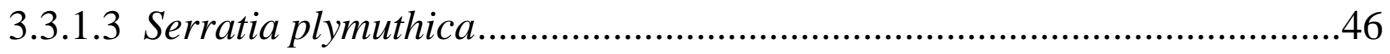

3.3.1.4 Isolates with No Antifungal Activity ............................................47

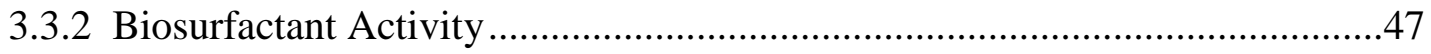

3.3.2.1 Bacillus Species, Oceanobacillus sojae, and Ochrobactrum anthropi.....47

3.3.2.2 Lactic Acid Bacteria Isolates ........................................................49

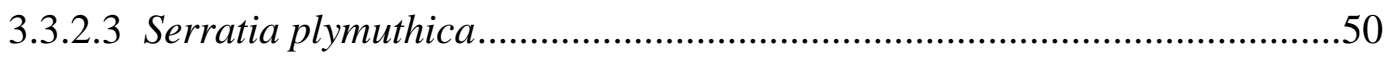

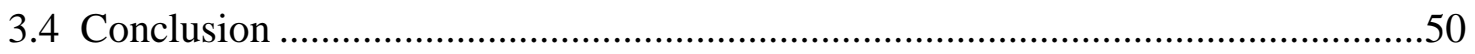

4. ANTIMICROBIAL SCREENING OF BIOPROTECTIVE ISOLATES AGAINST LISTERIA MONOCYTOGENES, SALMONELLA, AND ESCHERICHIA COLI O157:H7 AND ANTIMICROBIAL EFFICACY ON ICEBERG LETTUCE

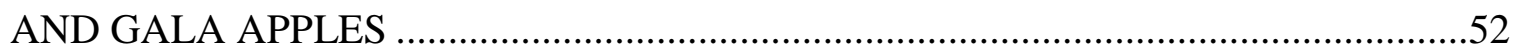

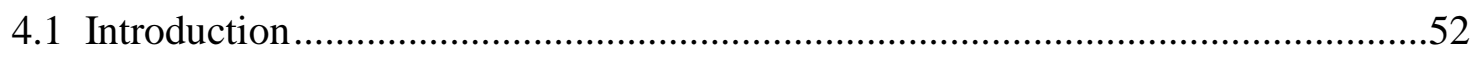

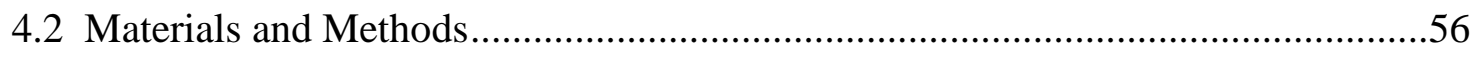

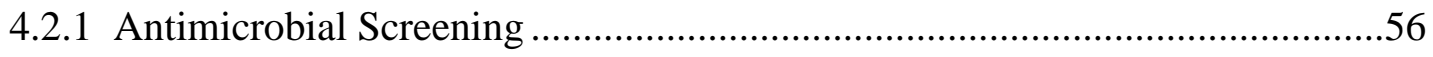

4.2.1.1 Bacterial Pathogen Preparation ......................................................56

4.2.1.2 Bioprotective Isolate and Bacillus subtilis Fermentate Preparation .........57

4.2.1.3 Lactic Acid Bacteria Cocktail Preparation .......................................58

4.2.1.4 Antimicrobial Screening of Bioprotective Isolates ..............................59 
4.2.2 Effect of $\mathrm{pH}$ on Antimicrobial Activity of Lactic Acid Bacteria Isolates .......60

4.2.2.1 Bacterial Pathogen Preparation ............................................................60

4.2.2.2 Lactic Acid Bacteria Isolate Cell-Free Supernatant and Neutralized

Cell-Free Supernatant Preparation

4.2.2.3 Effect of $\mathrm{pH}$ on the Antimicrobial Activity of Lactic Acid Bacteria Cell-Free Supernatant ...............................................................................60

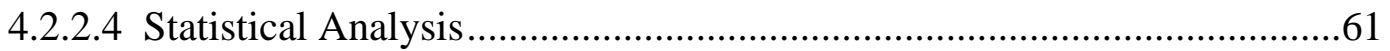

4.2.3 Application on Produce: Effect of Lactic Acid Bacteria Cocktail on

Listeria monocytogenes on Iceberg Lettuce .......................................................61

4.2.3.1 Iceberg Lettuce Preparation .............................................................61

4.2.3.2 Listeria monocytogenes Inoculation of Iceberg Lettuce ..........................61

4.2.3.3 Lactic Acid Bacteria Cocktail Treatment of Iceberg Lettuce ..................62

4.2.3.4 Bacterial Enumeration ................................................................62

4.2.3.5 Statistical Analysis ......................................................................63

4.2.4 Application on Produce: Effect of DF1 on Iceberg Lettuce ........................63

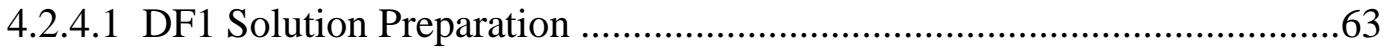

4.2.4.2 DF1 Treatment of Iceberg Lettuce.....................................................63

4.2.4.3 Bacterial Enumeration ....................................................................64

4.2.5 Application on Produce: Effect of DF1 on Listeria monocytogenes, Salmonella, and Escherichia coli $\mathrm{O} 157: \mathrm{H7}$ on Gala Apples ...................................64

4.2.5.1 Bacterial Pathogen Preparation ..........................................................64

4.2.5.2 Pathogen Inoculation of Gala Apples ..................................................64

4.2.5.3 DF1 Treatment of Gala Apples .......................................................65

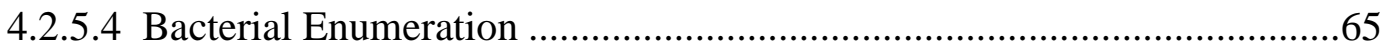

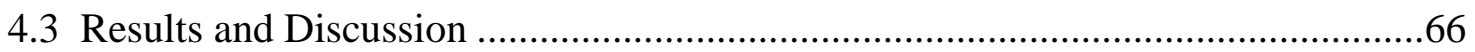

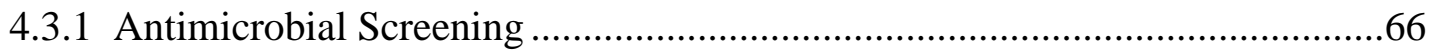

4.3.1.1 Appearance of Zones of Inhibition During Antimicrobial Screening ......66 
4.3.1.3 Bacillus Isolates, Serratia plymuthica, and Bacillus subtilis

Fermentate.

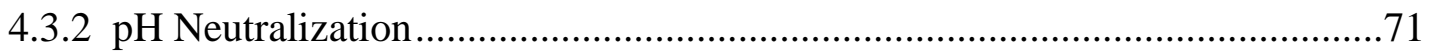

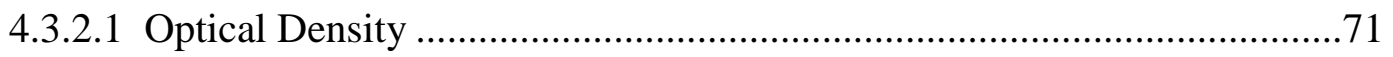

4.3.2.2 The Role of Organic Acids Produced by Lactic Acid Bactria Isolates

in the Inhibition of Listeria monocytogenes, Salmonella, and Escherichia coli $\mathrm{O} 157: \mathrm{H} 7$

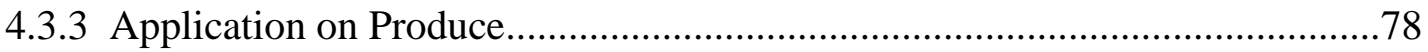

4.3.3.1 Effect of Lactic Acid Bacteria Cocktail on Listeria monocytogenes on Iceberg Lettuce................................................................................. 78

4.3.3.2 The Effect of DF1 Treatment on the Appearance of Iceberg Lettuce ......79

4.3.3.3 Effect of DF1 on Listeria monocytogenes, Salmonella, and

Escherichia coli $\mathrm{O} 157: \mathrm{H} 7$ on Gala Apples

4.3.3.3.1 The Fate of Listeria monocytogenes, Salmonella, and Escherichia coli O157:H7 on the Surface of Gala Apples

4.3.3.3.2 The Effect of DF1 on Listeria monocytogenes, Salmonella, and Escherichia coli $\mathrm{O} 157: \mathrm{H} 7$ on Gala Apples

4.3.3.3.3 The Effect of DF1 on the Appearance of Gala Apples

4.4 Conclusion

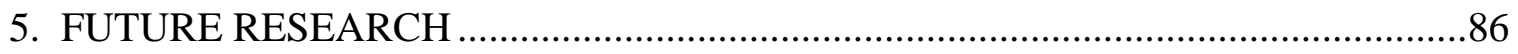

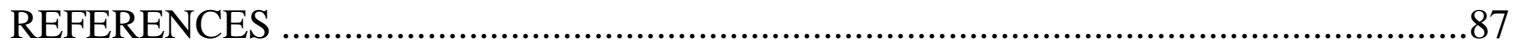

APPENDICES

APPENDIX A. ANTIFUNGAL SCREENING TEMPLATE, RAW DATA, AND PICTURES.

A.1 Antifungal Screening Inoculation Template

A.2 Average Diameters of Botrytis cinerea, Fusarium pallidoroseum, and Fusarium moniliforme Colonies in the Presence of Bioprotective Isolates. 108 
APPENDIX B. PICTURES OF the ANTIFUNGAL SCREENING OF BIOPROTECTIVE ISOLATES AGAINST BOTRYTIS CINEREA, FUSARIUM PALLIDOROSEUM, AND FUSARIUM MONILIFORME

B.1 Control Plates

B.2 Botrytis cinerea, Fusarium pallidoroseum, or Fusarium moniliforme Grown in the Presence of Bioprotective Isolates

APPENDIX C. ANTIMICROBIAL SCREENING PICTURES

C.1 Screening of Lactic Acid Bacteria Isolates and Cocktails Against Listeria monocytogenes, Salmonella, and Escherichia coli O157:H7

C.2 Screening of Non-Lactic Acid Bacteria Isolates and Bacillus subtilis

Fermentate Against Listeria monocytogenes, Salmonella, and Escherichia coli O157:H7.

APPENDIX D. OPTICAL DENSITY TABLE 


\section{LIST OF TABLES}

Table

Page

Table 1.1. Estimated economic loss due to major foodborne disease outbreaks in the United States (adapted from Hussain and Dawson, 2013)

Table 2.1. Number of foodborne disease outbreaks caused by Listeria monocytogenes, Salmonella, and Escherichia coli in fresh produce, 1998 to 2008 (adapted from Gould, Walsh, et al., 2013).

Table 2.2. Major Listeria monocytogenes, Salmonella, and Escherichia coli

O157:H7 outbreaks in fresh produce investigated by the CDC, 2006 to 2013

Table 2.3. Bacteriocins produced by Lactic Acid Bacteria species (adapted from

Sullivan et al., 2002).

Table 3.1. Bioprotective isolates and fungal phytopathogens

Table 3.2. Fungal inhibition of bioprotective isolates against Botrytis cinerea,

Fusarium moniliforme, and Fusarium pallidoroseum after $10 \mathrm{~d}$ incubation at $24^{\circ} \mathrm{C} \ldots \ldots . . .44$

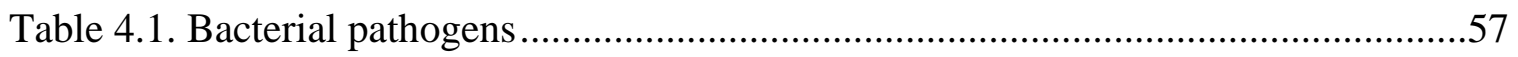

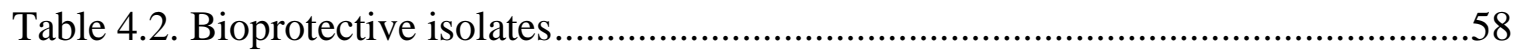

Table 4.3. Lactic Acid Bacteria cocktail formulation components ...............................59

Table 4.4. Antimicrobial activity of Lactic Acid Bacteria cocktails .............................69

Table 4.5. Antimicrobial activity of isolates and fermentates ...................................71

Table 4.6. Listeria monocytogenes, Salmonella, and Escherichia coli 0157:H7 on Gala apples treated with DF1 or DI water....

Table A1. Average diameters (in mm) of Botrytis cinerea, Fusarium pallidoroseum, or Fusarium moniliforme colonies in the presence of bioprotective isolates (X axis/Y axis)

Table D1. Optical densities of Listeria monocytogenes, Salmonella, and Escherichia coli O157:H7 grown in the presence of the CFS and NCFS of Lactic Acid Bacteria isolates after $48 \mathrm{~h}^{1}$ 


\section{LIST OF FIGURES}

Figure

Page

Figure 3.1. Antifungal screening of Bacillus amyloliquefaciens BA4 against

Botrytis cinerea (a), Fusarium pallidoroseum (b), and Fusarium moniliforme (c).

Markings indicate the border of the fungal colony each day of incubation, beginning

on Day 3.

Figure 3.2. Biosurfactant activity of bioprotective isolates. Error bars indicate standard deviation. Media used are designated by bars with corresponding patterns. Asterisks indicate drop diameters significantly larger than that of the media control $(\alpha=0.05)$

Figure 4.1. Antimicrobial screening of (top row) Lactobacillus plantarum and (bottom row) Bacillus amyloliquefaciens BA3 against (from left to right) Listeria monocytogenes, Salmonella, and Escherichia coli O157:H7. Handwritten numbers indicate zone size in $\mathrm{mm}$.

Figure 4.2. Antimicrobial activity of Lactic Acid Bacteria isolates. LAB isolates are differentiated by pattern. Error bars indicate standard error of the mean. Those results not sharing a letter are statistically different $(\alpha=0.05)$.

Figure 4.3. Optical density of Listeria monocytogenes, Salmonella, and Escherichia coli O157:H7 grown in Lactobacillus plantarum CFS and NCFS. Error bars indicate standard error of the mean.

Figure 4.4. Optical density of Listeria monocytogenes, Salmonella, and Escherichia coli 0157:H7 grown in Pediococcus acidilactici CFS and NCFS. Error bars indicate standard error of the mean.

Figure 4.5. Optical density of Listeria monocytogenes, Salmonella, and Escherichia coli O157:H7 grown in Pediococcus pentosaceus CFS and NCFS. Error bars indicate standard error of the mean.....

Figure 4.6. Listeria monocytogenes (a) and Lactic Acid Bacteria populations (b) on Iceberg lettuce treated with Lactic Acid Bacteria cocktail after $14 \mathrm{~d}$ incubation at $10^{\circ} \mathrm{C}$. Asterisks indicate microbial populations which are significantly different on each sample day $(\alpha=0.05)$

Figure 4.7. Iceberg lettuce treated with $\mathrm{DF} 1$ after $2 \mathrm{~d}$ incubation at $10^{\circ} \mathrm{C}$. 80

Figure 4.8. LAB population on DF1-treated Gala apples incubated at $20^{\circ} \mathrm{C}$ for $5 \mathrm{~d}$....... 83

Figure 4.9. Gala apple treated with DF1. 84

Figure A1. Antifungal screening inoculation template. 107 


\section{INTRODUCTION}

The United States agricultural industry is a multibillion dollar business. In 2012, vegetable, fruit, and nut production in the U.S. was valued at approximately US\$223 billion (USDA-National Agricultural Statistics Service, 2014). Products manufactured by the produce industry include fresh produce, fresh-cut fruits and vegetables, and packaged salads. Fresh produce refers to fruits and vegetables sold as whole pieces. Fresh-cut fruits and vegetables include overwrapped fruits, fresh-cut fruits (chunks, cubes, cored, etc.), fruit in jars and cups packed in juice, and vegetables washed, cut, and packaged for side dishes, trays, snacking, or meal preparation. The term packaged salad refers to pre-cut lettuce, vegetables, and fruits packaged together as a salad. (United Fresh Produce Association, 2013).

Because of the economic importance of the agricultural industry, maintaining the integrity of agricultural commodities both before and after harvest is key to ensuring the vitality of this sector of the U.S. economy. Factors rendering agricultural commodities unfit for consumption, be it commodity loss in the field due to phytopathogenic microorganisms or postharvest due to food safety concerns, have a dramatic economic impact on the agricultural industry. Globally, crop loss caused by pathogens, animals, and weeds is between 20 and 40\%; losses in major crops—wheat, maize, and soybeans—due to plant diseases were 10.2, 8.5, and 8.9\%, respectively, from 2001-2003 (Oerke, 2005; Savary et al., 2012). In the United States, crop disease losses amount to an estimated US\$220 billion annually (Chakraborty and Newton, 2011). Foodborne disease outbreaks 
are also costly to the agricultural industry. Food safety incidences cost the United States food industry approximately US\$7 billion a year (Hussain and Dawson, 2013); the cost of a single outbreak can exceed US\$100 million (Table 1.1). The mitigation of phytopathogenic and pathogenic microorganisms on produce is an important part of ensuring the vitality of the agricultural industry.

This study aimed to determine the potential use of non-pathogenic bacteria as biocontrol agents for the suppression of plant and foodborne pathogens on fresh produce. The objectives of this study were to screen several bacterial isolates for antifungal and antimicrobial activity in vitro and to evaluate the antimicrobial efficacy of select isolates on fresh produce.

Table 1.1. Estimated economic loss due to major foodborne disease outbreaks in the United States (adapted from Hussain and Dawson, 2013)

\begin{tabular}{cccc}
\hline Year & Food product & Pathogen & $\begin{array}{c}\text { Estimated economic loss } \\
\text { (US dollars) }\end{array}$ \\
\hline 2009 & Peanut products & Salmonella & $\$ 70$ million \\
2008 & Tomatoes & Salmonella & $\$ 250$ million \\
2007 & Peanut butter & Salmonella & $\$ 133$ million \\
2006 & Spinach & E. coli & $\$ 350$ million \\
\hline
\end{tabular}




\section{LITERATURE REVIEW}

\subsection{Fungal Phytopathogens}

\subsubsection{Economic Impact of Fungal Phytopathogens}

Fungal phytopathogens cause disease in plants and are a major concern to the agricultural industry; fungi such as Botrytis cinerea and Fusarium species are the causative agents of several plant diseases. Bot. cinerea, the fungus responsible for the diseases Gray Mold and Botrytis Rot, is a major issue for strawberry producers, as well as grape, almond, pistachio, tomato and orange growers. In the United States, approximately $15 \%$ of strawberry crops are lost to disease caused by Bot. cinerea (Haydu and Legard, 2003). Bot. cinerea colonizes dead or dying plant tissues, then continues on to kill and macerate adjacent healthy tissues; it is the ability to destroy healthy tissue that makes Bot. cinerea especially problematic for growers (Moorman, 2015). Fusarium Wilt and Fusarium Rot, caused by various Fusarium species, also affect a wide range of crops including lettuce, soybeans, strawberries, tomatoes, peppers, potatoes, and oranges. Fusarium Root Rot caused an average annual loss of 7.72 million bushels of soybeans between 2006 and 2009 in the United States (Koenning and Wrather, 2010), and Fusarium Head Blight has cost wheat growers in the Northern Great Plains and central United States an estimated US\$2.7 billion from 1998 to 2000 (Chakraborty and Newton, 2011). The fungus enters the plant through the roots and grows in the vascular system, clogging the conduits through which water flows, causing wilting and eventual death 
(Miller, et al., 1996; UC IPM, 2014c). The control of these plant pathogens is essential to maintaining and growing the U.S. agricultural industry.

\subsubsection{Pre-harvest Control of Phytopathogenic Fungi}

Careful crop management is used to limit the incidence of diseases caused by Bot. cinerea and Fusarium species in crops. Practices such as clearing fields of plant detritus and creating an open canopy to allow for the quick evaporation of water are used to prevent diseases caused by Bot. cinerea (Williamson et al., 2007). The management of Fusarium species can be challenging because the fungus persists in soil by forming chlamydospores (large, thickly-walled fungal spores), which are difficult to destroy. Selecting a location to plant crops without a history of Fusarium disease is the most effective way of preventing infection (UC IPM, 2014a).

Chemical control methods are also used to limit the impact of Bot. cinerea and Fusarium species on crops. Fungicides are used to inhibit Bot. cinerea with varying efficacy, but the phytopathogen has developed fungicide resistance (Williamson et al., 2007a; UC IPM, 2014b; Moorman, 2015). Fumigation before planting is used to treat fields where Fusarium chlamydospores are present (UC IPM, 2014a). The use of some broad-spectrum chemical fungicides, however, is being phased out because of their environmental impact. This, in addition to an increase in consumer demand for more "natural" products, has forced the agricultural industry to investigate other means of fungal phytopathogen suppression. 


\subsection{Foodborne Pathogens}

\subsubsection{Foodborne Illness Outbreaks in the United States}

Foodborne illness affects an estimated 48 million Americans each year. Between 1998 and 2008, the Centers for Disease Control and Prevention (CDC) recorded 13,405 foodborne disease outbreaks, with an average of 968 to 1,403 outbreaks per year. During this ten year period, there was an annual average of 19,951 to 28,895 cases of illness, 593 to 1261 hospitalizations and 9 to 48 deaths (Gould et al., 2013b). The CDC received reports of 1,527 foodborne disease outbreaks in 2009 and 2010 - 675 and 852 outbreaks, respectively — which resulted in 29,444 cases of illness, 1,184 hospitalizations and 23 deaths (Gould et al., 2013a). The foodborne pathogens Listeria monocytogenes, Salmonella, and Shiga toxin-producing Escherichia coli $\mathrm{O} 157: \mathrm{H7}$ have all been associated with foodborne disease outbreaks in the United States.

\subsubsection{Listeria monocytogenes}

Listeria monocytogenes is a Gram positive foodborne pathogen. It can grow in temperatures ranging from less than $0^{\circ} \mathrm{C}$ to $45^{\circ} \mathrm{C}$, with optimal growth at 30 to $37^{\circ} \mathrm{C}$, and can also proliferate in growth media with up to $20 \%$ sodium chloride. L. monocytogenes can be isolated from many different environments, including soil, vegetation, sewage, water, and the feces of healthy animals (De Vos et al., 2009).

This pathogen is usually transmitted to humans via contaminated food; its infectious dose is unknown, but is thought to be below 1,000 organisms. In healthy adults, L. monocytogenes infection causes gastroenteritis after 1-2 d incubation and 
symptoms typically last 1-3 d. However, L. monocytogenes infection can also result in the development of listeriosis.

Listeriosis is a much more serious concern among immunocompromised populations (pregnant women, young children, the elderly and those with suppressed immune systems) than for healthy adults. Within these immunocompromised groups, listerial infection can cause meningitis, meningoencephalitis, septicemia and spontaneous abortions in pregnant women (The Center for Food Security \& Public Health, 2005). Listeriosis is the third most common cause of death among foodborne diseases in the United States; in immunocompromised populations, the overall fatality rate is $20-30 \%$, and can be as high as 70\% (The Center for Food Security \& Public Health, 2005; Silk et al., 2013). From 2009 to 2011, L. monocytogenes caused 1,651 cases of invasive listeriosis and 292 deaths or fetal loses - $21 \%$ of foodborne illness-associated deaths (Silk et al., 2013). L. monocytogenes is of particular interest to the food industry because of the pathogen's ubiquitous distribution, its ability to proliferate at refrigeration temperatures and high sodium chloride concentrations, and its high mortality rate in immunocompromised populations.

Foodborne L. monocytogenes outbreaks are most commonly associated with cheese and dairy products. Twelve L. monocytogenes outbreaks were reported to the CDC from 2009 to 2011 — the contaminated food in six of the twelve outbreaks was identified as cheese (Silk et al., 2013). However, Listeria outbreaks in fresh produce, commodities not traditionally associated with L. monocytogenes, are occurring with more frequency (Tables 2.1 and 2.2). Of the 25 foodborne disease outbreaks reported to the CDC from 1998 to 2008, only one was associated with L. monocytogenes in fresh 
produce (sprouts) (Gould et al., 2013b). From 2009 to 2011 two L. monocytogenes outbreaks involving produce occurred—one outbreak associated with pre-cut celery and the other with whole cantaloupes (Silk et al., 2013).

The largest L. monocytogenes foodborne disease outbreak in United States history occurred in 2011. The outbreak involved contaminated whole cantaloupes from Jensen Farms' production fields in Granada, CO. During the outbreak, 147 cases of listeriosis across 28 states were reported; 33 deaths and one miscarriage were attributed to the consumption of the contaminated melons (CDC, 2012a). An investigation was conducted by the U.S. Food and Drug Administration (FDA) and Colorado state officials of the Jensen Farms cantaloupe fields and packing facility in September, 2011. Samples collected in the growing field were negative for L. monocytogenes, but the four outbreak strains were isolated from various sample sites in the packing facility (FDA, 2011a).

The investigation identified several factors that potentially contributed to $L$. monocytogenes contamination. Even though the outbreak strains of L. monocytogenes were not isolated from the growing fields, the fields were identified as a potential source of contamination. Jensen Farms did not precool the melons before refrigerated storage and the cantaloupes, still warm from the field, could have provided a warm, moist environment in which to promote $L$. monocytogenes growth. Poor facility design of the packing house allowed for the pooling of water around employee walkways and packaging equipment, and drains were not easily accessible for proper cleaning; both these conditions could allow for the establishment of harborage sites. Packaging equipment was not designed for easy and complete cleaning and sanitation; three of the four outbreak strains were isolated from the packaging equipment. Finally, Jensen Farms 
used a truck to haul culled cantaloupe to a cattle operation - this truck could have introduced L. monocytogenes into the packing facility (FDA, 2011a). The FDA investigation highlights the need for effective preventative control measures and the importance of sanitary facility and equipment design in produce postharvest processing.

Table 2.1. Number of foodborne disease outbreaks caused by Listeria monocytogenes, Salmonella, and Escherichia coli in fresh produce, 1998 to 2008 (adapted from Gould, Walsh, et al., 2013)

\begin{tabular}{|c|c|c|c|c|c|}
\hline Pathogen & $\begin{array}{c}\text { Fruits and } \\
\text { nuts }\end{array}$ & $\begin{array}{c}\text { Leafy } \\
\text { vegetables }\end{array}$ & Root & Sprouts & $\begin{array}{l}\text { Vine-stalk } \\
\text { vegetables }\end{array}$ \\
\hline L. monocytogenes & -- & -- & -- & 1 & -- \\
\hline Salmonella & 36 & 11 & 6 & 21 & 21 \\
\hline $\begin{array}{l}\text { Shiga-toxin producing } E \text {. } \\
\text { coli }\end{array}$ & 10 & 23 & -- & 6 & 1 \\
\hline
\end{tabular}

\subsubsection{Salmonella Species}

Salmonella is a Gram negative, non-spore forming bacteria commonly associated with animals, especially poultry and swine, but can also be found in water and soil. Salmonella infection can result in two kinds of illness depending on serotype: typhoid fever and non-typhoidal salmonellosis. Typhoid fever is caused by Salmonella enterica ser. Typhi and Salmonella enterica ser. Paratyphi A, with an infectious dose of fewer than 1,000 cells. Symptoms develop 1-3 weeks after exposure and include high fever, lethargy, abdominal pain, diarrhea or constipation, headache, achiness and sometimes a flat, rose colored rash. Typhoid fever generally lasts 2-4 weeks. Non-typhoidal salmonellosis is caused by all other Salmonella serotypes and is the disease most frequently associated with foodborne illness. The infectious dose can be as low as one cell, depending on the organism's serotype and the age and health of the host. 
Salmonellosis symptoms include nausea, vomiting, abdominal cramps, diarrhea, fever and headache; they develop 6-72 $\mathrm{h}$ after exposure and generally last for 4-7 $\mathrm{d}$. Complications with typhoid fever and non-typhoidal salmonellosis can result in septicemia, with the colonization of other tissues and organs, and also cause chronic health problems, such as reactive arthritis (FDA, 2012).

In the United States, approximately 42,000 cases of salmonellosis are reported each year (CDC, 2012b). Between 1998 and 2008 and 2009 to 2010, Salmonella was the cause of $26 \%$ and $30 \%$ of foodborne disease outbreaks with a single confirmed or suspected causative agent, respectively; it was the second most common etiology of foodborne disease outbreak in both time periods. Salmonella was the second most frequent cause of foodborne illness and hospitalization from 1998 to 2010 and the cause of $29 \%$ of the deaths from foodborne disease outbreaks in this period (Gould et al., 2013a; b). Salmonella outbreaks have traditionally been associated with animal products, such as meats, poultry and eggs (FDA, 2012). However, fresh produce has become an increasing source of foodborne Salmonella outbreaks.

Salmonella has caused numerous multistate outbreaks in a variety of types of produce (Tables 2.1 and 2.2). From 1998 to 2008, Salmonella outbreaks in fruits and nuts, leafy vegetables, root vegetables, sprouts, and vine-stalk vegetables were the cause of 6,764 illnesses (Gould et al., 2013b). In 2008, an outbreak of Salmonella enterica ser. Saintpaul—spanning 43 states, the District of Colombia, and Canada—caused 1,442 cases of salmonellosis, 286 hospitalizations and two deaths. An FDA investigation, with the cooperation of state and local agencies, determined the sources of the infection to be jalapeño peppers, serrano peppers, and Roma tomatoes. The FDA traced the 
contaminated produce back to a farm in Tamaulipas, Mexico which grew jalapeño peppers, serrano peppers and Roma tomatoes. Although the outbreak strain was not isolated from the farm, it was isolated from a nearby farm with whom it shared a packing facility; the packing facility was likely the source of contamination (Jungk et al., 2008).

Table 2.2. Major Listeria monocytogenes, Salmonella, and Escherichia coli O157:H7 outbreaks in fresh produce investigated by the CDC, 2006 to 2013

\begin{tabular}{|c|c|c|c|c|}
\hline Pathogen & Year & Commodity & Company & $\begin{array}{l}\text { Cases/ } \\
\text { deaths }\end{array}$ \\
\hline L. monocytogenes ${ }^{1}$ & 2011 & Cantaloupe & Jensen Farms & $147 / 34$ \\
\hline S. enterica ser. Saintpaul ${ }^{2}$ & 2013 & Cucumbers & $\begin{array}{c}\text { Daniel Cardenas } \\
\text { Izabal and } \\
\text { Miracle } \\
\text { Greenhouse }\end{array}$ & $84 / 0$ \\
\hline $\begin{array}{l}\text { S. enterica ser. } \\
\text { Braenderup }^{3}\end{array}$ & 2012 & Mangos & Agricola Daniella & $127 / 0$ \\
\hline $\begin{array}{l}\text { S. enterica ser. } \\
\text { Typhimurium and } S \text {. } \\
\text { enterica ser. Newport }\end{array}$ & 2012 & Cantaloupe & $\begin{array}{l}\text { Chamberlain } \\
\text { Farms Produce, } \\
\text { Inc. }\end{array}$ & $261 / 3$ \\
\hline S. enterica ser. Agona ${ }^{5}$ & 2011 & Papayas & $\begin{array}{c}\text { Agromod } \\
\text { Produce Inc. }\end{array}$ & 106/-- \\
\hline S. enterica ser. Saintpaul ${ }^{6}$ & 2008 & $\begin{array}{l}\text { Peppers and } \\
\text { tomatoes }\end{array}$ & $\begin{array}{l}\text { Unnamed packing } \\
\text { facility in Mexico }\end{array}$ & $1,442 / 2$ \\
\hline E. coli $\mathrm{O} 157: \mathrm{H}^{7}$ & 2013 & $\begin{array}{l}\text { Ready-to-eat } \\
\text { salads }\end{array}$ & $\begin{array}{l}\text { Glass Onion } \\
\text { Catering }\end{array}$ & $33 / 0$ \\
\hline E. coli $\mathrm{O} 157: \mathrm{H}^{8}$ & 2011 & $\begin{array}{c}\text { Romaine } \\
\text { lettuce }\end{array}$ & $\begin{array}{l}\text { No source } \\
\text { identified }\end{array}$ & $58 / 0$ \\
\hline E. coli $\mathrm{O} 157: \mathrm{H}^{9}$ & 2006 & Fresh spinach & $\begin{array}{c}\text { Natural Selection } \\
\text { Foods }\end{array}$ & $199 / 3$ \\
\hline
\end{tabular}

(--): no deaths reported

${ }^{1} \mathrm{CDC}, 2012 \mathrm{a} ;{ }^{2} \mathrm{CDC}, 2013 \mathrm{a} ;{ }^{3} \mathrm{CDC}, 2012 \mathrm{c} ;{ }^{4} \mathrm{CDC}, 2012 \mathrm{~d} ;{ }^{5} \mathrm{CDC}, 2011 \mathrm{a} ;{ }^{6} \mathrm{Jungk}$ et al., 2008; ${ }^{7} \mathrm{CDC}, 2013 \mathrm{~b}$;

${ }^{8} \mathrm{CDC}, 2012 \mathrm{e} ;{ }^{9} \mathrm{CDC}, 2006$. 


\subsubsection{Escherichia coli $\mathrm{O} 157: \mathrm{H} 7$}

Escherichia coli is a Gram negative bacteria that is part of the normal intestinal flora of the human gut. Most strains of E. coli are non-pathogenic, but a subgroup of enterohemorrhagic E. coli (EHEC) strains have been linked to numerous foodborne disease outbreaks. EHEC strains are characterized by the ability to produce Shiga toxin, and the E. coli strain O157:H7 accounts for approximately 75\% of EHEC infections worldwide. The infective dose of E. coli $\mathrm{O} 157: \mathrm{H} 7$ is between 10 and 100 cells; this toxinmediated infection causes hemorrhagic colitis. Symptoms appear 3-4 d after exposure, last for 2-9 d, and include severe cramping and abdominal pain, nausea or vomiting, no or low-grade fever, and bloody diarrhea. In 3-7\% of hemorrhagic colitis cases, the more serious diseases of hemolytic uremic syndrome (HUS) or thrombotic thrombocytopenia pupura (TTP) can develop, which can result in kidney failure (FDA, 2012).

Pathogenic E. coli has been associated with foodborne disease outbreaks in a variety of different commodities. Between 1998 and 2010, E. coli was responsible for 4\% of outbreaks with known etiology, causing $3 \%$ of the illnesses, $14 \%$ of the hospitalizations, and 12\% of the deaths in this period (Gould et al., 2013a; b). Shiga toxin-producing E. coli has been associated with many fresh produce commodities (Tables 2.1 and 2.2). From 1998 to 2008, E. coli O157:H7 was the cause of approximately $16 \%$ of the outbreaks that occurred in leafy vegetables, $7 \%$ of the outbreaks in fruits and nuts, and 5\% of outbreaks in sprouts (Gould et al., 2013a). Produce-associated E. coli outbreaks have caused devastating foodborne disease outbreaks not only in the United States, but also internationally. 
A multistate outbreak of E. coli O157:H7 involving fresh spinach caused 199 confirmed illnesses, 31 cases of HUS, and 3 deaths in 26 states (CDC, 2006). The source of the contamination was traced to spinach fields in San Juan Bautista, CA operated by Natural Selection Foods, LLC. FDA investigators isolated the outbreak strain in environmental samples from a field, river water, and cattle and wild pig feces from a nearby ranch. The likely source of the contamination was wild pigs in and around the spinach field (California Food Emergency Response Team, 2007).

Although a majority of outbreaks have been linked to E. coli $\mathrm{O} 157: \mathrm{H7}$, non-O157 strains of EHEC have also been identified as the cause of foodborne disease outbreaks. In 2011, an outbreak of E. coli O104:H4 sickened 4,075 people across 16 European countries and North America. The outbreak caused 908 cases of HUS and 50 deaths (WHO, 2011). The source of the outbreak was traced back to contaminated sprouts from a farm in Lower Saxony, Germany, and eventually to contaminated fenugreek seeds from Egypt (CDC, 2011a).

\subsection{Postharvest Control of Foodborne Pathogens}

\subsubsection{Temperature Control}

Temperature control is the most common means of microbial control on fresh produce; storage at low temperatures is used to slow or inhibit microbial growth. Minimum growth temperatures are a function of growth media. However, the minimum growth temperatures for L. monocytogenes, Salmonella, and E. coli 0157:H7 are 
considered to be $-0.4,5.2$, and $6.5^{\circ} \mathrm{C}$, respectively (FDA, 2011b). While maintaining produce at refrigeration temperatures (approximately $4^{\circ} \mathrm{C}$ ) will not inhibit the growth of L. monocytogenes, storage at lower temperatures slows the proliferation of most of the microflora present on produce, both native and pathogenic.

Maintaining produce at low temperatures throughout the entire distribution chain is critical to suppressing microbial growth. The FDA requires that ready-to-eat fruits and vegetables be stored at or below $5^{\circ} \mathrm{C}$ to suppress the proliferation of pathogens (FDA, 2013a). Temperature abuse during transport and retail storage could allow for the growth of pathogens. A study by Zeng et al. (2014) constructed temperature profiles of refrigerated truck transport and retail storage during fresh produce distribution, and determined the fate of E. coli $\mathrm{O} 157: \mathrm{H} 7$ and L. monocytogenes on pre-cut romaine lettuce under those temperature conditions. Average temperatures during transport in refrigerated trucks and in retail display cases ranged from ranged from -0.3 to $7.7^{\circ} \mathrm{C}$ and -1.1 to $9.7^{\circ} \mathrm{C}$, respectively. There was no significant increase in E. coli $\mathrm{O} 157: \mathrm{H} 7$ levels during transport or retail display storage; L. monocytogenes populations increased $\leq 0.6 \log$ and $1.1 \log$ CFU/g, respectively.

The largest temperature fluctuation and the greatest increase in pathogen populations were observed during retail storage. The average temperature ranged from 0.6 to $15.4^{\circ} \mathrm{C}$, with a maximum of $18.2^{\circ} \mathrm{C}$; both E. coli $\mathrm{O} 157: \mathrm{H} 7$ and L. monocytogenes populations increased approximately $3 \log \mathrm{CFU} / \mathrm{g}$ under this temperature profile (Zeng et al., 2014). This demonstrates the importance of good, consistent temperature management throughout the entire distribution chain in minimizing microbial hazards on fresh produce. 


\subsubsection{Mechanical Removal}

Often the first step in postharvest processing is the washing of produce, sometimes with the use of brushes and detergents, to facilitate the mechanical removal of soil and organic material from the surface (FDA, 2013b). Rinsing with water alone is not effective enough in reducing microbial populations, especially on produce with rough, uneven surfaces or on produce with a waxy cuticle (Ukuku, 2006; Keskinen and Annous, 2011; FDA, 2013b). However, the initial removal of surface debris increases the efficacy of following sanitizing steps by increasing surface contact and reducing the organic material that may interfere with disinfectants.

\subsubsection{Chlorine}

Chlorine is the most commonly used disinfectant in the produce industry because of its low cost and effectiveness against a broad spectrum of undesirable organisms. Hypochlorous acid $(\mathrm{HOCl})$, the active form of chlorine, is often referred to as free chlorine, reactive chlorine, and available chlorine. Chlorine is an effective disinfectant because $\mathrm{HOCl}$ is a powerful oxidizer and the bactericidal mechanism of $\mathrm{HOCl}$ works through several modes of action. Hypochlorous acid has been shown to denature DNA, enzymes, and proteins, disrupt adenosine triphosphate production and other membrane-

associated activity. It also damages the cell membranes of both Gram positive and Gram negative organisms, increasing cell membrane permeability and causing cellular leakage (Barrette et al., 1989; Prütz, 1996; McDonnell and Russell, 1999; Virto et al., 2005). Because chlorine is an effective and broad-spectrum disinfectant, it is widely used in the produce industry to control microbial populations. 
Chlorine is added to produce wash water as either a gas $\left(\mathrm{Cl}_{2}\right)$ or as a solid hypochlorite salt (Suslow, 1997). The FDA recommends a chlorine concentration of 50 to $200 \mathrm{ppm}$ to sanitize produce surfaces (FDA, 2013b), but in industry chlorine concentration is usually maintained below recommended levels because fresh produce processors wash the product several times, increasing the total produce-chlorine contact time. Lower levels of chlorine are also less costly, create a more comfortable environment for workers, and leave less of a residual odor on the product (W. Brown, personal communication, September 12, 2014).

The $\mathrm{pH}$ of the wash water can affect the antimicrobial activity of chlorine. The active form of chlorine, $\mathrm{HOCl}$, is a weak acid with a pKa of 7.52 (Brown et al., 2009). Chlorinated wash water is maintained at a $\mathrm{pH}$ of 6.5 to 7.5 ; this $\mathrm{pH}$ range increases the proportion of $\mathrm{HOCl}$ molecules and minimizes corrosion of equipment while maintaining acceptable antimicrobial activity (Suslow, 1997; FDA, 2013b). The presence of organic material in the wash water also affects efficacy; organic matter interacts with free chlorine, reducing the amount of $\mathrm{HOCl}$ available to react with microorganisms present on the produce (Suslow, 1997; Virto et al., 2005).

The wash water in a produce processing facility is a dynamic environment, and all of the factors affecting the antimicrobial activity of chlorine make the microbial reduction caused by chlorine insufficient to ensure the safety of fruits and vegetables. Studies have shown that washing leafy greens with chlorine causes close to or less than a $1 \log$ reduction in L. monocytogenes (Beuchat and Brackets, 1990; Zhang and Farber, 1996), Salmonella (Weissinger et al., 2000; Neal et al., 2012), and E. coli O157:H7 (Behrsing et al., 2000; Keskinen et al., 2009; Keskinen and Annous, 2011; Neal et al., 2012). 


\subsubsection{Surfactants}

Chlorine must come into direct contact with the target organism in order to have any bactericidal effect. Some produce have a naturally occurring hydrophobic, waxy coating; this coating can prevent chlorine-pathogen contact, thus reducing antimicrobial efficacy (Suslow, 1997; FDA, 2013b). Chlorine may also have less penetration into surface cracks and crevices, preventing contact with microorganisms in these areas. Surfactants, which are amphiphilic molecules that reduce the surface tension of the liquid in which they are dissolved, decrease surface hydrophobicity, increasing access of the chlorine to pathogens.

The combination of chlorine and surfactants in produce wash water has been investigated. A study by Predmore and Li (2011) investigated the effect of surfactant addition to chlorinated wash water for the removal of norovirus from various fruits and vegetables. The surfactants sodium dodecyl sulfate, NP-40, Triton X-100, and polysorbates (including Tween 20, Tween 65, and Tween 80 ) were added individually at $50 \mathrm{ppm}$ to a $200 \mathrm{pm}$ chlorine solution. The combination of chlorine and a surfactant resulted in an additional 1-2 log reduction on strawberries, a $1.5 \log$ reduction on raspberries, a 1 log reduction on cabbage, and a $1.6 \log$ reduction on lettuce over the reduction in norovirus levels when treated with chlorine alone (Predmore and Li, 2011). The addition of the surfactant sucrose monolaurate to a $200 \mathrm{ppm}$ chlorine solution resulted in an approximately $1 \log$ CFU/leaf of spinach greater reduction in E. coli O157:H7 than the reduction seen with chlorine alone (Xiao et al., 2011). A chlorine solution (at approximately 1,000 ppm and a pH of 6.5) with $0.1 \%$ Tween 80 improved 
Salmonella enterica reduction on whole cantaloupe by $0.65 \mathrm{log}$ CFU/g compared to chlorine alone (Bastos et al., 2005).

In contrast, the combination of chlorine and the surfactants Tergitol or Orenco Peel 40 did not decrease L. monocytogenes populations when compared to chlorine alone on lettuce or cabbage (Zhang and Farber, 1996). The surfactants dodecylbenzenesulfonic acid or sodium 2-ethyl hexyl sulfate also failed to increase the efficacy of a $200 \mathrm{ppm}$ chlorine solution against E. coli $\mathrm{O} 157: \mathrm{H} 7$ on romaine lettuce (Keskinen and Annous, 2011). The effect surfactant addition has on chlorine efficacy is dependent on surfactant type and concentration, target pathogen, and type of produce. The variation in efficacy of the combined methods demonstrates the need for a new approach.

\subsubsection{Other Disinfectants}

\subsubsection{Ozone}

Ozone $\left(\mathrm{O}_{3}\right)$ can be applied as an aqueous solution or as a gas and is used in the disinfection of drinking water. Ozone as a sanitizer has many advantages: it is generated on-site, reducing the amount of chemicals stored in the processing facility, and it decomposes into oxygen, leaving no chemical residue on produce (Rice, 2011). Ozone use is not common in produce sanitation because its powerful oxidizing capabilities can be deleterious to the sensory characteristics of produce, antimicrobial efficacy rapidly decreases in the presence of organic matter, it can corrode equipment, and it can pose a safety risk for workers (Suslow, 1997; Ölmez and Kretzschmar, 2009; fda, 2013b). An aqueous ozone dip was not more effective than chlorine in reducing Listeria innocua, 
Salmonella, or E. coli O157:H7 on spinach (Neal et al., 2012; Karaca and Velioglu, 2014).

\subsubsection{Peroxyacetic Acid}

Peroxyacetic acid, also called peracetic acid, is a mixture of hydrogen peroxide $\left(\mathrm{H}_{2} \mathrm{O}_{2}\right)$ and acetic acid $\left(\mathrm{CH}_{3} \mathrm{COOH}\right)$. It is sporicidal, bactericidal, virucidal, and fungicidal at low concentrations $(<0.3 \%)$ and is approved by the FDA for use in the sanitation of fruits and vegetables at a concentration not exceeding $80 \mathrm{ppm}$ (McDonnell and Russell, 1999; FDA, 2014a). The advantages of peroxyacetic acid include low reactivity with organic matter in wash water, it does not require $\mathrm{pH}$ control, it can be used at a lower concentration than chlorine, and it degrades into harmless acetic acid, oxygen, and water (University of Georgia, 2011). However, peroxyacetic acid is more expensive than chlorine and has not been shown to be more effective in reducing the microbial load of produce (Ölmez and Kretzschmar, 2009; University of Georgia, 2011; Neal et al., 2012).

\subsection{Biocontrol}

\subsubsection{Antifungal and Antimicrobial Modes of Action}

Due to the increasing number of foodborne disease outbreaks involving fresh produce, combined with the growing concern over the use of chemical fungicides in the control of plant pathogens, an alternative means of suppressing the growth and spread of 
fungal phytopathogens and foodborne pathogens are of interest to the agricultural industry. Biocontrol, which is the use of bioprotective organisms (such as nonpathogenic bacteria) to control undesirable organisms, offers an alternative means of microbial management. Several species of bacteria, including species of Lactic Acid Bacteria (LAB), Bacillus, Serratia, Ochrobactrum, and Oceanobacillus, have demonstrated antifungal and antimicrobial activity on fresh produce. However, because the antifungal and antimicrobial activity of bioprotective organisms is a function of not only species and strain, but also of the food system, the efficacy of each biocontrol agent must be confirmed in each new food matrix.

The antifungal and antimicrobial effect of the biocontrol agent can be exerted in two ways: specific suppression and general suppression. In specific suppression, the biocontrol agent inhibits a specific known pathogen; the bioprotective organism is chosen based on a known interaction with the target pathogen. General suppression occurs when the microbial population creates an environment generally unsuitable for pathogenic organisms (Singh and Vyas, 2009).

The mechanisms employed by biocontrol agents for the suppression or inhibition of undesirable microorganisms include antibiosis, predation of the target organism, stimulation of induced systemic resistance in the host plant, and competitive inhibition. In antibiosis, the bioprotective organism produces some kind of antibiotic compound that has a detrimental effect on the target organism. Predation of the target organism refers to the bioprotective organism directly feeding on the target organism, or producing enzymes or some other compound that kills the undesirable organism, allowing the biocontrol agent to feed on the dead target pathogen. Induced systemic resistance occurs when the 
exposure of the host plant to bioprotective organisms triggers an intrinsic response that increases its resistance to infection. Competitive inhibition is the suppression of undesirable organisms through the introduction of a microbial population that competes for nutrients and space in the environment (Singh and Vyas, 2009). Biocontrol agents can employ one or more modes of action to suppress the growth of phytopathogenic fungi and bacterial pathogens.

\subsubsection{Biocontrol Agents}

\subsubsection{Lactic Acid Bacteria}

Lactic Acid Bacteria (LAB) are a group of Gram positive, non-spore forming, rod and cocci shaped bacteria which ferment carbohydrates and alcohols to produce lactic acid and other metabolites (Stiles and Holzapfel, 1997). Lactic Acid Bacteria include the families Lactobacillaceae, Aerococcaceae, Carnobacteriaceae, Enterococcaceae, Leuconostocaceae, and Streptococcaceae (De Vos et al., 2009); the genera most commonly associated with foods are Carnobacterium, Enterococcus, Lactobacillus, Lactococcus, Leuconostoc, Oenococcus, Pediococcus, Streptococcus, Teragenococcus, Vagococcus, and Weissella (Stiles and Holzapfel, 1997).

Lactic Acid Bacteria have long been used in the biopreservation of foodscheese, yogurt, salami and sauerkraut are produced through fermentation by these organisms. During fermentation, growth of undesirable organisms, both spoilage and pathogenic, is inhibited by LAB through the production of organic acids (which reduces $\mathrm{pH}$ ) and antimicrobial compounds such as bacteriocins. Bacteriocins are small, heatstable, ribosomally synthesized proteins that exhibit antimicrobial activity against 
organisms closely related to the producer. Antimicrobial activity of bacteriocins produced by LAB is typically limited to Gram positive organisms, including L. monocytogenes (Delves-Broughton, 2005; Rodríguez et al., 2005; Mills et al., 2011). Antimicrobial activity against Gram negative pathogens is generally not as effective, but can be enhanced with the addition of membrane-disrupting compounds such as weak acids and chelators (Alakomi et al., 2000; Lu et al., 2011). Bacteriocin production has been identified in several genera of LAB (Table 2.3).

Table 2.3. Bacteriocins produced by Lactic Acid Bacteria species (adapted from Sullivan et al., 2002)

\begin{tabular}{|c|c|}
\hline Bacteriocin & Inhibition spectrum $^{1}$ \\
\hline \multicolumn{2}{|l|}{ Lactococcus spp. } \\
\hline Nisin & Broad-spectrum \\
\hline Lacticin 3147 & Broad-spectrum \\
\hline Lacticin 481 & Medium-spectrum \\
\hline Lactococcin A, B, and M & Narrow-spectrum \\
\hline \multicolumn{2}{|l|}{ Lactobacillus spp. } \\
\hline Lactocin 27 & Narrow-spectrum \\
\hline Sakacin A & Narrow-spectrum \\
\hline Sakacin B & Narrow-spectrum \\
\hline Plantaricin $\mathrm{C}$ & Broad-spectrum \\
\hline \multicolumn{2}{|l|}{ Pediococcus spp. } \\
\hline Pediocin A & Broad-spectrum \\
\hline Pediocin AcH (PA-1) & Broad-spectrum \\
\hline \multicolumn{2}{|l|}{ Leuconostoc spp. } \\
\hline Leucocin A-UAL187 & Broad-spectrum \\
\hline \multicolumn{2}{|l|}{ Enterococcus spp. } \\
\hline Enterocin A & Narrow-spectrum \\
\hline \multicolumn{2}{|l|}{ Carnobacterium spp. } \\
\hline Carnocin U149 & Broad-spectrum \\
\hline Piscicolin 126 & Broad-spectrum \\
\hline Divercin V41 & Broad-spectrum \\
\hline
\end{tabular}

${ }^{1}$ Broad-spectrum: inhibits most strains of a wide range of species of Gram positive bacteria. Medium-spectrum: inhibits some to most strains of producer and several other species of bacteria. Narrow-spectrum: inhibition of some strains within a species and no activity against others. 
Antibiosis caused by organic acids and bacteriocins alone is not enough to control both Gram positive and Gram negative pathogens. The addition of another antimicrobial mechanism of biocontrol, such as competitive inhibition, could enhance microbial control of L. monocytogenes, Salmonella, and E. coli O157:H7. A LAB strain capable of both survival and bacteriocin production at refrigeration temperatures may be more effective in controlling pathogen proliferation on produce during storage. Because many LAB are Generally Recognized as Safe (GRAS) for human consumption (Crowley et al., 2013), their use as biocontrol agents for the management of fungal phytopathogens and foodborne pathogens has been investigated.

\subsection{Antifungal Activity on Produce}

Lactic Acid Bacteria have shown antifungal activity against phytopathogenic fungi. The antifungal activity of LAB species has been attributed to low molecular weight peptides (Schnürer and Magnusson, 2005), fatty acids (Ryan et al., 2011), cyclic dipeptides (Strom et al., 2002; Magnusson et al., 2003; Ryan et al., 2011), and 3phenyllactic acid and other carboxylic acids (Strom et al., 2002; Ryan et al., 2011; Mu et al., 2012; Cortés-Zavaleta et al., 2014; Ryu et al., 2014). Strains of Lactobacillus plantarum and Pediococcus pentosaceus have demonstrated broad spectrum fungal inhibition in vitro, including the suppression of Fusarium culmorum (Crowley et al., 2013), Fusarium graminearum, and Bot. cinerea (Sathe et al., 2007). P. pentosaceus ATCC 25745, isolated from maize, inhibited five strains each of Fusarium verticillioides and Fusarium proliferatum. Two antifungal compounds were isolated; both were of low molecular weight (500-1,400 $\mathrm{Da}$ and 1,400-1,800 Da), heat stable, most effective at $\mathrm{pH}$ 
below 5, and maintained antifungal activity after exposure to proteases (Dalie et al., 2010). In vivo evaluation of Lb. plantarum showed its ability to suppress Bot. cinerea and F. graminearum on cucumbers (Sathe et al., 2007).

\subsection{Antimicrobial Activity on Produce}

\subsection{Lactic Acid Bacteria Isolates on Produce}

Many bacteriocin-producing LAB species have demonstrated antimicrobial activity against Gram positive organisms, and thus antimicrobial activity against foodborne pathogens on different types of produce has been investigated. Lactobacillus rhamnosus GG has shown inhibitory activity against L. monocytogenes on apples; there was an approximately $1 \log$ difference in L. monocytogenes levels between apple wedges inoculated with $L b$. rhamnosus GG and untreated apple wedges when incubated at 5 or $10^{\circ} \mathrm{C}$ for $28 \mathrm{~d}$. Lb. rhamnosus GG did not have an effect on Salmonella populations under the same conditions (Alegre et al., 2011). A study by Trias et al. (2008) determined the antimicrobial activity of two strains of Lactococcus lactis and three strains of Leuconostoc mesenteroides isolated from several fruit and vegetable sources on apples and lettuce; four of the five strains reduced L. monocytogenes to undetectable levels after $2 \mathrm{~d}$ incubation at $25^{\circ} \mathrm{C}$; one strain of Lc. lactis did not significantly affect $L$. monocytogenes populations. These five strains were less effective in suppressing Salmonella enterica ser. Typhimurium; inhibition on apples and lettuce ranged from no inhibition to approximately $2 \log$ (Trias et al., 2008a).

The food matrix has an effect of the efficacy of the bioprotective agent. In the previously mentioned study by Trias et al. (2008) the same five LAB strains were 
evaluated for antimicrobial activity against E. coli ATCC 11775 and S. enterica ser. Typhimurium on apples and lettuce. Of the five LAB strains tested, one strain of $L n$. mesenteroides caused a significant difference of less than $1 \log$ in E. coli levels $(\mathrm{P}<0.05)$ on apples compared to untreated apples; the other LAB strains did not cause a significant difference in $E$. coli levels. On lettuce, four of the five LAB strains caused a significant difference of less than $1 \log$ in E. coli levels ( $\mathrm{P}<0.05)$; one strain of Lc. lactis did not significantly inhibit E. coli. Regardless of produce type, inhibition of E. coli was less than $1 \log$ (Trias et al., 2008a).

\subsection{Bacteriocins on Produce}

The antimicrobial activity of LAB metabolites against the foodborne pathogens $L$. monocytogenes, Salmonella, and E. coli O157:H7 has been well studied. The bacteriocins produced by some strains of LAB have been assessed for their antimicrobial activity against L. monocytogenes on produce. Mundticin, a bacteriocin synthesized by Enterococcus mundtii, was able to suppress L. monocytogenes on mungbean sprouts; there was an approximately $2 \log \mathrm{CFU} / \mathrm{g}$ difference in L. monocytogenes levels between mundticin-treated sprouts and untreated sprouts after $13 \mathrm{~d}$ incubation at $8^{\circ} \mathrm{C}$ (Bennik et al., 1999). Iceberg lettuce sprayed with a bacteriocin from Lc. lactis RUC9 or Nisaplin® (a commercially available nisin product) had approximately 2.5 and $2 \log$ CFU/g less $L$. monocytogenes, respectively, than untreated lettuce after $7 \mathrm{~d}$ incubation at $4^{\circ} \mathrm{C}$ (Randazzo et al., 2009). Dips containing the bacteriocins coagulin or nisin $\mathrm{Z}$ caused a 3.2 to $3.5 \log$ CFU/g reduction in L. monocytogenes (initially $4.8 \pm 0.1 \log \mathrm{CFU} / \mathrm{g}$ ) on iceberg lettuce. However, after $7 \mathrm{~d}$ incubation at $4^{\circ} \mathrm{C}$, there was no statistical difference in $L$. 
monocytogenes between bacteriocin-treated and untreated lettuce (Allende et al., 2007). Bacteriocin treatments successfully decreased L. monocytogenes populations upon initial contact, but antimicrobial activity was not present at the end of $7 \mathrm{~d}$.

Purified bacteriocins alone do not typically inhibit Gram negative organisms, but antimicrobial activity can be enhanced with the addition other antimicrobial compounds. A study by Cobo Molinos et al. (2008) investigated the antimicrobial activity of the combination of the bacteriocin enterocin AS-48, produced by Enterococcus faecalis A48-32, with weak acids, chlorine, and the chelator EDTA against $S$. enterica on soybean sprouts. Enterocin AS-48 alone did not result in a significant decrease in S. enterica levels. However, combining enterocin AS-48 with $1.5 \%$ (w/v) lactic acid, $0.1 \%(w / v)$ polyphosphoric acid, $100 \mathrm{ppm}$ chlorine, or $100 \mathrm{mM}$ EDTA all resulted in approximately $4 \log$ reductions in S. enterica (initially approximately $5 \log$ CFU/g) compared to enterocin AS-48 alone. After $48 \mathrm{~h}$ incubation at $15^{\circ} \mathrm{C}$, S. enterica populations were significantly lower $(\mathrm{P}<0.05)$ in the enterocin AS-48 combination treatments than in enterocin AS-48 only treatments; the most effective combination was with lactic acid, followed by EDTA, chlorine, and polyphosphoric acid. The combination of enterocin AS-48 and 0.4\% (w/v) polyphosphoric acid was also applied to E. coli O157:H7 CECT 4972-inoculated soybeans; E. coli $\mathrm{O} 157: \mathrm{H} 7$ was undetectable after $48 \mathrm{~h}$ at $6^{\circ} \mathrm{C}$ and after $24 \mathrm{~h}$ at $15^{\circ} \mathrm{C}$, while soybeans treated with only enterocin AS- 48 had approximately 5.8 and $6.1 \log \mathrm{CFU} / \mathrm{g}$ E. coli after $48 \mathrm{~h}$ incubation at 6 and $15^{\circ} \mathrm{C}$, respectively. 


\subsubsection{Bacillus Species}

Bacillus are rod-shaped, Gram positive, aerobic or facultatively anaerobic bacteria. These endospore-formers are widespread throughout the environment, with soil being their primary habitat (De Vos et al., 2009). Several species of Bacillus, including Bacillus subtilis, Bacillus amyloliquefaciens, and Bacillus licheniformis, are extensively utilized in the industrial production of enzymes such as proteases, amylases, and lipases because of their ability to secrete these compounds in high quantity (Westers et al., 2004; Maarten van Dijl and Hecker, 2013). There is much diversity within the genus and a wide variety of secondary metabolites are synthesized, including lipopeptides, polyketides, and bacteriocins and bacteriocin-like compounds.

Lipopeptides are biosurfactants consisting of a cyclic peptide chain attached to a fatty acid; these compounds are produced through non-ribosomal synthesis. Lipopeptides are separated into three families based on their molecular structure: surfactin, iturin, and fengycin. These potent biosurfactants exert strong antifungal activity and some antimicrobial activity through membrane disruption (Arguelles-Arias et al., 2009; Sansinenea and Ortiz, 2011; Mongkolthanaruk, 2012; Christie, 2014).

Lipopeptides belonging to the surfactin family are powerful biosurfactants and exhibit antifungal, antimicrobial and antiviral activity. Two novel lipopeptides belonging to the surfactin family produced by $B$. amyloliquefaciens BO5A inhibited the growth of several fungal phytopathogens in vitro, including Fusarium oxysporum, Aspergillus niger, and Trichoderma harzianum (Romano et al., 2013). Surfactin has also shown antimicrobial and antiviral activity; it has demonstrated suppression of L. monocytogenes 
(Sabaté and Audisio, 2013), S. enterica ser. Enteritidis (Huang et al., 2011), and both enveloped and nonenveloped viruses (Kracht et al., 1999; Huang et al., 2006).

Iturin family lipopeptides are strongly antifungal. Iturin A suppressed the growth of Podosphaera fusca (Romero et al., 2007) and F. oxysporum (Chen et al., 2014), and decreased the disease incidence of the fungal phytopathogens Alternaria citri, Colletotrichum gloeosporioides, and Penicillium crustosum on Valencia oranges (Arrebola et al., 2010). The iturin bacillomycin D has demonstrated broad spectrum fungal inhibition in vitro, including the inhibition of the phytopathogens $F$. oxysporum (Moyne et al., 2001; Yuan et al., 2012), Aspergillus flavus, and C. gloeosporioides (Moyne et al., 2001). Mycosubtilin, also belonging to the iturin family, has antifungal activity; it decreased Lettuce Downy Mildew, caused by Bremia lactucae, by $82.7 \%$ when applied at $100 \mathrm{mg} / \mathrm{L}$ to growing lettuce (Deravel et al., 2014).

Lipopeptides belonging to the fengycin family are antifungal, with good inhibition of filamentous fungi (Tao et al., 2011). Fengycin suppressed the growth of Rhizopus stolonifer (Tao et al., 2011; Tang et al., 2014), F. oxysporum f. sp. spinaciae (Zhao et al., 2014) and Bot. cinerea in vitro (Romero et al., 2007). Fengycin also inhibited the fungal phytopathogens Pyricularia oryzae, Curvularia lunata, Alternaria kikuchiana, and Rhizoctonia solani (Vanittanakom and Leoffler, 1986).

In addition to exerting fungal inhibition, lipopeptide-producing species of Bacillus can also act as antimicrobial agents. B. amyloliquefaciens S20, a Iturin A-producing strain, inhibited the bacterial phytopathogen Ralstonia solanacearum, the causative agent of Brown Rot, Bacterial Wilt, or Southern Wilt in many different crops, in vitro (Chen et al., 2014). Broad spectrum inhibition of Gram positive and Gram negative foodborne 
pathogens, including L. monocytogenes, B. cereus, Salmonella, and E. coli 81 nr 149 SKN 541 has been demonstrated by strains of B. amyloliquefaciens ssp. plantarum producing surfactins, iturins, and other lipopeptides (Compaoré et al., 2013).

Proteinaceous antimicrobial compounds produced by some Bacillus species include polyketides and bacteriocins and bacteriocin-like compounds. Polyketides are synthesized by polyketide synthases, while bacteriocins and bacteriocin-like compounds are ribosomally synthesized. Some species of Bacillus produce the polyketides difficidin and bacillaene (Chen et al., 2006, 2009; Arguelles-Arias et al., 2009; Mongkolthanaruk, 2012). Difficidin has broad-spectrum antimicrobial activity against Gram positive and Gram negative foodborne pathogens including Staphylococcus aureus, E. coli, S. enterica ser. Typhimurium, Clostridium perfringes, and Clostridium difficile (Zimmerman et al., 1987), as well as the ability to inhibit Erwinia amylovora, the causative agent of Fire Blight in orchard trees (Chen et al., 2009).

In addition to polyketides, several different bacteriocins and bacteriocin-like compounds are produced by Bacillus species. Bacteriocins from Bacillus follow a classification scheme similar to that of LAB bacteriocins: Class I) post-translationally modified peptides, Class II) unmodified peptides, and Class III) large proteins (Abriouel et al., 2011). Subtilin, a Class I bacteriocin, is similar in structure to nisin and exhibits antimicrobial activity against a broad spectrum of Gram positive organisms, including Listeria species, by causing cell leakage (Parisot et al., 2008; Lee and Kim, 2011). Mersacidin, also a Class I bacteriocin, has shown inhibition of methicillin-resistant Staphylococccus aureus by inhibiting peptidoglycan synthesis (Brötz et al., 1995). The pediocin-like Class II bacteriocin coagulin has a narrow spectrum of inhibition against 
Gram positive bacteria, including L. monocytogenes (Hyronimus et al., 1998; Le Marrec et al., 2000). Cerein is a Class III bacteriocin that inhibits L. monocytogenes, but does not exert a strong effect on the Gram negative pathogens $S$. enterica ser. Enteritidis or E. coli (Bizani et al., 2005). Thuricin, another Class III bacteriocin, inhibits Gram positive organisms, especially those closely related to Bacillus thuringiensis (Favret and Yousten, 1989; Gray et al., 2006).

Members of the Bacillus genus synthesize a number of compounds that have antifungal, antimicrobial, and biosurfactant activity, making Bacillus potential biocontrol agents. Antifungal and antimicrobial compounds produced by species of this genus can potentially control pathogenic organisms on produce, and the addition of Bacillussynthesized biosurfactants to a produce wash system may increase the efficacy of an antimicrobial agent.

\subsection{Antifungal Activity on Produce}

Some B. subtilis and Bacillus megaterium strains have demonstrated fungal inhibition to varying degrees. In a study conducted by Donmez et al. (2011), several Bacillus species were screened for inhibitory activity against Bot. cinerea. Of the organisms screened, four strains of $B$. subtilis and one strain of B. megaterium showed strong inhibition of Bot. cinerea in vitro. Two of the B. subtilis isolates, B. subtilis MFD20 and B. subtilis MFD-Ü2, inhibited Bot. cinerea when inoculated directly onto strawberries; B. megaterium GC subgroup B CD-8 did not suppress Bot. cinerea (Donmez et al., 2011). B. subtilis has also shown broad-spectrum fungal suppression. $B$. 
subtilis $\mathrm{B} 25$, isolated from banana rhizosphere, inhibited several fungal species, including Bot. cinerea and F. oxysporum f. sp. cubense (Tan et al., 2013).

\subsection{Antimicrobial Activity on Produce}

Bacillus species that suppress foodborne pathogens have also been identified.

Bacillus licheniformis VPS50.2 inhibited L. monocytogenes in vitro; a novel bacteriocin, licheniocin, was identified as the antimicrobial compound (Berić et al., 2013). B. thuringiensis ssp. kurstaki produces the bacteriocin thuricin $\mathrm{Bn} 1$, which exhibits anitlisterial activity in vitro (Ugras et al., 2013). Bacillus YD1 also demonstrated inhibitory activity on bell peppers; $\log$ reductions of $3.4,3.6$, and 3.3 of $L$. monocytogenes, S. enterica ser. Mbandaka, and E. coli O157:H7, respectively, were observed after $2 \mathrm{~d}$ incubation at $20^{\circ} \mathrm{C}$ (Liao, 2009).

\subsubsection{Other Bioprotective Species}

\subsection{Serratia plymuthica}

Serratia plymuthica is a member of the Enterobacteriaceae family; it is a Gram negative, facultatively anaerobic, rod-shaped bacterium that occurs in the natural environment (soil, water, plant surfaces) (Brenner et al., 2005a). Strains of S. plymuthica produce bioactive compounds. The antifungal compound haterumalide produced by $S$. plymuthica A 153 demonstrated broad-spectrum activity that suppressed the spore germination of Sclerotinia sclerotiorum, the fungus responsible for White Mold on legumes and several fruits and vegetables, as well as inhibition of several other filamentous fungi in vitro (Levenfors et al., 2004). S. plymuthica IC14, producing the 
antifungal compound pyrrolnitrin in addition to proteases and chitinolytic enzymes, reduced Leaf Mold caused by Bot. cinerea and S. sclerotiorum on cucumber seedlings by $62.7 \%$ and $69.4 \%$, respectively (Kamensky et al., 2003).

\subsection{Ochrobactrum anthropi}

Ochrobactrum anthropi is a rod shaped, Gram negative, obligatorily aerobic bacteria that can be isolated from soil (Brenner et al., 2005b). This species has demonstrated broad-spectrum antifungal activity in vitro. O. anthropi inhibited the fungal phytopathogens Scelorotium sp. (Chaiharn et al., 2009), Phellinus noxius, Poria hypolaterita (Chakraborty et al., 2009), F. oxysporum, and $R$. solani (Sowndhararajan et al., 2013). Antifungal activity was most likely the result of cellulase, $\beta$ 1,3 glucanase, and chitinase production (Chaiharn et al., 2009).

The bioprotective activity of $O$. anthropi has also been evaluated on tea plants. When applied to the soil of tea plants, O. anthropi TRS-2 promoted plant growth (based on an increase in plant height, number of branches, and number of leaves) and reduced the incidence of Brown Rot, caused by P. noxius (Chakraborty et al., 2009). O. anthropi BMO-111 also reduced Blister Blight disease, a fungal plant disease caused by Exobasidium vexans (Sowndhararajan et al., 2013).

\subsection{Oceanobacillus Species}

Oceanobacillus species are Gram positive, endospore-forming bacteria that are alkaliphilic and aerobic or facultatively anaerobic. Members of this genus are halotolerant or halophilic, with optimal growth occurring at $\mathrm{NaCl}$ concentrations of $3-10 \%(\mathrm{w} / \mathrm{v})$; 
some species of Oceanobacillus are able to grow in up to $20 \% \mathrm{NaCl}$ (De Vos et al., 2009). Oceanobacillus sp. BRI 10, isolated from Antarctic sea water, produced a biosurfactant composed of carbohydrates, lipid, and amino acids. The biosurfactant was inhibitory of E. coli NCIM 2065, but showed no antimicrobial activity against Gram positive S. aureus or Streptococcus faecalis (Jadhav et al., 2013). Biosurfactant production has also been identified in Oceanobacillus picturae, and its lysate demonstrated antifungal activity; it was inhibitory of Fusarium species in vitro (Pakpitcharoen et al., 2008).

\subsection{Commercially Available Biocontrol Products}

\subsubsection{Antifungal Biocontrol Products}

Biocontrol products are commercially available for the suppression of fungal phytopathogens. Serenade ${ }^{\circledR}$ Optimum, manufactured by Bayer CropScience, utilizes $B$. subtilis QST 713 to control Bot. cinerea and Colletotrichum, among other fungal phytopathogens, on berries, bulb vegetables, tomatoes, and stone fruit, and Sclerotinia on leafy greens (Bayer CropScience LP, 2013a). Sonata ${ }^{\circledR}$, also manufactured by Bayer CropScience, contains Bacillus pumilus QST 2808. It is used for the suppression of Powdery Mildew on a variety of crops, including berries, leafy vegetables, fruiting vegetables, cucumbers, melon, and squash (Bayer CropScience LP, 2013b). DoubleNickel LC is another commercially available biocontrol product that can be applied to the soil or to the plant; B. amyloliquefaciens strain D747 is the active 
ingredient. It is used for the suppression of a variety of fungal phytopathogens including Bot. cinerea, Fusarium, Rhizoctonia, and Colletotrichum (Certis USA LLC, 2012).

\subsubsection{Antimicrobial Biocontrol Product}

Lactic Acid Bacteria blends are available commercially for the control of foodborne pathogens in foods. LactiGuard ${ }^{\mathrm{TM}}$, a commercially available LAB product produced by Nutrition Physiology Company, LLC, is used to control Listeria, Salmonella, E. coli, Campylobacter, and other pathogenic bacteria on raw whole and ground meat, meat and poultry carcasses, and ready-to-eat meat products (Nutrition Physiology Company, 2012). LactiGuard ${ }^{\mathrm{TM}}$ significantly suppressed the growth of $L$. monocytogenes in frankfurters (Koo et al., 2012), Salmonella in turkey and beef (Echeverry et al., 2010; Dow et al., 2011), and E. coli O157:H7 in beef (Echeverry et al., 2010). Because of the ability of LactiGuard ${ }^{\mathrm{TM}}$ to suppress Gram positive and Gram negative pathogen growth during storage, research into its application has been expanded to fresh produce.

The antimicrobial activity of LactiGuard ${ }^{\mathrm{TM}}$ against $E$. coli $\mathrm{O} 157: \mathrm{H} 7$ and $S$. enterica on spinach has recently been investigated. LactiGuard ${ }^{\mathrm{TM}}$ (applied at 7-8 log $\mathrm{CFU} / \mathrm{g}$ ) reduced both pathogen populations by $1-2 \log \mathrm{CFU} / \mathrm{g}$ after $6 \mathrm{~d}$ storage at $4-7^{\circ} \mathrm{C}$, although the magnitude of the difference was affected by pathogen inoculation level. After $6 \mathrm{~d}$ storage at $4-7^{\circ} \mathrm{C}$, E. coli $\mathrm{O} 157: \mathrm{H} 7$ populations for all inoculation levels were between 5 and $6.3 \log$ CFU/g on untreated spinach. LactiGuard ${ }^{\mathrm{TM}}$-treated spinach had lower levels of E. coli $\mathrm{O} 157: \mathrm{H7}$; spinach inoculated with E. coli $\mathrm{O} 157: \mathrm{H} 7$ at 2, 4, and 6 $\log \mathrm{CFU} / \mathrm{g}$ had a 2.1, 0.7, and $1.43 \log \mathrm{CFU} / \mathrm{g}$ difference in E. coli $\mathrm{O} 157: \mathrm{H} 7$ levels 
between LactiGuard ${ }^{\mathrm{TM}}$-treated and untreated spinach (Brown et al., 2011; Cálix-Lara et al., 2014).

S. enterica at 2 and $4 \log \mathrm{CFU} / \mathrm{g}$ inoculation levels followed a pattern similar to $E$. coli $\mathrm{O} 157: \mathrm{H} 7$. After $6 \mathrm{~d}$ storage at $7^{\circ} \mathrm{C}$, S. enterica populations on untreated spinach were between 4 and $5 \log$ CFU/g for both inoculation levels. There was a 0.7 and $1.9 \log$ CFU/g difference in S. enterica between LactiGuard ${ }^{\mathrm{TM}}$-treated and untreated spinach, respectively (Cálix-Lara et al., 2014).

Although LactiGuard ${ }^{\mathrm{TM}}$ was able to suppress the growth of E. coli $\mathrm{O} 157: \mathrm{H} 7$ and S. enterica inoculated at low and high levels for $6 \mathrm{~d}$ at refrigeration temperatures, it did not maintain its antimicrobial activity over a longer storage period. At both pathogen inoculation levels, E. coli $\mathrm{O} 157: \mathrm{H} 7$ and $S$. enterica populations on untreated spinach were approximately 6 and $5 \log \mathrm{CFU} / \mathrm{g}$, respectively, after $12 \mathrm{~d}$ incubation at $7^{\circ} \mathrm{C}$. Spinach inoculated with $2 \log \mathrm{CFU} / \mathrm{g}$ pathogen had $0.3 \log$ and $0.7 \log$ less E. coli O157:H7 and S. enterica, respectively, on LactiGuard ${ }^{\text {TM}}$-treated spinach than on untreated spinach. There was no statistical difference between LactiGuard ${ }^{\mathrm{TM}_{-}}$-treated and untreated spinach in E. coli $\mathrm{O} 157: \mathrm{H} 7$ or $S$. enterica populations at a 4 log CFU/g inoculation level (Cálix-Lara et al., 2014).

\subsection{Conclusion}

The consumption of fresh fruits and vegetables is increasing in the United States, and maintaining crop and consumer health is important in sustaining the growing 
agricultural industry. With the increase in consumer demand for more natural products and the phasing out of chemical fumigants and pesticides, the need for an alternative or additional means of the microbial control of phytopathogens affecting crop health is needed. The incidence of foodborne disease outbreaks involving L. monocytogenes, Salmonella, and E. coli $\mathrm{O} 157: \mathrm{H} 7$ on fresh and fresh-cut produce has also demonstrated the need for a novel approach to pathogen management to ensure consumer safety. Biocontrol offers a possible supplement to conventional treatments in the management of plant and foodborne pathogens on produce.

A biologically-based approach to enhancing the safety of minimally processed fruits and vegetables is a novel way to exert control over undesirable microorganisms. Several species of bacteria produce compounds with antifungal and antimicrobial activity. The production of bioactive compounds such as bacteriocins, lipopeptides, and enzymes has been identified in many species of LAB, Bacillus, Serratia, Ochrobactrum, and Oceanobacillus and suppression of plant and foodborne pathogens has been observed both in vitro and on fresh produce. Application of these bioprotective species to fresh and fresh-cut produce has yielded promising but mixed results; the effect of these biocontrol bacteria on fungal phytopathogens, L. monocytogenes, Salmonella, and E. coli O157:H7 is not only dependent on the bioprotective agent and the pathogen, but also on food matrix. Therefore, antifungal and antimicrobial efficacy must be evaluated for each bioprotective agent-pathogen-matrix combination. 


\section{ANTIFUNGAL SCREENING OF BIOPROTECTIVE ISOLATES AGAINST}

BOTRYTIS CINEREA, FUSARIUM PALLIDOROSEUM, AND FUSARIUM MONILIFORME

\subsection{Introduction}

Crop loss due to phytopathogenic microorganisms has a dramatic impact on the agricultural industry. Botrytis cinerea and Fusarium species are fungal phytopathogens that cause substantial losses across a wide variety of crops both before and after harvest. In the field, Bot. cinerea, the fungi responsible for the plant diseases gray mold and Botrytis rot, affects over 200 crop species, ranging from ornamentals to fruits and vegetables like lettuce, grapes, and strawberries (Elmer and Reglinski, 2006; Williamson et al., 2007). Fusarium Wilt and Fusarium Rot, caused by various Fusarium species, also affect a wide array of crops pre-harvest including lettuce, soybeans, strawberries, tomatoes, peppers, potatoes, and oranges (Miller et al., 1996; Díaz Arias et al., 2013; UC IPM, 2014a). Postharvest, Bot. cinerea and Fusarium species continue to contribute to commodity loss. Bot. cinerea causes the rapid decay of fresh produce because of its ability invade damaged, weak, or rapidly senescing tissue (Swartzberg et al., 2007), decreasing shelf life. Fusarium species are also problematic during postharvest storage, particularly in cereal grains and animal feeds (D’Mello et al., 1999). The mycotoxins fumonisin $\mathrm{B}_{1}$ and $\mathrm{B}_{2}$, trichothecenes, and zearalenone are produced by species of Fusarium, can cause disease in humans and animals (Peraica et al., 1999; Zinedine et al., 
2007). While there are many steps taken before and after harvest to mitigate the impact of these fungi, they are still problematic to the agricultural industry.

Management of fungal phytopathogen before harvest includes clearing fields of plant detritus, selecting locations without a history of fungal disease, using chemical fungicides (Williamson et al., 2007b; UC IPM, 2014a). Postharvest, the microbial load of fruits and vegetables is reduced by mechanical scrubbing and washing in disinfectants such as chlorine, and fungal growth is slowed by storing produce at low temperatures (Suslow, 1997; FDA, 2013b). Fumigation with fungicides and sulfur dioxide and irradiation are also used to control spoilage and phytopathogenic fungi after harvest (Smilanick et al., 1990; U.S. EPA, 2002, 2004; FDA, 2014b). The postharvest control of fungi in cereals and grains includes quick and efficient drying and maintaining a moisture content of less than $14 \%$, storage in hygienic silos, and treatment with salts of propionic and sorbic acids (Magan and Aldred, 2007). Although the use of chemicals to control fungal phytopathogens before and after harvest is widespread, increases in fungicide resistance and health and environmental concerns associated with the use of harsh chemicals have created the need for an alternative means of treatment.

The use of bioprotective bacteria in an integrated pest management plan or as a postharvest treatment could help to protect crops against fungi and extend the shelf life of fresh produce. Several bacterial species across a range of genera produce compounds active against phytopathogenic fungi. Synthesis of the antifungal lipopeptides have been identified in species of Bacillus, including B. amyloliquefaciens (Romero et al., 2007; Arrebola et al., 2010; Zhao et al., 2014), B. subtilis (Vanittanakom and Leoffler, 1986; Moyne et al., 2001), and B. thuringiensis (Kim et al., 2004; Roy et al., 2013). Species of 
LAB also produce antifungal compounds; these include organic acids, phenyllactic acid, 3-hydroxy fatty acids, and cyclic dipeptides (Strom et al., 2002; Magnusson et al., 2003; Ryan et al., 2011). The antifungal activity of bioprotective bacteria in vitro has translated into fungal suppression when applied both in the field and postharvest.

Bioprotective bacteria have shown antifungal efficacy when applied to crops before harvest. Species of Bacillus have reduced the incidence of Fusarium disease in maize and tomato plants when applied pre-harvest (Bressan and Figueiredo, 2010; Prabhukarthikeyan et al., 2014) and decreased fruit rot caused by Bot. cinerea on strawberry plants (Ilhan and Karabulut, 2013). Biocontrol agents have also suppressed fungal growth on fruits and vegetables when applied postharvest. Various species of Bacillus have been shown to reduce Bot. cinerea infection on pears, strawberries and tomatoes (Mari et al., 1996a; b; Donmez et al., 2011). Lb. plantarum suppressed Bot. cinerea and $F$. graminearum on cucumbers (Sathe et al., 2007), and P. pentosaceus suppressed the growth of Penicillium expansum on pears (Crowley et al., 2013). Fungal suppression by various bacterial species demonstrates their potential use as biocontrol agents for the control of fungal phytopathogens both before and after harvest. Several species of Bacillus are commercially available as pre-harvest biocontrol treatments for various fruits and vegetables; Serenade ${ }^{\circledR}$ Optimum utilizes B. subtilis (Bayer CropScience LP, 2013a), Sonata ${ }^{\circledR}$ contains B. pumilus (Bayer CropScience LP, 2013b), and DoubleNickel LC uses B. amyloliquefaciens as the active ingredient (Certis USA LLC, 2012). 
The purpose of this study was to screen 22 bacterial isolates, which included Bacillus and LAB species, for antifungal activity against Botrytis cinerea, Fusarium pallidoroseum, and Fusarium moniliforme.

\subsection{Materials and Methods}

\subsubsection{Antifungal Screening}

\subsubsection{Fungal Pathogens}

All fungi were obtained from American Type Culture Collection (ATCC;

Manassas, VA). Working cultures of Botrytis cinerea ATCC 46522, Fusarium

pallidoroseum ATCC 48152, and Fusarium moniliforme ATCC 60846 (Table 3.1) were maintained on Potato Dextrose Agar (PDA, Becton, Dickson and Company; Sparks, MD) at $4^{\circ} \mathrm{C}$ and as fungal-colonized PDA plugs suspended in Potato Dextrose Broth (PDB, Becton, Dickson and Company; Sparks, MD) with $25 \%$ glycerol at $-70^{\circ} \mathrm{C}$ for long term storage.

\subsubsection{Bioprotective Isolates}

All bioprotective isolates were provided by BiOWiSH Technologies (Cincinnati, $\mathrm{OH})$. Working cultures of LAB isolates were maintained on de Man, Rogosa, Sharpe agar (MRS; Oxnoid; Basingstoke, Hampshire, UK) at $4{ }^{\circ} \mathrm{C}$ and all other bioprotective isolates on Tryptic Soy Agar (TSA; Remel, Lenexa, KS) or TSA with 5\% $\mathrm{NaCl}(w / w)$ at room temperature. For long term storage, isolates were kept in the appropriate growth media 
(Table 3.1) with $15 \%$ glycerol at $-70^{\circ} \mathrm{C}$ with the exception of Bacillus clausii and Bacillus firmus - these two isolates were stored as spore crops at $6^{\circ} \mathrm{C}$. Bacillus subtilis fermentate were stored at $6^{\circ} \mathrm{C}$. Prior to use in screening, LAB isolates were inoculated into $10 \mathrm{~mL}$ of MRS Broth and incubated at $35^{\circ} \mathrm{C}$ for $18-24 \mathrm{~h}$. All other isolates were inoculated into $10 \mathrm{~mL}$ of Tryptic Soy Broth (TSB; Remel, Lenexa, KS) or TSB with 5\% $\mathrm{NaCl}(\mathrm{w} / \mathrm{w})$ and incubated with agitation on an orbital shaker at either 30 or $35^{\circ} \mathrm{C}$, depending on the isolate, for 18-24 h.

\subsubsection{Antifungal Screening}

A loopful of prepared bioprotective cultures was spot-inoculated in two locations on the surface of solidified media; the type of screening media was determined by the growth requirements of the isolate (Table 3.1). Using a cork borer, a $9 \mathrm{~mm}$ plug was cut from the perimeter of a working culture of fungal pathogen and placed in the center of the isolate-inoculated plate. Plates were wrapped in Parafilm ${ }^{\circledR}$ and incubated at $24^{\circ} \mathrm{C}$ for 10 d. The diameter of the fungal colony between the two isolate inoculation locations was measured daily, beginning on Day 3. A fungus-inoculated plate of each screening media was used as a control. Percent fungal inhibition was determined using the following equation:

$\frac{\text { (control fungus diameter)-(isolate fungus diameter) }}{\text { (control fungus diameter) }} \times 100 \%=\%$ inhibition Equation 1. Percent fungal inhibition 
Table 3.1. Bioprotective isolates and fungal phytopathogens

\begin{tabular}{|c|c|c|c|}
\hline Isolate & Growth medium & $\begin{array}{c}\text { Incubation } \\
\text { temperature }\end{array}$ & $\begin{array}{c}\begin{array}{c}\text { Screening } \\
\text { medium }\end{array} \\
\end{array}$ \\
\hline \multicolumn{4}{|l|}{ Bioprotective isolate } \\
\hline Bacillus amyloliquefaciens BA1 & TSB & $35^{\circ} \mathrm{C}$ & PDA \\
\hline Bacillus amyloliquefaciens BA2 & TSB & $35^{\circ} \mathrm{C}$ & PDA \\
\hline Bacillus amyloliquefaciens BA3 & TSB & $35^{\circ} \mathrm{C}$ & PDA \\
\hline Bacillus amyloliquefaciens BA4 & TSB & $35^{\circ} \mathrm{C}$ & PDA \\
\hline Bacillus amyloliquefaciens BA5 & TSB & $35^{\circ} \mathrm{C}$ & PDA \\
\hline Bacillus clausii & TSB & $30^{\circ} \mathrm{C}$ & PDA \\
\hline Bacillus coagulans & TSB & $35^{\circ} \mathrm{C}$ & PDA \\
\hline Bacillus firmus & TSB & $30^{\circ} \mathrm{C}$ & TSA \\
\hline Bacillus licheniformis & TSB & $35^{\circ} \mathrm{C}$ & PDA \\
\hline Bacillus megaterium & TSB & $35^{\circ} \mathrm{C}$ & PDA \\
\hline Bacillus pumilus & TSB & $35^{\circ} \mathrm{C}$ & PDA \\
\hline Bacillus sphaericus & TSB & $30^{\circ} \mathrm{C}$ & PDA \\
\hline Bacillus thiaminolyticus & TSB & $30^{\circ} \mathrm{C}$ & TSA \\
\hline Bacillus thuringiensis BT1 & TSB & $35^{\circ} \mathrm{C}$ & PDA \\
\hline Bacillus thuringiensis $\mathrm{BT} 2$ & TSB & $35^{\circ} \mathrm{C}$ & PDA \\
\hline Lactobacillus amylovorus & MRS & $35^{\circ} \mathrm{C}$ & MRS \\
\hline Lactobacillus plantarum & MRS & $35^{\circ} \mathrm{C}$ & MRS \\
\hline Oceanobacillus sojae & $\mathrm{TSB} \mathrm{w} / 5 \% \mathrm{NaCl}(\mathrm{w} / \mathrm{w})$ & $35^{\circ} \mathrm{C}$ & TSA \\
\hline Ochrobactrum anthropi & TSB & $35^{\circ} \mathrm{C}$ & PDA \\
\hline Pediococcus acidilactici & MRS & $35^{\circ} \mathrm{C}$ & MRS \\
\hline Pediococcus pentosaceus & MRS & $35^{\circ} \mathrm{C}$ & MRS \\
\hline Serratia plymuthica & TSB & $30^{\circ} \mathrm{C}$ & PDA \\
\hline \multicolumn{4}{|l|}{ Fungal phytopathogen } \\
\hline Botrytis cinerea & PDA & $24^{\circ} \mathrm{C}$ & $\mathrm{N} / \mathrm{A}^{1}$ \\
\hline Fusarium pallidoroseum & PDA & $24^{\circ} \mathrm{C}$ & N/A \\
\hline Fusarium moniliforme & PDA & $24^{\circ} \mathrm{C}$ & N/A \\
\hline
\end{tabular}

${ }^{\mathrm{T}} \mathrm{N} / \mathrm{A}:$ not applicable 


\subsubsection{Biosurfactant Screening}

\subsubsection{Bioprotective Isolates}

Bioprotective isolates were inoculated as previously described and incubated for 7 d; all isolates but LAB were incubated with agitation on an orbital shaker. After incubation, cultures were centrifuged at 3,000 RPM for 15 min and the supernatant was used in the biosurfactant screening.

\subsubsection{Drop-Collapse Test}

The drop collapse test, which was used to detect biosurfactant production, was adapted from Turgrul and Cansunar (2005). Briefly, the surface of a petri dish was coated with mineral oil and allowed to sit at room temperature for at least $1 \mathrm{~h}$. A $20 \mu \mathrm{L}$ aliquot of bioprotective culture supernatant was placed onto the oiled surface at a $45^{\circ}$ angle and the diameter of the drop was measured after $2 \mathrm{~min}$.

\subsubsection{Statistical Analysis}

The drop-collapse test was completed twice in duplicate. Data were analyzed using Analysis of Variance (ANOVA); analysis was completed with Minitab 16 (Minitab Inc., State College, PA). Dunnett's test was used to identify isolate drop diameters that were significantly larger than the diameter of the media control, which indicated biosurfactant production by the bioprotective isolates. An isolate was considered to be a biosurfactant producer if the diameter of the supernatant drop was significantly larger than the diameter of the media control $(\alpha=0.05)$. 


\subsection{Results and Discussion}

\subsubsection{Antifungal Activity}

\subsubsection{Bacillus Species}

Bacillus species have been investigated as possible biocontrol agents because of their ability to synthesize antifungal compounds, including lipopeptides and other antibiotics. Several Bacillus species have demonstrated antifungal activity against fungal phytopathogens, including Bot. cinerea and/or Fusarium species, in vitro (Agarry et al., 2005; Tendulkar et al., 2007; Saidi et al., 2009; Gomaa, 2012; Wang et al., 2014). However, antifungal capability is a function of bacterial strain and fungal pathogen. In this study, eight of the Bacillus isolates suppressed the growth of Bot. cinerea, F. pallidoroseum, and F. moniliforme (Table 3.2, Figure 3.1, Appendix B); Bacillus megaterium was the most effective against all three fungi, followed by Bacillus coagulans and several strains of B. amyloliquefaciens. Fungal inhibition by these isolates ranged from 51-62\% for Bot. cinerea, 60-69\% for $F$. pallidoroseum, and 40-61\% for $F$. moniliforme (Table 3.2). Three Bacillus isolates inhibited Bot. cinerea but did not suppress the growth of the Fusarium species tested. This screening identified eleven Bacillus isolates capable of fungal suppression in vitro; additional evaluation is required to determine the antifungal ability of these isolates when applied to produce.

Inhibition of fungal phytopathogens by Bacillus species has not only been observed in vitro, but also in planta. The application of Bacillus species pre-harvest reduced the incidence and severity of diseases caused by F. oxysporum (Saidi et al., 2009), Alternaria solani, and Phytophthora infestans (Chowdappa et al., 2013) on tomato 
plants and Bot. cinerea fruit rot on strawberry plants (Ilhan and Karabulut, 2013).

Postharvest application of Bacillus species has also caused fungal suppression; decay was reduced on pears, tomatoes, bananas, and oranges (Mari et al., 1996a; b; Alvindia and Natsuaki, 2009; Arrebola et al., 2010). Further testing of the isolates used in this study, including challenge studies on various types of produce, is needed to determine their possible use as biocontrol agents.

Table 3.2. Fungal inhibition of bioprotective isolates against Botrytis cinerea, Fusarium moniliforme, and Fusarium pallidoroseum after $10 \mathrm{~d}$ incubation at $24^{\circ} \mathrm{C}$

\begin{tabular}{|c|c|c|c|}
\hline \multirow[b]{2}{*}{ Bioprotective isolate } & \multicolumn{3}{|c|}{$\%$ inhibition } \\
\hline & $\begin{array}{l}\text { Botrytis } \\
\text { cinerea }\end{array}$ & $\begin{array}{c}\text { Fusarium } \\
\text { pallidoroseum }\end{array}$ & $\begin{array}{c}\text { Fusarium } \\
\text { moniliforme }\end{array}$ \\
\hline B. amyloliquefaciens BA1 & $52 \%$ & $62 \%$ & $53 \%$ \\
\hline B. amyloliquefaciens BA2 & $56 \%$ & $63 \%$ & $60 \%$ \\
\hline B. amyloliquefaciens BA3 & $58 \%$ & $67 \%$ & $61 \%$ \\
\hline B. amyloliquefaciens BA4 & $60 \%$ & $67 \%$ & $60 \%$ \\
\hline B. amyloliquefaciens BA5 & $61 \%$ & $69 \%$ & $61 \%$ \\
\hline B. clausii & $30 \%$ & $\mathrm{~N} / \mathrm{I}^{1}$ & $\mathrm{~N} / \mathrm{I}$ \\
\hline B. coagulans & $62 \%$ & $66 \%$ & $59 \%$ \\
\hline B. firmus & $49 \%$ & $\mathrm{~N} / \mathrm{I}$ & $\mathrm{N} / \mathrm{I}$ \\
\hline B. licheniformis & $\mathrm{N} / \mathrm{I}$ & $\mathrm{N} / \mathrm{I}$ & $\mathrm{N} / \mathrm{I}$ \\
\hline B. megaterium & $62 \%$ & $68 \%$ & $61 \%$ \\
\hline B. pumilus & $\mathrm{N} / \mathrm{I}$ & $\mathrm{N} / \mathrm{I}$ & $\mathrm{N} / \mathrm{I}$ \\
\hline B. sphaericus & N/I & N/I & N/I \\
\hline B. thiaminolyticus & $50 \%$ & N/I & N/I \\
\hline B. thuringiensis BT1 & $\mathrm{N} / \mathrm{I}$ & $\mathrm{N} / \mathrm{I}$ & $\mathrm{N} / \mathrm{I}$ \\
\hline B. thuringiensis BT2 & $56 \%$ & $68 \%$ & $58 \%$ \\
\hline Lb. amylovorus & $\mathrm{N} / \mathrm{I}$ & $\mathrm{N} / \mathrm{I}$ & $\mathrm{N} / \mathrm{I}$ \\
\hline Lb. plantarum & $36 \%$ & N/I & N/I \\
\hline O. sojae & $\mathrm{N} / \mathrm{I}$ & N/I & N/I \\
\hline O. anthropi & N/I & N/I & N/I \\
\hline P. acidilactici & $56 \%$ & N/I & $\mathrm{N} / \mathrm{I}$ \\
\hline$P$. pentosaceus & $46 \%$ & $\mathrm{~N} / \mathrm{I}$ & $\mathrm{N} / \mathrm{I}$ \\
\hline S. plymuthica & $51 \%$ & $60 \%$ & $40 \%$ \\
\hline
\end{tabular}

${ }^{\mathrm{I}} \mathrm{N} / \mathrm{I}$ : no inhibition; fungal colony grew over/around bacterial isolate colony. 


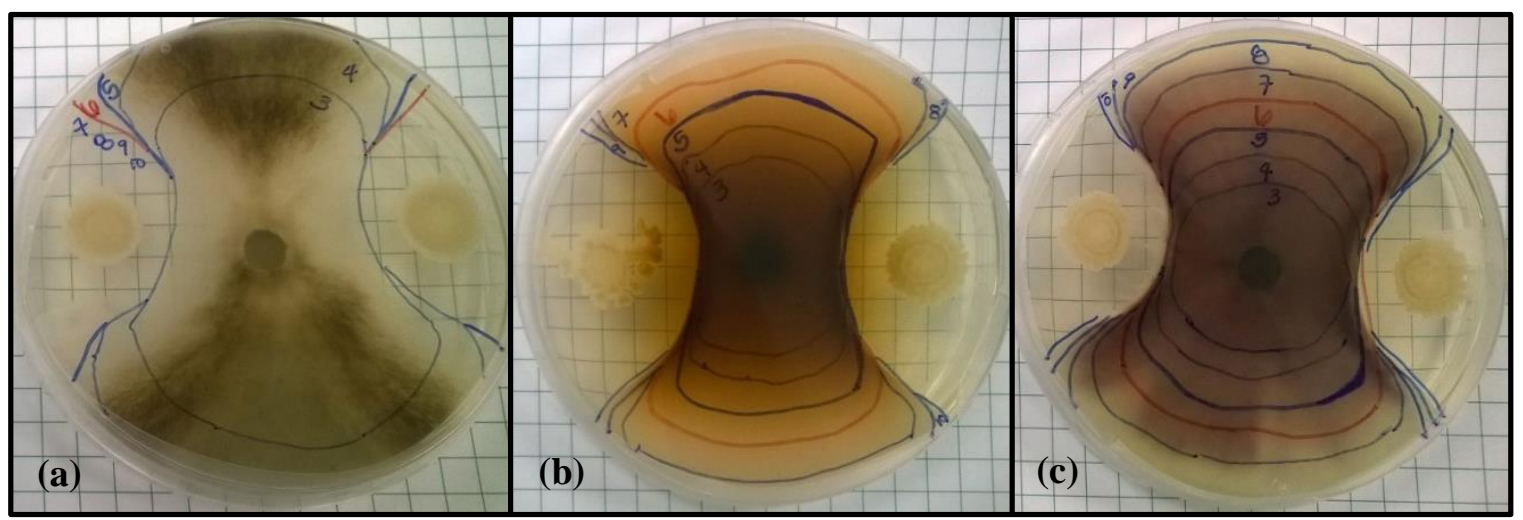

Figure 3.1. Antifungal screening of Bacillus amyloliquefaciens BA4 against Botrytis cinerea (a), Fusarium pallidoroseum (b), and Fusarium moniliforme (c). Markings indicate the border of the fungal colony each day of incubation, beginning on Day 3.

\subsubsection{Lactic Acid Bacteria}

Antifungal activity has also been detected from some LAB species; bioactive compounds produced by LAB include organic acids, phenyllactic acid, 3-hydroxy fatty acids, bacteriocins and bacteriocin-like substances, and cyclic dipeptides (Strom et al., 2002; Magnusson et al., 2003; Voulgari et al., 2010; Ryan et al., 2011; Gerez et al., 2013; Cortés-Zavaleta et al., 2014). Three of the four LAB isolates used in this study inhibited Bot. cinerea, but not F. pallidoroseum or F. moniliforme (Appendix B). P. acidilactici demonstrated the strongest antifungal activity, followed by $P$. pentosaceus and $L b$. plantarum; inhibition was $56 \%, 46 \%$, and $36 \%$ respectively (Table 3.2). Although these isolates were only effective against Bot. cinerea, other LAB species have demonstrated broad spectrum fungal inhibition when used as biocontrol agents on produce, but again efficacy varies between LAB and fungus species.

Pre- and postharvest application of LAB to agricultural crops has shown mixed results. $P$. acidilactici and $P$. pentosaceus decreased Fusarium infection on wheat seeds when germinated on PDA, but failed to significantly reduce disease incidence during greenhouse trials (Suproniene et al., 2014). In contrast, Lactobacillus species 
administered to tomato plants as a seed treatment or soil drench have promoted plant growth and mitigated the impact of F. oxysporum in potted trials (Hamed et al., 2011). When applied as a postharvest treatment, LAB have reduced the decay caused by Bot. cinerea and $F$. graminearum on cucumbers (Sathe et al., 2007) and decay by $P$. expansum on apples (Trias et al., 2008b) and pears (Crowley et al., 2013). Again, additional investigation of the three antifungal LAB isolates identified in this study is needed to evaluate their use as biocontrol agents for the control of phytopathogenic fungi on produce.

\subsubsection{Serratia plymuthica}

Serratia plymuthica is another species of bacteria that has demonstrated suppression of fungal phytopathogens. Synthesis of antifungal compounds such as pyrrolnitrin, haterumalide, siderophores, chitinolytic enzymes, and proteases has been detected in strains of S. plymuthica (Kamensky et al., 2003; Levenfors et al., 2004). In this study, S. plymuthica suppressed the growth of Bot. cinerea, F. pallidoroseum, and F. moniliforme (Table 3.2), making it a possible candidate for additional evaluation. The use of other strains of S. plymuthica as a biocontrol agent both pre- and postharvest has been investigated. Foliar application of S. plymuthica reduced disease caused by Bot. cinerea and Sclerotinia sclerotiorum in cucumber plants (Kamensky et al., 2003) and postharvest treatment of potatoes decreased the severity of dry rot caused by Fusarium sambucinum (Gould et al., 2008). 


\subsubsection{Isolates with No Antifungal Activity}

Antifungal activity is not only a function of bioprotective isolate and fungus species, it can also be affected by growth conditions. Culture conditions such as media composition, $\mathrm{pH}$, and incubation period and temperature can affect the production of antifungal compounds (Mandal et al., 2008; Shih et al., 2008). In this study, four Bacillus isolates, Lactobacillus amylovorus, Oceanobacillus sojae, and Ochrobactrum anthropi did not suppress Bot. cinerea, F. pallidoroseum, or F. moniliforme. Although these seven isolates did not inhibit any of the fungi against which they were challenged, this does not mean these isolates are incapable of producing antifungal compounds. The culture media and testing conditions used in this study may not have been optimal for the synthesis of bioactive compounds; further investigation is required to determine if these seven isolates truly do not inhibit Bot. cinerea, F. pallidoroseum, or F. moniliforme.

\subsubsection{Biosurfactant Activity}

\subsubsection{Bacillus Species, Oceanobacillus sojae, and Ochrobactrum anthropi}

In addition to reducing the surface tension of water, biosurfactant lipopeptides produced by bacteria have demonstrated antifungal activity (Kalinovskaya et al., 2002; Huszcza and Burczyk, 2006; Arguelles-Arias et al., 2009; Troyano Pueyo et al., 2009; Romano et al., 2013; Chen et al., 2014). These bioactive lipopeptides, including surfactin, mycosubtilin, fengycin, and iturin, affect cell membranes, causing membrane disruption and cell leakage (Makovitzki and Shai, 2005). In this study, biosurfactant production was identified in seven Bacillus isolates (Figure 3.2). B. megaterium, B. coagulans, B. thuringiensis BT2 and several B. amyloliquefaciens isolates demonstrated both strong 
biosurfactant activity and suppression of Bot. cinerea, F. pallidoroseum, and $F$. moniliforme, implying the ability to synthesize antifungal lipopeptides. The production of antifungal lipopeptides has been identified in other strains of the species of Bacillus used in this study, including B. amyloliquefaciens (Arrebola et al., 2010; Romano et al., 2013; Zhao et al., 2014), B. coagulans (Huszcza and Burczyk, 2006), B. megaterium (Troyano Pueyo et al., 2009), and B. thuringiensis (Hathout et al., 2000; Kim et al., 2004; Roy et al., 2013). B. pumilus and $O$. sojae demonstrated weak biosurfactant activity but no fungal suppression, suggesting that the biosurfactants secreted either did not have antifungal capabilities against the three fungi against which they were challenged or were not produced in large enough quantities to suppress fungal growth.

Bacillus species also produce other compounds with antifungal activity including antibiotics (Schneider et al., 2007; Saidi et al., 2009; Arguelles-Arias et al., 2009; Yuan et al., 2012), proteinaceous substances (Tan et al., 2013; Wang et al., 2014), siderophores (Arguelles-Arias et al., 2009; Chaiharn et al., 2009), and chitinolytic enzymes (Aktuganov et al., 2003; Bressan and Figueiredo, 2010; Gomaa, 2012). In this study, five Bacillus isolates demonstrated antifungal activity, but biosurfactant secretion was not detected; this indicates either the production of antifungal lipopeptides at low levels or that antifungal activity was not due to synthesized lipopeptides, but some other bioactive compound. Biosurfactant production and antifungal activity was not detected in four Bacillus isolates and $O$. anthropi. The lack of both fungal inhibition and biosurfactant activity suggests that these strains did not secrete antifungal lipopeptides. 


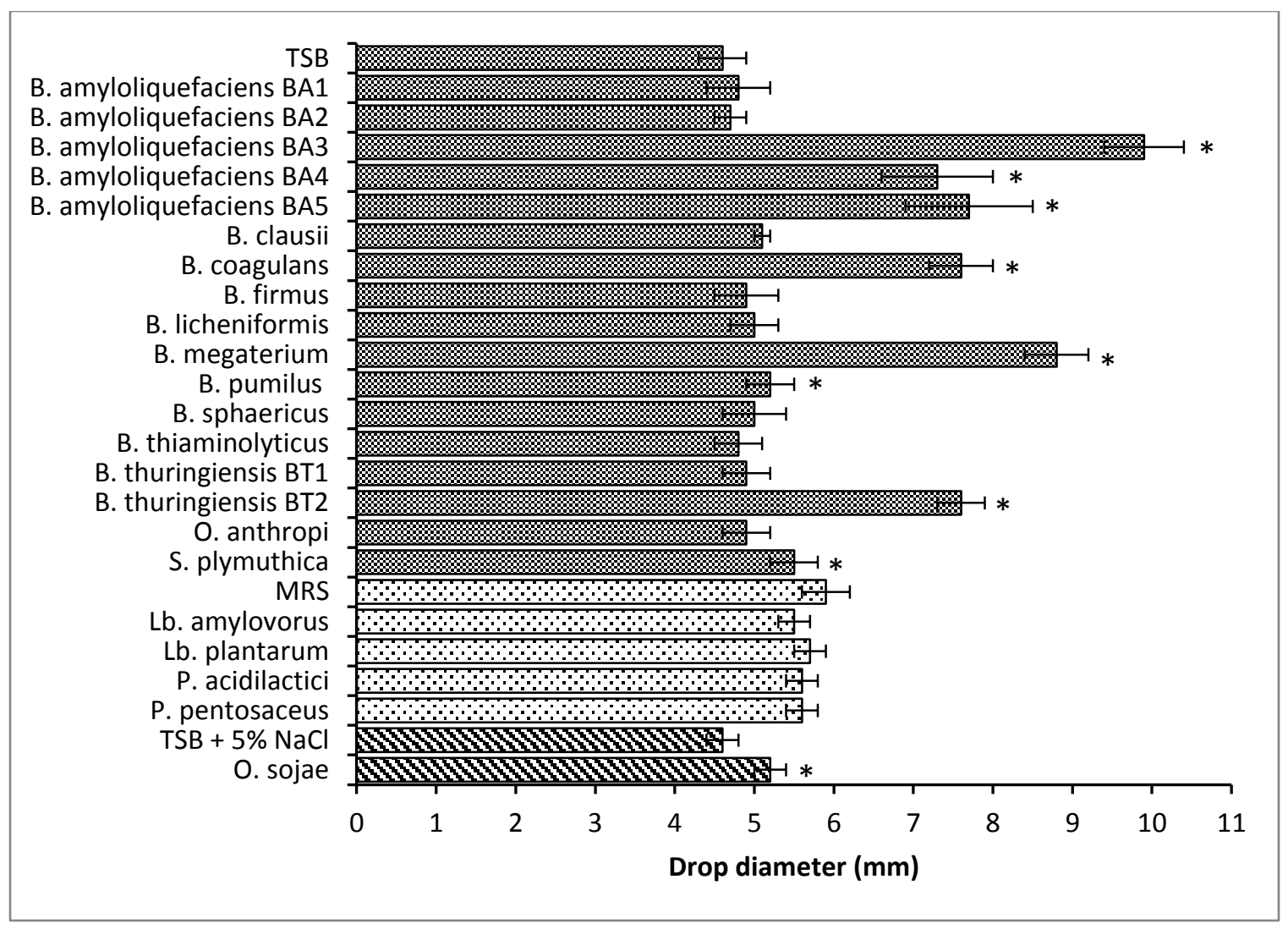

Figure 3.2. Biosurfactant activity of bioprotective isolates. Error bars indicate standard deviation. Media used are designated by bars with corresponding patterns. Asterisks indicate drop diameters significantly larger than that of the media control $(\alpha=0.05)$.

\subsubsection{Lactic Acid Bacteria Isolates}

Biosurfactant production was not detected in the four LAB isolates used in this study (Figure 3.2), but this does not mean these isolates are incapable of producing biosurfactants. Biosurfactants produced by bacteria can be either be excreted or remain cell-bound. Gudiña et al. (2011), found that Lactobacillus coryniformis, Lactobacillus paracasei, Lb. plantarum, and Ln. mesenteroides produced cell-bound biosurfactants at higher levels than excreted ones. Cell-bound biosurfactant production has been observed in several species of Lactobacillus (Gomaa, 2013a), including Lb. plantarum (Velraeds et al., 1996). The drop-collapse test used in this study to determine biosurfactant production was only able to detect excreted biosurfactants and not those which are cell-bound; LAB 
isolates should be rescreened for the production of biosurfactants with the addition of an extraction step.

\subsubsection{Serratia plymuthica}

The production of antifungal compounds including pyrrolnitrin, haterumalide, siderophores, chitinolytic enzymes, and proteases has been identified in strains of $S$. plymuthica. The S. plymuthica isolate used in this study demonstrated weak biosurfactant activity (Figure 3.2) and suppressed the growth of Bot. cinerea, F. pallidoroseum, and F. moniliforme (Table 3.2). This suggests that antifungal activity was due to the production of antifungal lipopeptides at low levels, the synthesis of some other type of bioactive compound, or a combination of lipopeptides and antibiotics.

\subsection{Conclusion}

Of the 22 isolates tested, nine isolates-eight Bacillus isolates and $S$. plymuthica - suppressed the growth of Bot. cinerea, F. pallidoroseum, and F. moniliforme and six isolates - three Bacillus and three LAB — inhibited only Bot. cinerea. Biosurfactant production was detected in many of the Bacillus species which showed antifungal activity, suggesting the production of antifungal lipopeptides. Characterization of antifungal compounds produced by the bioprotective isolates used in this study and further investigation into their antifungal efficacy on produce both before and after harvest is needed to evaluate their potential use as biocontrol agents in the agricultural 
industry. Based on the results of this screening, six isolates-B. amyloliquefaciens strains BA3, BA4, and BA5, B. coagulans, B. megaterium, and B. thuringiensis BT2-are recommended for further evaluation. 


\section{ANTIMICROBIAL SCREENING OF BIOPROTECTIVE ISOLATES AGAINST}

LISTERIA MONOCYTOGENES, SALMONELLA, AND ESCHERICHIA COLI O157:H7 AND ANTIMICROBIAL EFFICACY ON ICEBERG LETTUCE AND GALA APPLES

\subsection{Introduction}

Foodborne illness affects an estimated 48 million Americans annually. Between 2006 and 2008, approximately $22 \%$ of foodborne illness outbreaks were produceassociated (Gould et al., 2013b). Major outbreaks in produce involving $L$. monocytogenes, Salmonella, and E. coli O157:H7 have resulted in hundreds of illnesses and several deaths. In 2014 an outbreak of L. monocytogenes on prepackaged caramel apples produced by Bidart Bros. Apples caused 35 illnesses and 7 deaths (CDC, 2015) and L. monocytogenes on cantaloupes from Jensen Farms resulted in 147 cases of listeriosis and 34 deaths in 2011 (CDC, 2012a). An outbreak of Salmonella enterica ser. Saintpaul in peppers and tomatoes from Mexico in 2008 caused 1,442 illnesses and 2 deaths in the United States (Jungk et al., 2008). More recently, outbreaks of Salmonella have been linked to cucumbers, mangos, cantaloupe, and papayas (CDC, 2011b, 2012c; d, 2013a). Shiga-toxin producing E. coli outbreaks have been associated with sprouts, ready-to-eat salads, and Romaine lettuce (CDC, 2012e, 2013b, 2014), but one of the largest produce-associated E. coli O157:H7 outbreaks occurred in 2006 in spinach, which sickened 199 people and caused 3 deaths (CDC, 2006). Because of the devastating effects 
of foodborne illness outbreaks, multiple steps are taken to ensure the safety of agricultural commodities.

The postharvest processing of fresh produce can be challenging because of the nature of the product. Many fruits and vegetables are consumed raw, and thus the use of high temperatures to reduce microbial load is not an option. Fresh produce manufacturers must use a series of less harsh treatments to control microbial populations and growth during postharvest processing, transport, and storage. Storage at low temperatures throughout postharvest processing and the distribution chain is the most common method used for slowing microbial growth; minimum growth temperatures for L. monocytogenes, Salmonella, and E. coli $\mathrm{O} 157: \mathrm{H} 7$ are $-0.4,5.2$, and $6.5^{\circ} \mathrm{C}$, respectively (FDA, 2011b). The FDA requires ready-to-eat fruits and vegetables to be stored at or below $5^{\circ} \mathrm{C}$ (FDA, 2013a), however L. monocytogenes can grow at and below this low temperature and temperature abuse or deviations during processing, storage, and transport can also lead to the growth of Salmonella and E. coli O157:H7.

In addition to temperature control, produce is often washed in a disinfectant to reduce microbial populations. Chlorine is often used because it is cheap with broadspectrum antimicrobial activity; studies have shown that washing leafy greens with chlorine causes close to or less than a 1 log reduction in L. monocytogenes (Beuchat and Brackets, 1990; Zhang and Farber, 1996), Salmonella (Weissinger et al., 2000; Neal et al., 2012), and E. coli O157:H7 (Behrsing et al., 2000; Keskinen et al., 2009; Keskinen and Annous, 2011; Neal et al., 2012). Peroxyacetic acid is another disinfectant used by the produce industry, however it is more expensive than chlorine and has not been shown to be more effective in reducing the microbial load of produce (Ölmez and Kretzschmar, 
2009; University of Georgia, 2011; Neal et al., 2012). The methods used by the agricultural industry to reduce and control the microbial populations on produce have been shown to be insufficient, as evidenced by an increase in foodborne illness linked to produce, and therefore new or additional steps in postharvest processing are needed to enhance the safety of fruits and vegetables.

Biocontrol, which is the use of bioprotective organisms (such as non-pathogenic bacteria) to control undesirable organisms, offers an additional means of microbial management. The mechanisms employed by biocontrol agents for the suppression of undesirable microorganisms include antibiosis, predation of the target organism, and competitive inhibition (Singh and Vyas, 2009). Isolated compounds produced by biocontrol agents can be used to suppress the target organism (antibiosis), but when the whole organism is used one or more modes of action may be engaged to suppress the growth of the target organism, which may result in more effective inhibition.

Various species of bacteria, such as LAB, have been evaluated for the potential use as biocontrol agents on fresh produce. In addition to organic acids, some species of LAB produce bacteriocins, which are small, proteinaceous compounds active against organisms closely related to the producer; this typically includes Gram positive organisms, such as L. monocytogenes (O'Sullivan et al., 2002; Delves-Broughton, 2005; Rodríguez et al., 2005; Mills et al., 2011). Antimicrobial activity against Gram negative pathogens is generally not as strong, but can be enhanced with the addition of membranedisrupting compounds such as weak acids and chelators (Alakomi et al., 2000; Lu et al., 2011). 
Species of Bacillus also synthesize antimicrobial compounds, including bacteriocins and bacteriocin-like substances, lipopeptides, and other antibiotics. Bacteriocins produced by Bacillus species are similar in function to those produced by LAB. Lipopeptides are biosurfactants consisting of a cyclic peptide chain attached to a fatty acid; these compounds exert antimicrobial activity through membrane disruption (Arguelles-Arias et al., 2009; Sansinenea and Ortiz, 2011; Mongkolthanaruk, 2012; Christie, 2014). Broad-spectrum activity by Bacillus-synthesized lipopeptides includes the inhibition of L. monocytogenes (Sabaté and Audisio, 2013; Compaoré et al., 2013), Salmonella (Huang et al., 2011; Compaoré et al., 2013), E. coli (Compaoré et al., 2013), and both enveloped and non-enveloped viruses (Kracht et al., 1999; Huang et al., 2006). Other antibiotics produced by Bacillus species include macrolactin, difficidin, and bacillaene (Chen et al., 2006; Schneider et al., 2007; Sohn et al., 2008; Arguelles-Arias et al., 2009). The identification of antimicrobial compounds synthesized by LAB and Bacillus species has prompted investigation into their use as biocontrol agents on fresh produce.

Antimicrobial activity on fruits and vegetables is dependent on biocontrol agent strain and target pathogen, as well as produce type. Inhibition by LAB of $L$. monocytogenes, Salmonella, and E. coli $\mathrm{O} 157: \mathrm{H} 7$ on produce can range from a $2 \mathrm{log}$ reduction to complete inhibition on lettuce, apple wedges, and spinach (Trias et al., 2008a; Alegre et al., 2011; Cálix-Lara et al., 2014) and a 3 log reduction by Bacillus species on bell peppers (Liao, 2009). Antimicrobial efficacy of LAB and Bacillus strains on fruits and vegetables has led to further investigation into their use as an additional hurdle for foodborne pathogens on fresh produce. 
The purpose of this study was 1) to screen 22 bacterial isolates for antimicrobial activity against Listeria monocytogenes, Salmonella, and Escherichia coli O157:H7, 2) to evaluate antimicrobial efficacy of the three most inhibitory LAB isolates against $L$. monocytogenes on Iceberg lettuce, and 3) to determine the antimicrobial efficacy of DF1, a dry product containing the three LAB isolates, against L. monocytogenes, Salmonella, and E. coli $\mathrm{O} 157: \mathrm{H} 7$ on Gala apples.

\subsection{Materials and Methods}

\subsubsection{Antimicrobial Screening}

\subsubsection{Bacterial Pathogen Preparation}

Five strains each of Listeria monocytogenes, Salmonella, and Escherichia coli O157:H7 (Table 4.1) were used in this study. Bacterial cultures were maintained on TSA slants at room temperature and in TSB with $15 \%$ glycerol at $-70^{\circ} \mathrm{C}$ for long term storage. Cultures were prepared for screening by placing a loopful of culture into $10 \mathrm{~mL}$ of TSB and incubating for $24 \mathrm{~h}$ at $35^{\circ} \mathrm{C}$. After incubation, strains were combined by organism to form five-strain cocktails of L. monocytogenes, Salmonella, and E. coli O157:H7. 
Table 4.1. Bacterial pathogens

\begin{tabular}{ccc}
\hline Pathogen & Strain number & Source $^{1}$ \\
\hline Listeria monocytogenes & NFPA 6301 & NFL \\
Listeria monocytogenes & NFPA 6306 & NFL \\
Listeria monocytogenes & NRRL B-33000 & ARS \\
Listeria monocytogenes & NRRL B-33233 & ARS \\
Listeria monocytogenes & FSL J1-177 & ILSI NA \\
& & \\
Salmonella enteriditis ser. Enteriditis & NFPA 7100 & NFL \\
Salmonella enteriditis ser. Oranienburg & NFPA 7201 & NFL \\
Salmonella enteriditis ser. Tennessee & FSL R8-5221 & ILSI NA \\
Salmonella enteriditis ser. Montevideo & ATCC BAA 710 & NFL \\
Salmonella enteriditis ser. Antaum & ATCC BAA 1592 & NFL \\
& & \\
Escherichia coli O157:H7 & NFPA 4200 & NFL \\
Escherichia coli O157:H7 & NFPA 4213 & NFL \\
Escherichia coli O157:H7 & NFPA 4212 & NFL \\
Escherichia coli O157:H7 1516 NFL \\
Escherichia coli O157:H7 & NFPA 4216 & NFL
\end{tabular}

${ }^{1}$ ARS: Agricultural Research Service (College Park, MD); ILSI NA: International Life Sciences Institute, North America (Cornell University; Ithaca, NY); NFL: National Food Lab (Livermore, CA).

\subsubsection{Bioprotective Isolate and Bacillus subtilis Fermentate Preparation}

All bioprotective isolates were provided by BiOWiSH Technologies (Cincinnati, $\mathrm{OH})$. Working cultures of LAB isolates were stored on MRS agar at $4^{\circ} \mathrm{C}$. Working cultures of all other isolates were stored on TSA at room temperature; Oceanobacillus sojae was maintained on TSA with $5 \% \mathrm{NaCl}(\mathrm{w} / \mathrm{w})$, and the remaining isolates were maintained on TSA. All isolates were kept in the proper growth media (Table 4.2) with $15 \%$ glycerol at $-70^{\circ} \mathrm{C}$ for long term storage except B. clausii and B. firmus - these two isolates were stored as spore crops at $6^{\circ} \mathrm{C}$. B. subtilis fermentate were stored at $6^{\circ} \mathrm{C}$. Prior to use, isolates were inoculated into $10 \mathrm{~mL}$ of the appropriate growth media and incubated at either 30 or $35^{\circ} \mathrm{C}$, depending on the isolate, for $18-24 \mathrm{~h}$ (Table 4.2). All isolates but LAB were incubated with agitation on an orbital shaker. 
Table 4.2. Bioprotective isolates

\begin{tabular}{lcc}
\hline \multicolumn{1}{c}{ Isolate } & Growth medium & Incubation temperature \\
\hline Bacillus amyloliquefaciens BA1 & TSB & $35^{\circ} \mathrm{C}$ \\
Bacillus amyloliquefaciens BA2 & TSB & $35^{\circ} \mathrm{C}$ \\
Bacillus amyloliquefaciens BA3 & TSB & $35^{\circ} \mathrm{C}$ \\
Bacillus amyloliquefaciens BA4 & TSB & $35^{\circ} \mathrm{C}$ \\
Bacillus amyloliquefaciens BA5 & TSB & $35^{\circ} \mathrm{C}$ \\
Bacillus clausii & TSB & $30^{\circ} \mathrm{C}$ \\
Bacillus coagulans & TSB & $35^{\circ} \mathrm{C}$ \\
Bacillus firmus & TSB & $30^{\circ} \mathrm{C}$ \\
Bacillus licheniformis & TSB & $35^{\circ} \mathrm{C}$ \\
Bacillus megaterium & TSB & $35^{\circ} \mathrm{C}$ \\
Bacillus pumilus & TSB & $35^{\circ} \mathrm{C}$ \\
Bacillus sphaericus & TSB & $30^{\circ} \mathrm{C}$ \\
Bacillus thiaminolyticus & TSB & $30^{\circ} \mathrm{C}$ \\
Bacillus thuringiensis BT1 & TSB & $35^{\circ} \mathrm{C}$ \\
Bacillus thuringiensis BT2 & TSB & $35^{\circ} \mathrm{C}$ \\
Lactobacillus amylovorus & MRS broth & $35^{\circ} \mathrm{C}$ \\
Lactobacillus plantarum & MRS broth & $35^{\circ} \mathrm{C}$ \\
Oceanobacillus sojae & TSB w/ 5\% NaCl & $35^{\circ} \mathrm{C}$ \\
Ochrobactrum anthropi & TSB & $35^{\circ} \mathrm{C}$ \\
Pediococcus acidilactici & MRS broth & $35^{\circ} \mathrm{C}$ \\
Pediococcus pentosaceus & MRS broth & $35^{\circ} \mathrm{C}$ \\
Serratia plymuthica & TSB & $30^{\circ} \mathrm{C}$ \\
\hline
\end{tabular}

\subsubsection{Lactic Acid Bacteria Cocktail Preparation}

The LAB cocktails LM1, NP1B, and FGA, provided by BiOWiSH Technologies (Cincinnati, OH) contained Lb. plantarum, P. acidilactici, and P. pentosaceus combined with other components (Table 4.3). The LAB cocktails were stored in heat-sealed bags at room temperature. Prior to screening, the cocktails were rehydrated in sterile DI water (target concentration of $7 \log \mathrm{CFU} / \mathrm{mL}$ ), then diluted to a target concentration of $6 \log$ $\mathrm{CFU} / \mathrm{mL}$ with either sterile DI water or MRS broth. Cocktails rehydrated in DI water were immediately screened for antimicrobial activity and cocktails in MRS broth were incubated at $35^{\circ} \mathrm{C}$ for $18-24 \mathrm{~h}$ then screened. 
Table 4.3. Lactic Acid Bacteria cocktail formulation components

\begin{tabular}{ccl}
\hline Formulation & Log CFU/g & \multicolumn{1}{c}{ Other components } \\
\hline LM1 & 9.60 & Anhydrous dextrose \\
NP1B & 10.23 & $\begin{array}{l}\text { MRS fermentation media } \\
\text { Rice flour, whey protein, inulin, salt, calcium carbonate, } \\
\text { FGA }\end{array}$ \\
magnesium sulfate, sodium phosphate, ferrous sulfate \\
DF1 & 10.11 & \begin{tabular}{l} 
Soy peptone, yeast extract, soy protein, dextrose \\
\hline
\end{tabular}
\end{tabular}

\subsubsection{Antimicrobial Screening of Bioprotective Isolates}

Lactic Acid Bacteria isolates and cocktails were screened using a seeded-overlay method; all other isolates were screened using a pour-plate method. Antimicrobial activity was determined by the presence of a zone of inhibition. Each organism was screened twice in triplicate.

Seeded Overlay Method. A loopful of prepared LAB culture or cocktail was spotted onto MRS agar and incubated at $35^{\circ} \mathrm{C}$ for $24 \mathrm{~h}$. The plates were then overlaid with TSA seeded with pathogen cocktail (6 log CFU/mL). Plates were incubated at $35^{\circ} \mathrm{C}$ for $24 \mathrm{~h}$ then the zone of inhibition was measured from the border of the bacterial colony to the perimeter of the clearing.

Pour Plate method. A pathogen-seeded plate was prepared by placing $1 \mathrm{~mL}$ of pathogen cocktail (6 log CFU/mL) into a petri dish, then adding 15-20 mL molten TSA tempered to $50^{\circ} \mathrm{C}$. When the TSA had solidified, a loopful of prepared bioprotective isolate culture was spotted onto the agar in three separate locations. All plates were incubated at $35^{\circ} \mathrm{C}$ for $24 \mathrm{~h}$ then the zone of inhibition was measured from the border of the bacterial colony to the perimeter of the clearing. 
4.2.2 Effect of $\mathrm{pH}$ on Antimicrobial Activity of Lactic Acid Bacteria Isolates

\subsubsection{Bacterial Pathogen Preparation}

Cocktails of L. monocytogenes, Salmonella, and E. coli O157:H7 were prepared as described in Section 4.2.1.1. Cocktails were centrifuged at 3,000 RPM for 15 min then resuspended in fresh TSB. Pathogen cocktail concentrations were adjusted to 4 log $\mathrm{CFU} / \mathrm{mL}$ with TSB.

4.2.2.2 Lactic Acid Bacteria Isolate Cell-Free Supernatant and Neutralized Cell-Free Supernatant Preparation

Lb. plantarum, $P$. acidilactici, and $P$. pentosaceus were individually inoculated into $10 \mathrm{~mL}$ of MRS broth and incubated at $35^{\circ} \mathrm{C}$ for $48 \mathrm{~h}$. After incubation, LAB cultures were centrifuged, then the supernatant was filter-sterilized using $0.22 \mu \mathrm{m}$ syringe filters (Thermo Fisher Scientific, Inc.; Waltham, MA) to make cell-free supernatant (CFS). The $\mathrm{pH}$ of a portion of CFS was adjusted to 6.5-7.0 with $1 \mathrm{M} \mathrm{NaOH}$ (Thermo Fisher Scientific, Inc.; Waltham, MA) then filter-sterilized again to make neutralized cell-free supernatant (NCFS).

\subsubsection{Effect of $\mathrm{pH}$ on the Antimicrobial Activity of Lactic Acid Bacteria Cell-Free} Supernatant

A Bio-Rad XMark ${ }^{\mathrm{TM}}$ spectrophotometer (Hercules, CA) was used to measure the optical density (OD) of pathogen cocktails in the presence of LAB isolate CFS and NCFS. In a 96 well microplate, $100 \mu \mathrm{L}$ of pathogen cocktail was combined with $100 \mu \mathrm{L}$ of either LAB isolate CFS or NCFS. Pathogen cocktail mixed with MRS broth was used 
as a control. Samples were incubated at $25^{\circ} \mathrm{C}$ and OD was measured at $600 \mathrm{~nm}$ every hour for $48 \mathrm{~h}$.

\subsubsection{Statistical Analysis}

The experiment was conducted three times in duplicate. All statistical analyses were conducted with MiniTab 16 (Minitab Inc., State College, PA) software. Data were log-transformed, then analyzed using Analysis of Variance (ANOVA); Tukey's test was used to identify significant differences between treatments $(\alpha=0.05)$.

\subsubsection{Application on Produce: Effect of Lactic Acid Bacteria Cocktail on Listeria} monocytogenes on Iceberg Lettuce

\subsubsection{Iceberg Lettuce Preparation}

Whole heads of Iceberg lettuce were purchased from a local grocery store (Albertsons; San Luis Obispo, CA) and stored at refrigeration temperatures for no more than $24 \mathrm{~h}$ prior to use. In a biosafety cabinet, the four outermost leaves of the lettuce head were removed and the head was cut into quarters with a flame-sterilized chef's knife. The lettuce leaves were separated, portioned into $15 \mathrm{~g}$ samples and arranged in a single layer, outer surface facing up, in a biosafety cabinet.

\subsubsection{Listeria monocytogenes Inoculation of Iceberg Lettuce}

L. monocytogenes cocktail was prepared as described in Section 4.2.1.1. L. monocytogenes cocktail was washed twice and resuspended in $0.1 \%$ peptone water (PW, Becton, Dickinson and Company; Sparks, MD). L. monocytogenes inoculum was 
adjusted to $4.7 \log \mathrm{CFU} / \mathrm{mL}$ with $0.1 \% \mathrm{PW}$. Each $15 \mathrm{~g}$ Iceberg lettuce sample was inoculated with 15 spots of $20 \mu \mathrm{L}$ of prepared L. monocytogenes inoculum (resulting in 3 $\log \mathrm{CFU} / \mathrm{g}$ lettuce) and allowed to dry at room temperature for $1 \mathrm{~h}$ in a biosafety cabinet.

\subsubsection{Lactic Acid Bacteria Cocktail Treatment of Iceberg Lettuce}

Lb. plantarum, $P$. acidilactici, and $P$. pentosaceus were each individually inoculated into $240 \mathrm{~mL}$ MRS broth and incubated at $35^{\circ} \mathrm{C}$ for $18-24 \mathrm{~h}$. After incubation, LAB cultures were washed twice and resuspended in $80 \mathrm{~mL}$ of $0.1 \% \mathrm{PW}$, then combined in an ethanol-sterilized spray bottle to form the LAB cocktail. Each $15 \mathrm{~g}$ lettuce sample was sprayed with approximately $1 \mathrm{~mL}$ LAB cocktail and allowed to dry for $1 \mathrm{~h}$. Lettuce samples were then placed in Whirl-Pak® bags and stored at $4{ }^{\circ} \mathrm{C}$ for $24 \mathrm{~h}$, then $10^{\circ} \mathrm{C}$ for $13 \mathrm{~d}$ (14 d incubation total). Untreated lettuce was used as a control.

\subsubsection{Bacterial Enumeration}

The experiment was conducted twice. L. monocytogenes and LAB cocktail populations were enumerated in duplicate on Days $0,1,3,7,10$, and 14 . To prepare Iceberg lettuce samples, $135 \mathrm{~g}$ of $0.1 \% \mathrm{PW}$ was added to the lettuce sample and then homogenized in a stomacher for 60 s. The sample was plated on Modified Oxford Agar with antimicrobic supplement (MOX; Becton, Dickson and Company; Sparks, MD) to recover L. monocytogenes and MRS agar to recover LAB cocktail. Serial dilutions were prepared as needed with $0.1 \% \mathrm{PW}$. All plates were incubated at $35^{\circ} \mathrm{C}$ for $48 \mathrm{~h}$. 


\subsubsection{Statistical Analysis}

The experiment was conducted twice in duplicate. All statistical analyses were conducted with MiniTab 16 (Minitab Inc., State College, PA) software. Data were logtransformed, then analyzed using Analysis of Variance (ANOVA); Tukey's test was used to identify significant differences between treatments $(\alpha=0.05)$.

\subsubsection{Application on Produce: Effect of DF1 on Iceberg Lettuce}

\subsubsection{DF1 Solution Preparation}

DF1, a powder that contained $L b$. plantarum, $P$. acidilactici, and $P$. pentosaceus and various dried media (Table 4.3), was provided by BiOWiSH Technologies (Cincinnati, OH). DF1 was stored at refrigeration temperatures until use. Immediately before application, $6 \mathrm{~g}$ DF1 was mixed with $20 \mathrm{~g}$ DI water (23\% DF1 solution, by weight). The DF1 solution was transferred to an ethanol-sterilized plastic spray bottle for lettuce application.

\subsubsection{DF1 Treatment of Iceberg Lettuce}

Whole heads of Iceberg lettuce were purchased from a local grocery store (Albertsons; San Luis Obispo, CA) and stored at refrigeration temperatures for no more than $24 \mathrm{~h}$ prior to use. Before DF1 treatment, the four outermost leaves of the lettuce head were removed and the head was cut into $5 \times 5 \mathrm{~cm}$ pieces with a flame-sterilized chef's knife in a biosafety cabinet. Lettuce pieces were arranged in a single layer in a biosafety cabinet and sprayed with DF1 solution until evenly coated. Lettuce was then

dried in a residential salad spinner (OXO; New York, NY), divided into $15 \mathrm{~g}$ samples and 
placed into Whirl-Pak® bags. Lettuce samples were incubated at $10^{\circ} \mathrm{C}$ for $2 \mathrm{~d}$ and visually evaluated daily.

\subsubsection{Bacterial Enumeration}

Lactic Acid Bacteria populations were enumerated on Days 0 and 2. Lettuce samples were prepared as described in Section 4.2.3.4. Samples were plated on MRS agar to recover LAB; all plates were incubated at $35^{\circ} \mathrm{C}$ for $48 \mathrm{~h}$.

4.2.5 Application on Produce: Effect of DF1 on Listeria monocytogenes, Salmonella, and Escherichia coli O157:H7 on Gala Apples

\subsubsection{Bacterial Pathogen Preparation}

Cocktails of L. monocytogenes, Salmonella, and E. coli O157:H7 were prepared as described in Section 4.2.1.1. Cocktails were washed twice and resuspended with $0.1 \%$ PW.

\subsubsection{Pathogen Inoculation of Gala Apples}

Organic unwaxed Gala apples were purchased from a local grocery store (Albertsons; San Luis Obispo, CA) and held at refrigeration temperatures for no more than $48 \mathrm{~h}$ prior to use. Apples were spot-inoculated with $20 \mu \mathrm{L}$ of pathogen cocktail (8-9 $\log \mathrm{CFU} / \mathrm{mL}$ ) and allowed to sit in a biosafety cabinet for $2 \mathrm{~h}$ at room temperature. The pathogen-inoculated apples were then stored at $4^{\circ} \mathrm{C}$ overnight to allow for bacterial attachment. 


\subsubsection{DF1 Treatment of Gala Apples}

Immediately before application, a 20\% DF1 solution was prepared by combining 25 g DF1 with 100 g DI water. The DF1 solution was then transferred to an ethanolsterilized spray bottle. The pathogen-inoculated apples were arranged in a single layer in a biosafety cabinet and each sprayed with approximately $3 \mathrm{~mL}$ of DF1 at the pathogen inoculation sites. DI water was sprayed onto apples as a control. The apples remained in the biosafety cabinet for $2 \mathrm{~h}$ at room temperature to dry, then were incubated at $20^{\circ} \mathrm{C}$ for $5 \mathrm{~d}$.

\subsubsection{Bacterial Enumeration}

Bacterial populations were enumerated in duplicate on Days $0,1,2,3$, and 5 . To prepare the apple sample, a plug $12 \mathrm{~mm}$ in diameter was cut from the apple at the pathogen inoculation site with a cork borer. The plug was placed into a Whirl-Pak® bag containing $9 \mathrm{~mL} 0.1 \% \mathrm{PW}$ and homogenized by hand for $1 \mathrm{~min}$, then serially diluted with $0.1 \% \mathrm{PW}$ for plating. The native microflora and LAB populations were enumerated using TSA and MRS agar, respectively. An overlay method adapted from Al-Holy et al. (2008) was used for the recovery of stressed or injured L. monocytogenes, Salmonella, and E. coli $\mathrm{O} 157: \mathrm{H7}$. Briefly, apple samples were pour-plated in TSA and incubated at $35^{\circ} \mathrm{C}$ for 2-3 h to allow stressed and injured cells to repair themselves. Plates were then overlaid with selective/differential media and incubated at $35^{\circ} \mathrm{C}$ for $22-46 \mathrm{~h}$, depending on the requirements of the media. The selective/differential media used to enumerate pathogen populations were MOX for L. monocytogenes, Xylose Lysine Deoxycholate Agar (XLD; 
Oxnoid; Basingstoke, Hampshire, UK) for Salmonella, and Sorbitol MacConkey Agar (SMAC; Oxnoid; Basingstoke, Hampshire, UK) for E. coli O157:H7.

\subsection{Results and Discussion}

\subsubsection{Antimicrobial Screening}

\subsubsection{Appearance of Zones of Inhibition During Antimicrobial Screening}

The size and appearance of the zone of inhibition produced in the antimicrobial screening could be correlated to the efficacy of the antimicrobial compounds produced by the bioprotective isolate. When the LAB isolates and cocktails were screened, the clearings produced were large and visually free of pathogen growth (Figure 4.1, Appendix C), indicating strong inhibition of L. monocytogenes, Salmonella, and E. coli O15:H7. This suggests that the antimicrobial compounds produced by the LAB isolates were strongly inhibitory to Gram positive and Gram negative pathogens.

However, during the antimicrobial screening of the non-LAB isolates, the appearance of the zones of inhibition were small compared to those produced by the LAB isolates and differed between Gram positive and Gram negative pathogens. Clearings were visually free of $L$. monocytogenes colonies across all inhibitory isolates and $B$. subtilis fermentate, but those clearings produced when testing against Salmonella and E. coli $\mathrm{O} 157: \mathrm{H} 7$ were hazy and contained pathogen colonies; the colonies were smaller and less dense within the clearing (Figure 4.1, Appendix C). The difference in the appearance of the clearings of Gram positive L. monocytogenes and Gram negative Salmonella and 
E. coli $\mathrm{O} 157: \mathrm{H} 7$ suggests that the presence of an outer membrane reduces the efficacy of the antimicrobial compounds produced by the bioprotective isolates.

The difference in size between the zones of inhibition of the LAB isolates and non-LAB isolates could have been the result of the difference in testing protocols. When screening the LAB isolates, cultures were incubated for $24 \mathrm{~h}$ on MRS agar plates before pathogen inoculation, providing time for the isolates grow and produce antimicrobial substances before the introduction of the pathogen. In the screening of non-LAB isolates, isolate and pathogen cultures were inoculated on the same day. The non-LAB isolates were not able to grow for $24 \mathrm{~h}$ unchallenged as the $\mathrm{LAB}$ isolates were, and the presence of the pathogen during isolate growth may have affected antibiotic production.

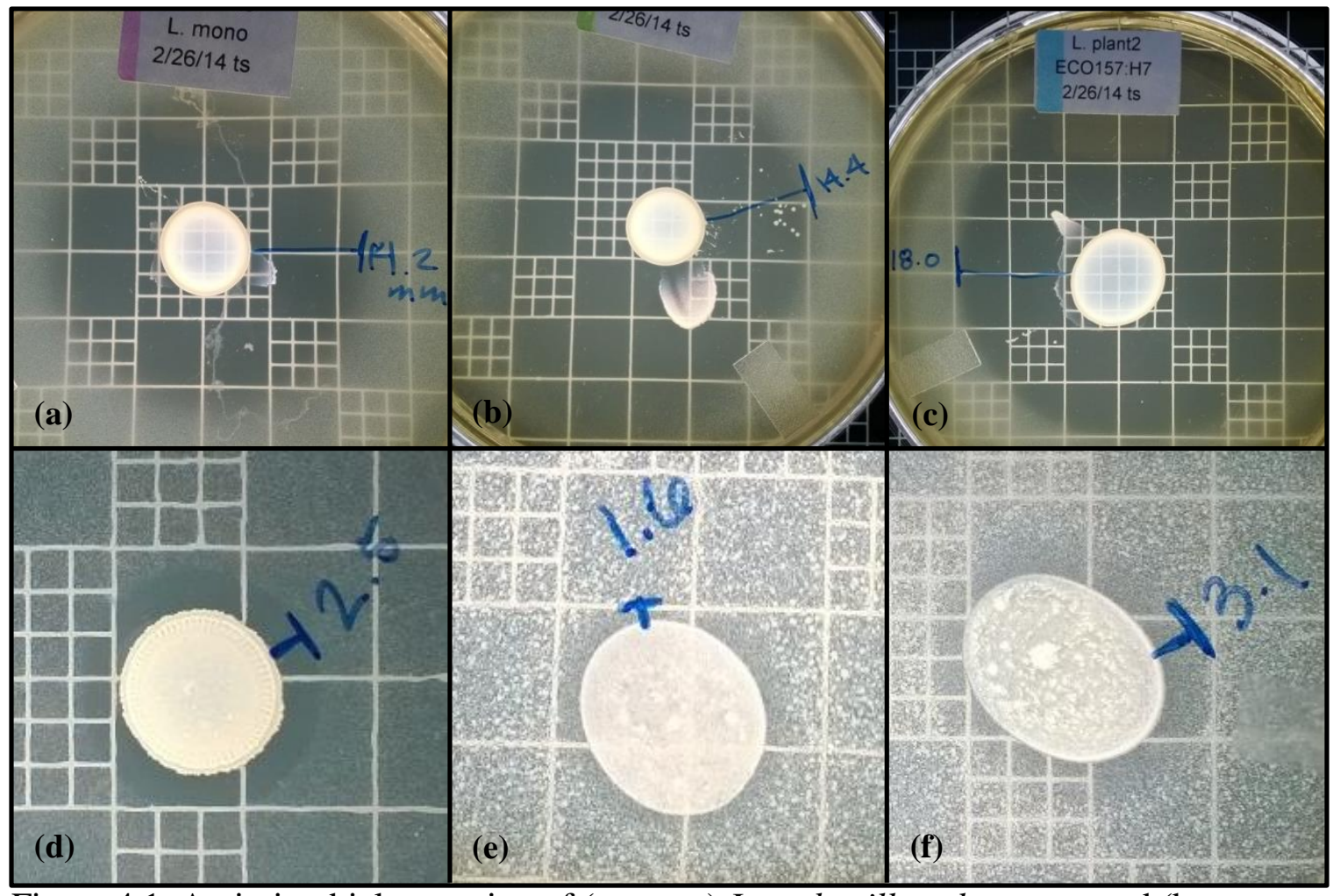

Figure 4.1. Antimicrobial screening of (top row) Lactobacillus plantarum and (bottom row) Bacillus amyloliquefaciens BA3 against (from left to right) Listeria monocytogenes, Salmonella, and Escherichia coli $\mathrm{O} 157: \mathrm{H} 7$. Handwritten numbers indicate zone size in $\mathrm{mm}$. 


\subsubsection{Lactic Acid Bacteria Isolates and Cocktails}

Several species of LAB synthesize antimicrobial compounds, including organic acids, bacteriocins, and other antibiotics (Bhunia et al., 1988; Diep et al., 2006; Mandal et al., 2008; Xie et al., 2011). Lactic acid — a major metabolite of all LAB species — exerts microbial inhibition by reducing environmental $\mathrm{pH}$ and disrupting bacterial membranes (Alakomi et al., 2000). Bacteriocins produced by LAB typically inhibit Gram positive organisms, but efficacy against Gram negative organisms can be increased with the addition of membrane disruptors (Cobo Molinos et al., 2008). Therefore, a bacteriocinproducing strain of LAB could potentially inhibit both Gram positive and Gram negative organisms. In this study, three of the four LAB isolates and all three LAB cocktails suppressed L. monocytogenes, Salmonella, and E. coli O157:H7. Lb. plantarum isolate demonstrated the strongest inhibition of all three pathogens (Figure 4.2, Appendix C). NP1B produced the largest clearings of the LAB cocktails when rehydrated in either DI water or MRS broth (Table 4.4, Appendix C). Inhibition of both Gram positive and Gram negative pathogens suggests that the organic acids produced by the LAB contributed to their antimicrobial efficacy. The role of organic acids in the antimicrobial ability of these LAB isolates was further investigated in this study, but more testing is needed to evaluate bacteriocin production by $L b$. plantarum, $P$. acidilactici, and $P$. pentosaceus isolates used in this study. Based on the results of the screening, Lb. plantarum, $P$. acidilactici, and $P$. pentosaceus were selected for further evaluation. 


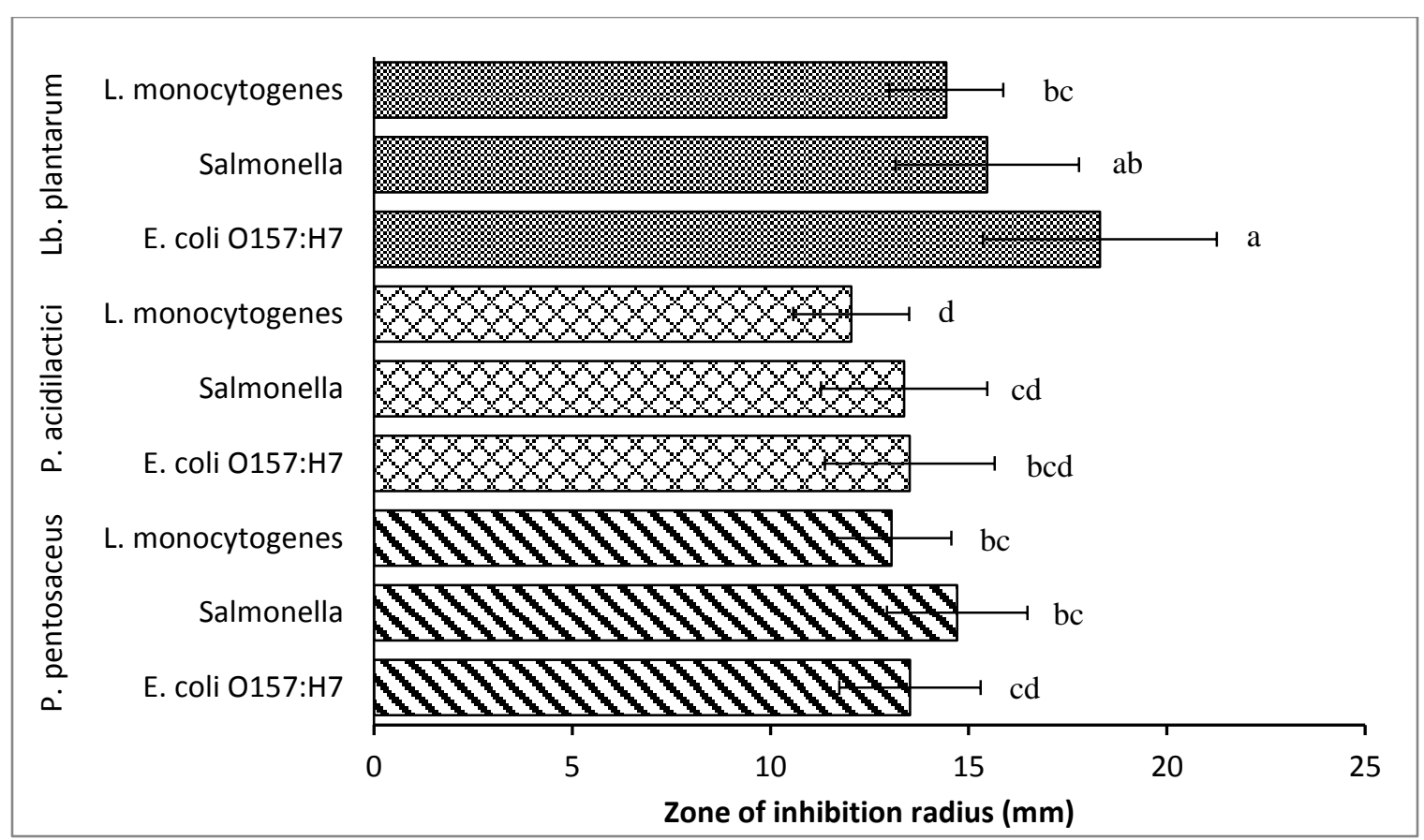

Figure 4.2. Antimicrobial activity of Lactic Acid Bacteria isolates. LAB isolates are differentiated by pattern. Error bars indicate standard error of the mean. Those results not sharing a letter are statistically different $(\alpha=0.05)$.

Table 4.4. Antimicrobial activity of Lactic Acid Bacteria cocktails

\begin{tabular}{lccc}
\hline \multicolumn{1}{c}{ Cocktail } & \multicolumn{3}{c}{ Bacterial pathogens } \\
\cline { 2 - 4 } & L. monocytogenes & Salmonella & E. coli O157:H7 \\
\hline FGA-DI & + & + & + \\
FGA-MRS & ++ & ++ & ++ \\
LM1-DI & + & + & + \\
LM1-MRS & ++ & ++ & ++ \\
NP1B-DI & + & + & + \\
NP1B-MRS & +++ & ++++ & ++++ \\
\hline
\end{tabular}

(+): 0.1-12.0 mm zone; (++): 12.1-14.0 mm zone; (+++): 14.1-16.0 mm zone; (++++): $\geq 16.1 \mathrm{~mm}$ zone.

DI: DI water sample; MRS: MRS sample.

\subsubsection{Bacillus Isolates, Serratia plymuthica, and Bacillus subtilis Fermentate}

Several bacteria produce various types of antimicrobial compounds and lipopeptides are among the bioactive compounds produced by some species of Bacillus. Bacillus-synthesized lipopeptides have shown antimicrobial activity against $L$. monocytogenes, Salmonella, and E. coli (Huang et al., 2011; Gomaa, 2013b; Płaza et al., 
2013; Sabaté and Audisio, 2013). Lipopeptide production in the Bacillus isolates and $S$. plymuthica used in this study was discussed in Chapter III; all isolates that produced biosurfactants—with the exception of $O$. sojae —also demonstrated antimicrobial activity. B. amyloliquefaciens BA3 and B. megaterium, the two isolates that demonstrated strong biosurfactant activity, also inhibited L. monocytogenes, Salmonella, and E. coli O157:H7 (Table 4.5). Pathogen inhibition and biosurfactant activity implies the production of antimicrobial lipopeptides by some of the Bacillus isolates used in this study.

In addition to lipopeptide synthesis, some Bacillus species are able to produce bacteriocins and bacteriocin-like compounds and other antibiotics. Similar to bacteriocins produced by LAB, inhibition by Bacillus-synthesized bacteriocins is typically seen in Gram positive organisms (Martirani et al., 2002; Gray et al., 2006), including $L$. monocytogenes (Lisboa et al., 2006; Kamoun et al., 2011; Berić et al., 2013), with enhanced activity against Gram negative organisms with the addition of a membrane disruptor (Bizani et al., 2005). Other antibiotics synthesized by some Bacillus species include polyketides such as macrolactin, bacillaene, and difficidin (Zimmerman et al., 1987; Chen et al., 2006; Schneider et al., 2007; Sohn et al., 2008; Yuan et al., 2012). In this study, antimicrobial activity was observed from B. amyloliquefaciens BA1 and BA2 and $B$. licheniformis, but biosurfactant production was not detected; this suggests the synthesis of antimicrobial compounds other than lipopeptides by these isolates. 
Table 4.5. Antimicrobial activity of isolates and fermentates

\begin{tabular}{|c|c|c|c|}
\hline \multirow{2}{*}{ Organism } & \multicolumn{3}{|c|}{ Bacterial Pathogens } \\
\hline & L. monocytogenes & Salmonella & E. coli $\mathrm{O} 157: \mathrm{H} 7$ \\
\hline \multicolumn{4}{|l|}{ Isolates } \\
\hline B. amyloliquefaciens BA1 & +++ & ++ & ++ \\
\hline B. amyloliquefaciens BA2 & ++++ & N/I & + \\
\hline B. amyloliquefaciens BA3 & ++ & ++ & +++ \\
\hline B. amyloliquefaciens BA4 & ++ & + & ++ \\
\hline B. amyloliquefaciens BA5 & + & $\mathrm{N} / \mathrm{I}$ & + \\
\hline B. clausii & $\mathrm{N} / \mathrm{I}$ & $\mathrm{N} / \mathrm{I}$ & $\mathrm{N} / \mathrm{I}$ \\
\hline B. coagulans & ++ & ++ & ++ \\
\hline B. firmus & $\mathrm{N} / \mathrm{I}$ & $\mathrm{N} / \mathrm{I}$ & $\mathrm{N} / \mathrm{I}$ \\
\hline B. licheniformis & ++ & $\mathrm{N} / \mathrm{I}$ & $\mathrm{N} / \mathrm{I}$ \\
\hline B. megaterium & +++ & ++ & ++ \\
\hline B. pumilus & + & $N / I$ & $N / I$ \\
\hline B. sphaericus & $\mathrm{N} / \mathrm{I}$ & $\mathrm{N} / \mathrm{I}$ & $N / I$ \\
\hline B. thiaminolyticus & $\mathrm{N} / \mathrm{I}$ & $\mathrm{N} / \mathrm{I}$ & $\mathrm{N} / \mathrm{I}$ \\
\hline B. thuringiensis $\mathrm{BT} 1$ & $\mathrm{~N} / \mathrm{I}$ & $\mathrm{N} / \mathrm{I}$ & $N / I$ \\
\hline B. thuringiensis $\mathrm{BT} 2$ & +++ & + & ++ \\
\hline O. anthropi & $\mathrm{N} / \mathrm{I}$ & $\mathrm{N} / \mathrm{I}$ & $\mathrm{N} / \mathrm{I}$ \\
\hline O. sojae & $\mathrm{N} / \mathrm{I}$ & $\mathrm{N} / \mathrm{I}$ & $\mathrm{N} / \mathrm{I}$ \\
\hline S. plymuthica & + & $\mathrm{N} / \mathrm{I}$ & + \\
\hline \multicolumn{4}{|l|}{ Fermentates } \\
\hline B. subtilis fermentate & + & + & + \\
\hline
\end{tabular}

\subsection{2 $\mathrm{pH}$ Neutralization}

\subsubsection{Optical Density}

In this experiment, the $\mathrm{OD}$, which is a measure of turbidity, was used to observe the growth of L. monocytogenes, Salmonella, and E. coli $\mathrm{O} 157: \mathrm{H} 7$ in the presence of $L b$. plantarum, P. acidilactici, or $P$. pentosaceus CFS (with a $\mathrm{pH}$ of 3.81-4.27, depending on LAB isolate) or NCFS ( $\mathrm{pH}$ of $6.5-7.0$ ) over a $48 \mathrm{~h}$ period. An increase in OD correlated to an increase in microbial population, and so the impact of the organic acids produced by the isolates on pathogen growth was seen by comparing the OD of CFS, NCFS, and 
pathogen controls. Although other antimicrobial compounds may have been produced by the LAB isolates, their detection was beyond the capabilities of the testing protocol; this will be addressed further in this discussion.

The experiment was conducted three times and, in some trials, the results were not as expected. The pathogen control should have an OD higher than CFS and NCFS because the MRS used in the controls to take the place of CFS and NCFS was fresh and thus had a higher nutrient content than CFS and NCFS, both of which had been used to grow LAB for $48 \mathrm{~h}$. In some trials, the OD of the NCFS was significantly higher than that of the pathogen control $(\alpha=0.05)$, indicating some type of contamination (Appendix D). Those trials where the OD of NCFS was significantly higher than the pathogen control were not included in the final statistical analysis.

4.3.2.2 The Role of Organic Acids Produced by Lactic Acid Bactria Isolates in the Inhibition of Listeria monocytogenes, Salmonella, and Escherichia coli O157:H7

Lactic acid, a major metabolite of LAB, has antimicrobial potential. Organic acids exert antimicrobial activity by decreasing extracellular $\mathrm{pH}$ and acidifying the internal environment of the cell, disrupting of metabolic reactions and stressing intracellular homeostasis (Brul and Coote, 1999). The pH growth limits for L. monocytogenes, Salmonella, and E. coli O157:H7 are 4.4, 3.7, and 4.0 respectively (FDA, 2011b). In this study, the CFS of $L b$. plantarum, $P$. acidilactici, and $P$. pentosaceus, with a $\mathrm{pH}$ of $3.81 \pm$ $0.05,4.27 \pm 0.13$, and $4.10 \pm 0.13$ respectively, greatly inhibited the growth of $L$ monocytogenes, Salmonella, and E. coli O157:H7; OD did not increase over the $48 \mathrm{~h}$ incubation period (Figures 4.3,4.4, and 4.5). The $\mathrm{pH}$ of the CFS of all three LAB isolates 
were near or below the lower growth limits of L. monocytogenes, Salmonella, and E. coli O157:H7 and capable of suppressing the growth of these pathogens. When neutralized, the antimicrobial activity of the CFS of the three LAB isolates was greatly diminished. After $48 \mathrm{~h}$ incubation, OD of L. monocytogenes, Salmonella, and E. coli O157:H7 cultured in the NCFS of Lb. plantarum, P. acidilactici, or P. pentosaceus were significantly higher than when grown in CFS $(\alpha=0.05)$, illustrating the role of lactic acid in the inhibition of pathogen growth.

The impact of organic acids and low $\mathrm{pH}$ was clearly demonstrated in this experiment, but pathogen suppression could also be the result of antimicrobial compounds other than organic acids. The synthesis of bacteriocins and other antibiotics by LAB species was discussed in Section 4.3.1.2. Neutralizing the CFS of the LAB isolates removes the effect of organic acids on pathogen growth, and an OD from NCFS lower than the pathogen control OD would suggest the presence of other antimicrobial compounds. However, the protocol used in this experiment was not sufficient to identify the production of other antimicrobial compounds by the LAB isolates.

To prepare the pathogen controls, fresh MRS was combined with the pathogen inoculum. The NCFS used had been incubating the LAB isolates for $48 \mathrm{~h}$, and thus would have had lower levels of the nutrients needed to sustain growth. Therefore, lower OD from NCFS could have been the result of lower nutrient levels in the media or the presence of antimicrobial compounds. In this study, The NCFS of $P$. pentosaceus caused a small but significant reduction of 0.025 in the $\mathrm{OD}$ of $L$. monocytogenes compared to the pathogen control $(\alpha=0.05)$ (Figure 4.5); Lb. plantarum and $P$. acidilactici NCFS did not affect L. monocytogenes OD. The OD of Salmonella was significantly lower in the 
presence of the NCFS of all three LAB, with the NCFS of $P$. pentosaceus causing the largest difference of 0.453 (Figure 4.4). Only the NCFS of $P$. acidilactici caused a significant decrease in the OD of $E$. coli $\mathrm{O} 157: \mathrm{H} 7(\alpha=0.05)$; OD was 0.243 lower than the control (Figure 4.4). Because of the limitations of the testing protocol used in this experiment, the results obtained could not conclusively determine the production of antimicrobial compounds other than lactic acid by Lb. plantarum, P. acidilactici, or $P$. pentosaceus, and further analysis of the isolates and their metabolites is needed to identify the production of bacteriocins or other antibiotics. 

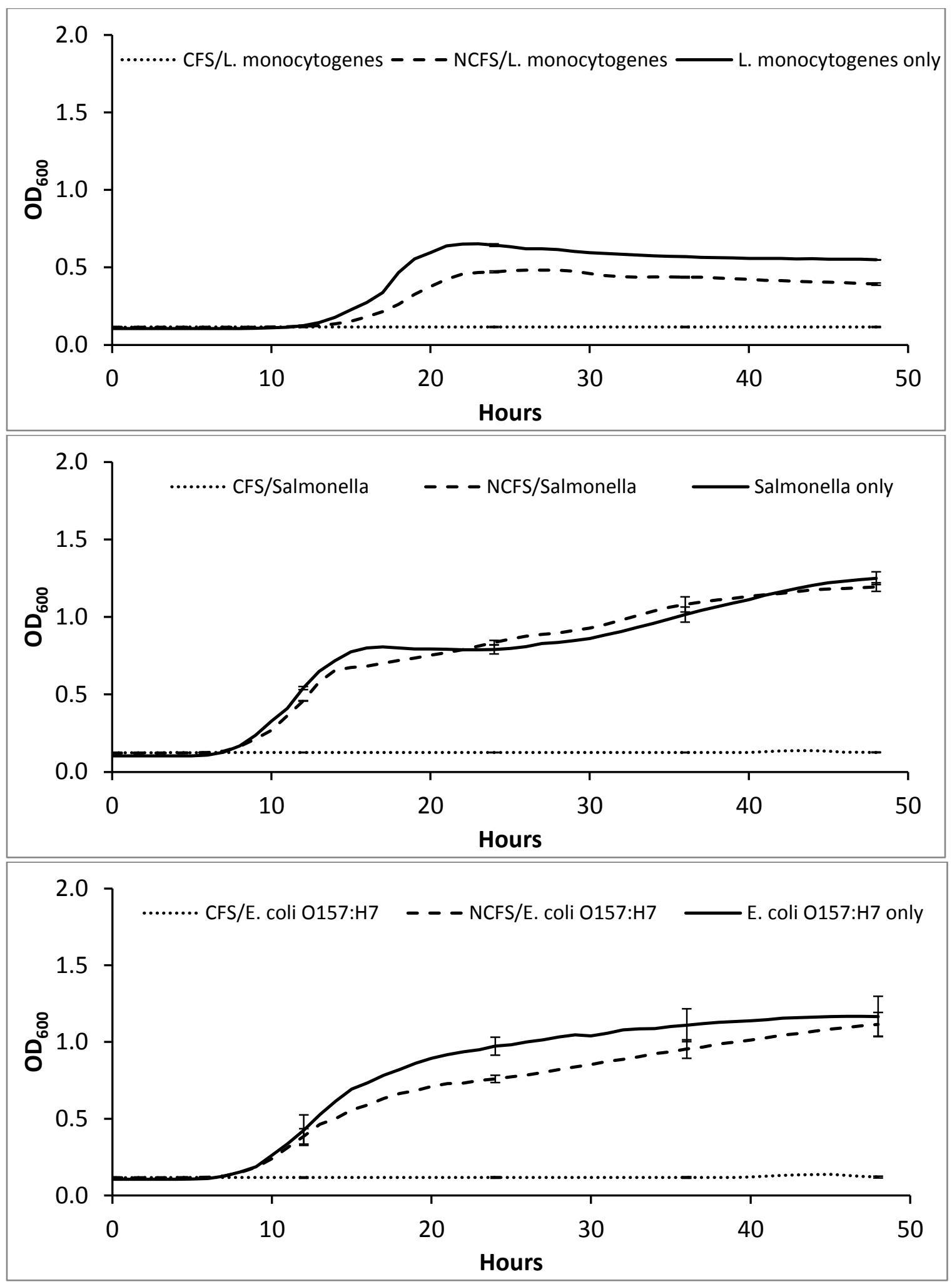

Figure 4.3. Optical density of Listeria monocytogenes, Salmonella, and Escherichia coli O157:H7 grown in Lactobacillus plantarum CFS and NCFS. Error bars indicate standard error of the mean. 


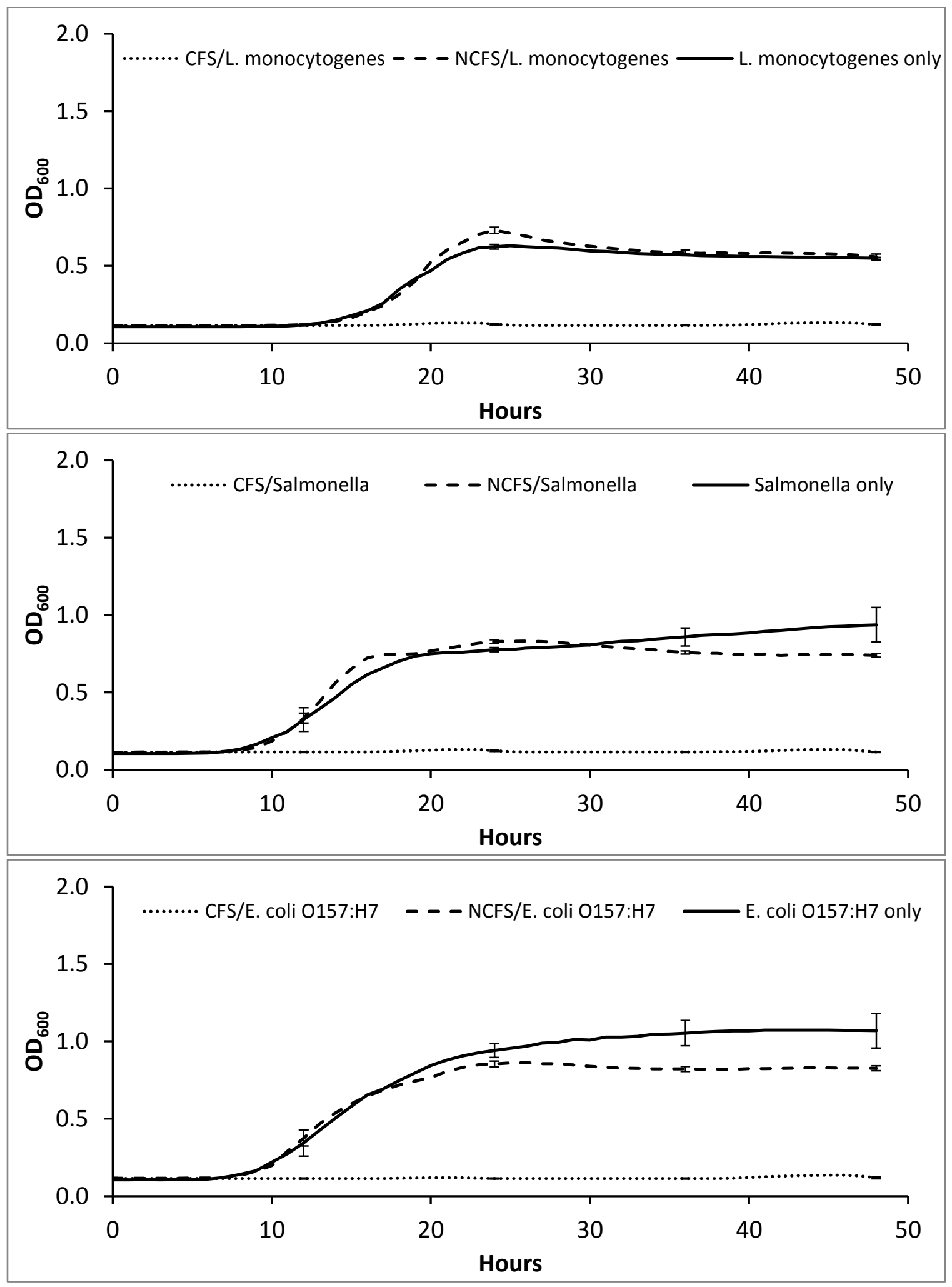

Figure 4.4. Optical density of Listeria monocytogenes, Salmonella, and Escherichia coli O157:H7 grown in Pediococcus acidilactici CFS and NCFS. Error bars indicate standard error of the mean. 


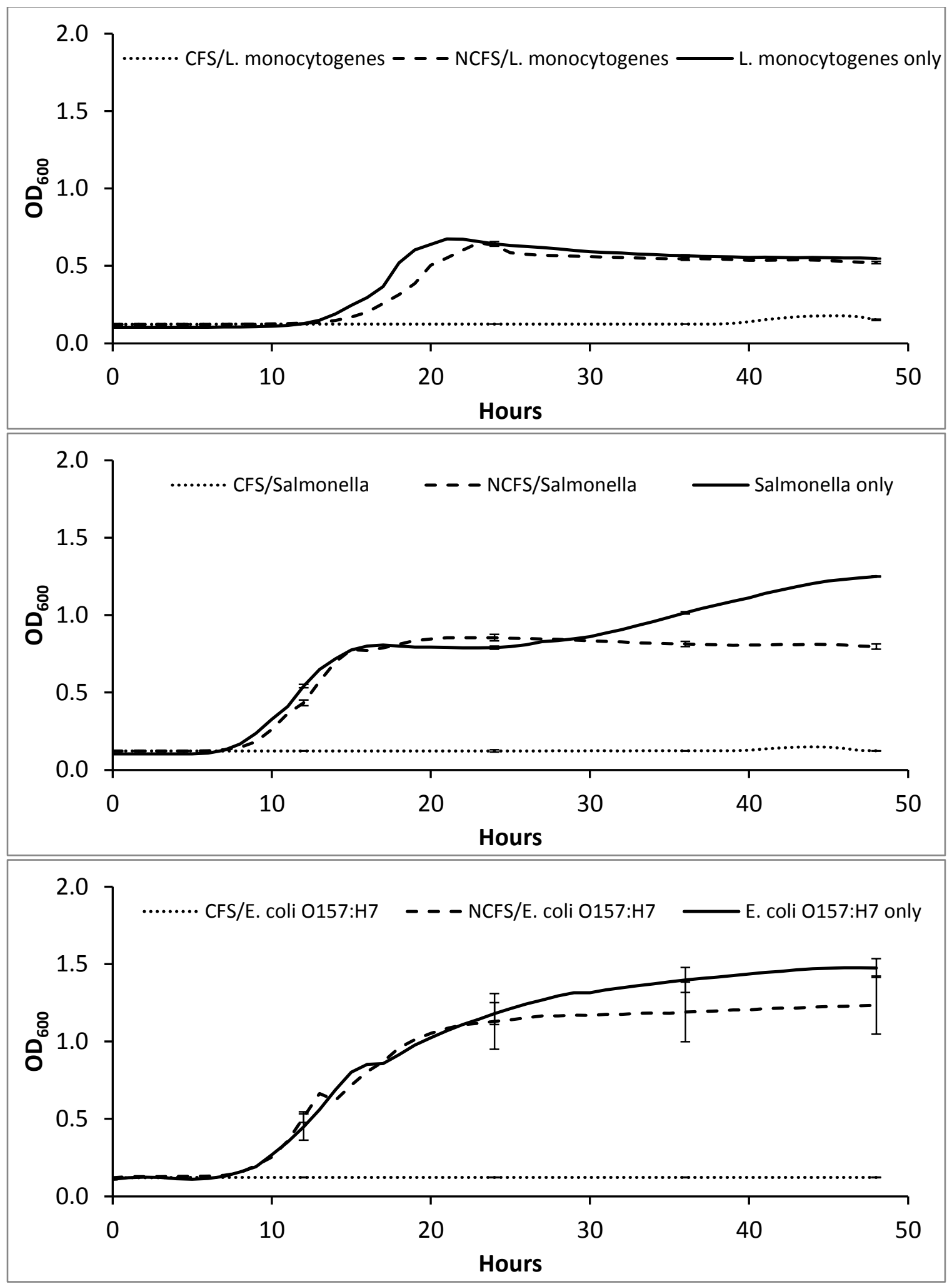

Figure 4.5. Optical density of Listeria monocytogenes, Salmonella, and Escherichia coli O157:H7 grown in Pediococcus pentosaceus CFS and NCFS. Error bars indicate standard error of the mean. 


\subsubsection{Application on Produce}

\subsubsection{Effect of Lactic Acid Bacteria Cocktail on Listeria monocytogenes on Iceberg}

\section{Lettuce}

Lactic Acid Bacteria have long been used in the production of fermented foods such as cheese, yogurt, and sauerkraut. Their use as biocontrol agents on fresh produce is of interest to the food industry because of their GRAS status and ability to synthesize antimicrobial compounds. This preliminary experiment was used to evaluate the capability of the LAB isolates used in this study to translate in vitro pathogen inhibition to the suppression of pathogen growth on produce stored at refrigeration temperatures and to assess LAB survival.

When applied to Iceberg lettuce, the LAB cocktail suppressed the growth of $L$. monocytogenes; levels were significantly lower on LAB-treated lettuce $(\alpha=0.05)$ and remained lower throughout the incubation period (Figure 4.6a). After $14 \mathrm{~d}, L$. monocytogenes populations were $1.84 \log$ lower on LAB-treated lettuce. These results were as expected; efficacy against L. monocytogenes varies between produce type and LAB species. Application of bioprotective LAB species has resulted in a 1 log reduction to complete inhibition of L. monocytogenes on apple wedges (Trias et al., 2008a; Alegre et al., 2011) and a half log reduction to complete inhibition on Iceberg lettuce (Allende et al., 2007; Trias et al., 2008a). The LAB used in this study suppressed the growth of $L$. monocytogenes and LAB levels remained unchanged throughout the $14 \mathrm{~d}$ incubation period (Figure 4.6b), therefore testing with these isolates continued. 


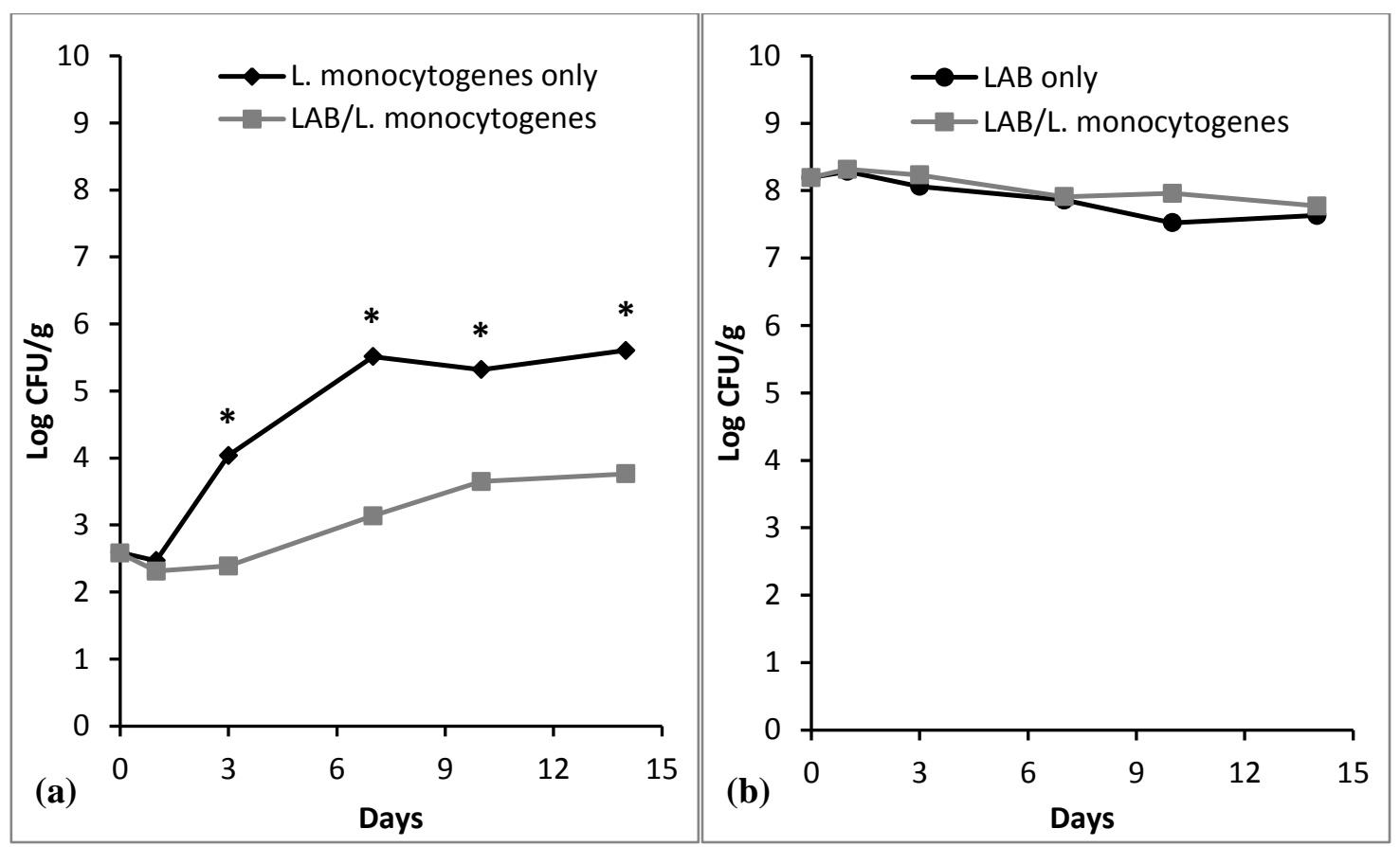

Figure 4.6. Listeria monocytogenes (a) and Lactic Acid Bacteria populations (b) on Iceberg lettuce treated with Lactic Acid Bacteria cocktail after $14 \mathrm{~d}$ incubation at $10^{\circ} \mathrm{C}$. Asterisks indicate microbial populations which are significantly different on each sample day $(\alpha=0.05)$.

\subsubsection{The Effect of DF1 Treatment on the Appearance of Iceberg Lettuce}

In order to be an effective antimicrobial treatment for food products, the method must not only control microbial populations, but also not have a deleterious effect of the product's shelf life or sensory characteristics. The DF1 formulation was selected for testing on produce because it contained the three LAB isolates used in the previous Iceberg lettuce experiment. The purpose of this experiment was to evaluate the effects of DF1, a powder containing Lb. plantarum, P. acidilactici, $P$. pentosaceus, and other media (Table 4.3), on the sensory characteristics on chopped Iceberg lettuce during refrigerated storage and to determine LAB survival under those conditions. 


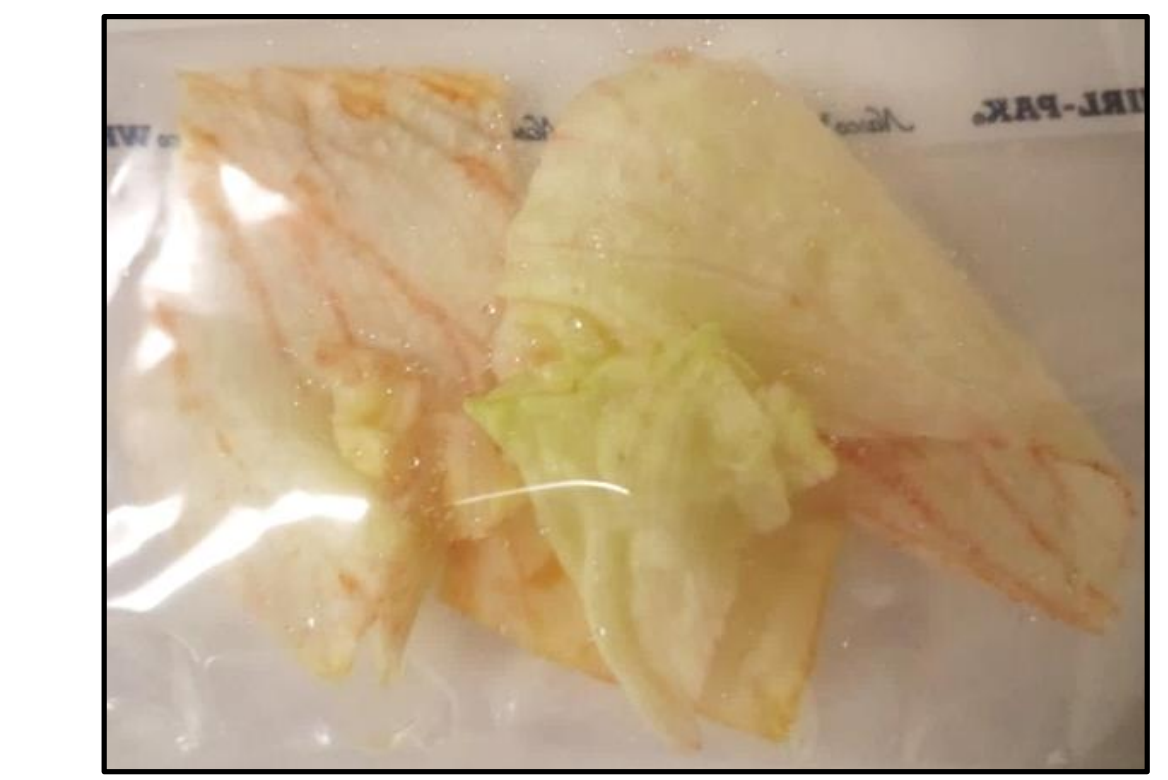

Figure 4.7. Iceberg lettuce treated with DF1 after $2 \mathrm{~d}$ incubation at $10^{\circ} \mathrm{C}$.

As in the previous experiment on Iceberg lettuce, LAB population levels did not change over the $2 \mathrm{~d}$ incubation period. However, DF1 solution was brown and cloudy when mixed with DI water; it left a faint brown tint on the lettuce after spin-drying. After $2 \mathrm{~d}$ incubation at $10^{\circ} \mathrm{C}$, DF1-treated lettuce had substantial browning (Figure 4.7). No browning was observed in untreated lettuce or lettuce treated with LAB cocktail in the previous experiment with Iceberg lettuce after $2 \mathrm{~d}$, indicating that media components in DF1 were most likely the cause the browning. Damaging the lettuce leaves by cutting them could have allowed for the uptake of DF1 into the vascular system of the lettuce, also contributing to the rapid color change. Because the application of DF1 left a brown tint on lettuce and caused browning after only $2 \mathrm{~d}$ incubation, it was deemed unacceptable for use on light-colored, chopped produce. Gala apples were chosen for further evaluation of DF1 because of their dark color and because apples are commonly stored and consumed as whole fruit. 


\subsubsection{Effect of DF1 on Listeria monocytogenes, Salmonella, and Escherichia coli}

\section{O157:H7 on Gala Apples}

\subsection{The Fate of Listeria monocytogenes, Salmonella, and Escherichia coli}

O157:H7 on the Surface of Gala Apples

The recent outbreak of L. monocytogenes in caramel apples has focused a spotlight onto the survival of pathogenic bacteria on apples. In this experiment, $L$. monocytogenes, Salmonella, and E. coli O157:H7 levels were monitored over a total of 6 d; the pathogen-inoculated apples were incubated at $4{ }^{\circ} \mathrm{C}$ for the first $24 \mathrm{~h}$, then at $20^{\circ} \mathrm{C}$ for the remaining 5 d. L. monocytogenes and Salmonella did not survive well on the surface of Gala apples over the $6 \mathrm{~d}$ incubation period. The populations of $L$.

monocytogenes and Salmonella decreased by 2 and $3 \log$, respectively, when incubated at $4^{\circ} \mathrm{C}$ overnight, then rapidly decreased over $5 \mathrm{~d}$ at $20^{\circ} \mathrm{C}$ to below detection levels. E. coli O157:H7 was more robust than L. monocytogenes or Salmonella. After a decrease of approximately $3 \log$ after 24 h, E. coli O157:H7 levels remained around $3 \log$ CFU/plug for the duration of the incubation period (Table 4.6). The rapid decrease in pathogen populations was most likely caused by the harsh conditions on the surface of the apple, where water and nutrients were not available in abundance. Apple peels also contain antimicrobial compounds such as polyphenols. Polyphenols extracted from apple peels have demonstrated inhibition of $E$. coli (Alberto et al., 2006; Fratianni et al., 2007), $S$. aureus, and L. monocytogenes (Alberto et al., 2006). The rapid decline in pathogen population was most likely the result of the severe surface conditions and antimicrobial compounds within the apple's peel. 
Table 4.6. Listeria monocytogenes, Salmonella, and Escherichia coli O157:H7 on Gala apples treated with DF1 or DI water

\begin{tabular}{|c|c|c|c|c|c|c|}
\hline \multirow{2}{*}{ Treatment } & \multicolumn{6}{|c|}{ Day $\left(\log\right.$ CFU/plug) $^{1}$} \\
\hline & Inoculation & 0 & 1 & 2 & 3 & 5 \\
\hline $\begin{array}{l}\text { L. monocytogenes } \\
\text { only }\end{array}$ & $\begin{array}{l}6.91 / 6.99 \\
(6.95)\end{array}$ & $\begin{array}{c}4.80 / 5.06 \\
\quad(4.95)\end{array}$ & $\begin{array}{l}3.29 / 2.60 \\
(3.07)^{2}\end{array}$ & $\begin{array}{l}3.05 / 3.01 \\
(3.03)\end{array}$ & $\begin{array}{c}3.64 / 2.98 \\
(3.43)\end{array}$ & $\begin{array}{c}0.70 /<1 \\
(0.40)^{2}\end{array}$ \\
\hline $\begin{array}{l}\text { L. monocytogenes/ } \\
\mathrm{H}_{2} \mathrm{O}\end{array}$ & -- & $\begin{array}{c}2.70 /<3 \\
(2.40)^{2}\end{array}$ & $\begin{array}{c}1.18 / 1.18 \\
(1.18)^{2}\end{array}$ & $\begin{array}{l}<1 /<1 \\
\quad(<1)\end{array}$ & $\begin{array}{c}1.00 /<1 \\
(0.70)^{2}\end{array}$ & $\begin{array}{c}0.70 / 0.70 \\
(0.70)^{2}\end{array}$ \\
\hline $\begin{array}{l}\text { L. monocytogenes/ } \\
\text { DF1 }\end{array}$ & -- & $\begin{array}{l}5.29 / 5.41 \\
\quad(5.36)\end{array}$ & $\begin{array}{c}5.10 /<1 \\
(4.80)\end{array}$ & $\begin{array}{l}4.82 / 5.09 \\
\quad(4.98)\end{array}$ & $\begin{array}{l}4.63 / 4.44 \\
(4.55)\end{array}$ & $\begin{array}{l}4.73 / 5.26 \\
\quad(5.07)\end{array}$ \\
\hline Salmonella only & $\begin{array}{l}6.02 / 6.14 \\
(6.09)\end{array}$ & $\begin{array}{c}3.30 / 2.70 \\
(3.05)^{2}\end{array}$ & $\begin{array}{c}0.70 /<1 \\
(0.40)^{2}\end{array}$ & $\begin{array}{c}<1 /<1 \\
(<1)\end{array}$ & $\begin{array}{c}0.70 /<1 \\
(0.40)^{2}\end{array}$ & $\begin{array}{c}<1 /<1 \\
(<1)\end{array}$ \\
\hline Salmonella $/ \mathrm{H}_{2} \mathrm{O}$ & -- & $\begin{array}{c}<3 /<3 \\
(<3)\end{array}$ & $\begin{array}{c}<1 /<1 \\
(<1)\end{array}$ & $\begin{array}{c}<1 /<1 \\
(<1)\end{array}$ & $\begin{array}{l}<1 /<1 \\
(<1)\end{array}$ & $\begin{array}{c}<1 /<1 \\
(<1)\end{array}$ \\
\hline Salmonella/DF1 & -- & $\begin{array}{l}2.70 /<3 \\
(2.40)^{2}\end{array}$ & $\begin{array}{c}3.13 /<1 \\
(2.83)\end{array}$ & $\begin{array}{c}2.71 /<1 \\
(2.41)\end{array}$ & $\begin{array}{c}<1 /<1 \\
(<1)\end{array}$ & $\begin{array}{c}3.95 /<1 \\
(3.35)\end{array}$ \\
\hline $\begin{array}{l}\text { E. coli } \mathrm{O} 157: \mathrm{H} 7 \\
\text { only }\end{array}$ & $\begin{array}{l}6.44 / 6.81 \\
\quad(6.66)\end{array}$ & $\begin{array}{c}3.54 / 3.81 \\
(3.70)^{2}\end{array}$ & $\begin{array}{l}3.25 / 1.65 \\
(2.96)\end{array}$ & $\begin{array}{l}3.01 / 3.31 \\
(3.23)\end{array}$ & $\begin{array}{l}3.05 / 1.30 \\
(2.75)\end{array}$ & $\begin{array}{l}2.79 / 3.24 \\
\quad(3.07)\end{array}$ \\
\hline $\begin{array}{l}\text { E. coli } \mathrm{O} 157: \mathrm{H} 7 / \\
\mathrm{H}_{2} \mathrm{O}\end{array}$ & -- & $\begin{array}{c}<3 /<3 \\
(<3)\end{array}$ & $\begin{array}{c}1.00 /<1 \\
(0.70)^{2}\end{array}$ & $\begin{aligned}<1 /<1 \\
\quad(<1)\end{aligned}$ & $\begin{aligned}<1 /<1 \\
\quad(<1)\end{aligned}$ & $\begin{array}{c}2.43 /<1 \\
2.13\end{array}$ \\
\hline $\begin{array}{l}\text { E. coli } \mathrm{O} 157: \mathrm{H} 7 / \\
\mathrm{DF} 1\end{array}$ & -- & $\begin{array}{c}<3 /<3 \\
(<3)\end{array}$ & $\begin{array}{l}2.51 / 3.26 \\
(3.03)\end{array}$ & $\begin{array}{c}2.64 /<1 \\
(2.34)\end{array}$ & $\begin{array}{c}1.18 / 1.90 \\
(1.68)^{2}\end{array}$ & $\begin{array}{c}4.86 /<1 \\
(4.56)\end{array}$ \\
\hline
\end{tabular}

(--): not applicable.

${ }^{1}$ Counts for each of the samples tested; average of the two counts in parentheses.

${ }^{2}$ Estimated counts.

\subsection{The Effect of DF1 on Listeria monocytogenes, Salmonella, and Escherichia} coli $\mathrm{O} 157: \mathrm{H7}$ on Gala Apples

The use of LAB on various fruits and vegetables for the suppression of $L$.

monocytogenes, Salmonella, and E. coli $0157: \mathrm{H} 7$ has yielded mixed results; inhibition has ranged from 1 log to complete depending on LAB isolate, pathogen, and produce type (Trias et al., 2008a; Gragg and Brashears, 2010; Alegre et al., 2011; Cálix-Lara et 
al., 2014). In this study, the DF1 formulation was chosen for evaluation because it contained Lb. plantarum, $P$. acidilactici, and P. pentosaceus - the three LAB strains that demonstrated antimicrobial activity during in vitro screening. However, the application of DF1 allowed for the survival of L. monocytogenes, Salmonella, and E. coli O157:H7 on Gala apples; no treatment at all and treating the apples with DI water were more effective in reducing pathogen populations. After $5 \mathrm{~d}$ incubation at $20^{\circ} \mathrm{C}$, L. monocytogenes, Salmonella, and E. coli O157:H7 levels on DF1-treated apples were approximately 4, 2, and $2 \log$ higher than levels on apples treated with DI water, respectively(Table 4.6). The LAB from DF1 also survived well; levels on DF1-treated apples remained consistent throughout incubation (Figure 4.8). The media components and dextrose in DF1 could have provided nutrients to the pathogens and $\mathrm{LAB}$, aiding in their survival on the harsh surface of the apple.

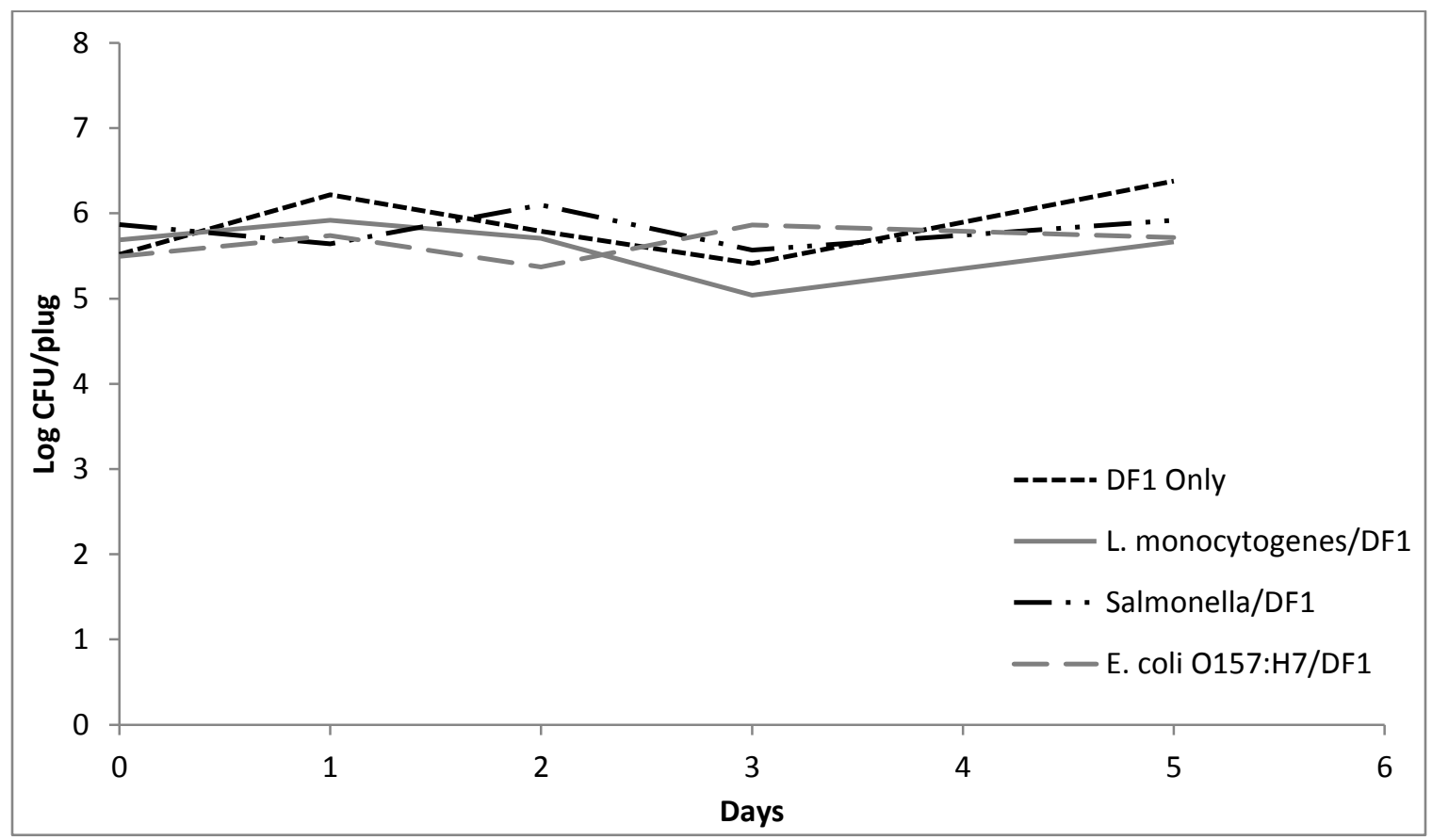

Figure 4.8. LAB population on DF1-treated Gala apples incubated at $20^{\circ} \mathrm{C}$ for $5 \mathrm{~d}$. 


\subsection{The Effect of DF1 on the Appearance of Gala Apples}

In addition to aiding in pathogen survival, DF1 also negatively affected the appearance and feel of the apples. When DF1 was sprayed onto the apples it beaded up, leaving a brown, tacky residue on the surface (Figure 4.9). The tackiness was most likely the result of the dextrose present in the formulation. Based on the results of this experiment, DF1 is not the appropriate formulation for the biocontrol of $L$. monocytogenes, Salmonella, and E. coli O157:H7 on fresh produce because its application promotes the growth of these pathogens and is detrimental to the sensory characteristics of the product.

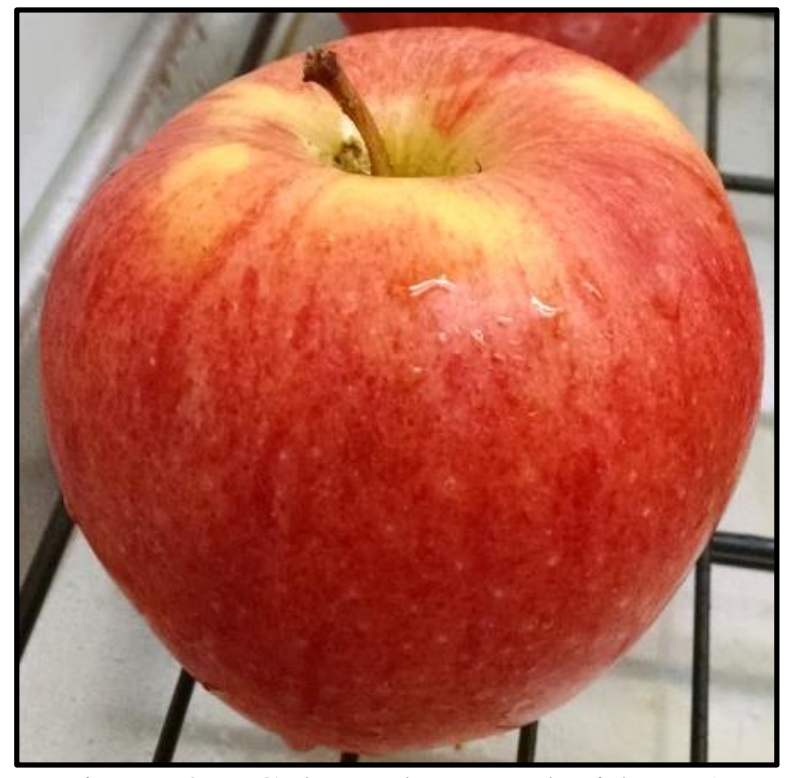

Figure 4.9. Gala apple treated with DF1. 


\subsection{Conclusion}

The antimicrobial screening identified three LAB isolates and six Bacillus isolates capable of inhibiting the growth of L. monocytogenes, Salmonella, and E. coli O157:H7 in vitro. The organic acids produced by the LAB isolates significantly contributed to the suppression of all three bacterial pathogens. Based on the results of the screening, the three LAB isolates-Lb. plantarum, P. acidilactici, and P. pentosaceus-were selected for evaluation on fresh produce.

The LAB isolates were cocktailed and activity against L. monocytogenes was evaluated on Iceberg lettuce. The LAB cocktail suppressed, but did not completely inhibit, the growth of L. monocytogenes over $14 \mathrm{~d}$. However, the antimicrobial efficacy of the LAB cocktail on Iceberg lettuce prompted investigation into the use of DF1, a formulation containing the three LAB isolates and media components, for the inhibition of L. monocytogenes, Salmonella, and E. coli O157:H7 on produce.

DF1 treatment of chopped Iceberg lettuce caused rapid browning after $2 \mathrm{~d}$, demonstrating that DF1 may not be appropriate for use on cut produce. Therefore, apples were chosen for further testing because the fruit did not need to be cut before treatment. When applied to apples, DF1 did not reduce L. monocytogenes, Salmonella, or E. coli O157:H7 on apples, but in fact aided in the survival of these pathogens. DF1 was also detrimental to the appearance and feel of the apples. Based on the results of these experiments, DF1 is not the optimal formulation for biocontrol of L. monocytogenes, Salmonella, and E. coli O157:H7 on fresh produce. 


\section{FUTURE RESEARCH}

This research identified several bacterial isolates with potential agricultural application. Of the 22 isolates investigated, nine demonstrated strong fungal suppression and nine showed strong antimicrobial activity. Investigation into these isolates is needed to assess their possible use in the agricultural industry.

Future research should include the characterization of the bioactive compounds produced by the inhibitory isolates to gain a better understanding of their antifungal and antimicrobial abilities. This information would allow for the optimization of product formulation and application; this could include alternative media and growth conditions and their effect on bioactive compound production. After optimization, challenge studies on produce should be conducted to assess the commercial viability of the product; produce quality, application methods, and pathogen efficacy must all be evaluated. 


\section{REFERENCES}

Abriouel, H., C. Franz, N. Ben Omar, and A. Gálvez. 2011. Diversity and applications of Bacillus bacteriocins. FEMS Microbiol. Rev. 35(1): 201-232.

Agarry, O.O., F.A. Akinyosoye, and F.C. Adetuyi. 2005. Antagonistic properties of microogranisms associated with cassava (Manihot esculenta Crantz) products. African J. Biotechnol. 4(7): 627-632.

Aktuganov, G.E., A.I. Melent'ev, L.Y. Kuz'mina, N.F. Galimzyanova, and A. V Shirokov. 2003. The chitinolytic activity of Bacillus cohn bacteria antagonistic to phytopathogenic fungi. Microbiology 72(3): 313-317.

Alakomi, H.L., E. Skyttä, M. Saarela, T. Mattila-Sandholm, K. Latva-Kala, and I.M. Helander. 2000. Lactic acid permeabilizes gram-negative bacteria by disrupting the outer membrane. Appl. Environ. Microbiol. 66(5): 2001-2005.

Alberto, M.R., M.A. Rinsdahl Canavosio, and M.C. Manca De Nadra. 2006. Antimicrobial effect of polyphenols from apple skins on human bacterial pathogens. Electron. J. Biotechnol. 9(3): 205-209.

Alegre, I., I. Viñas, J. Usall, M. Anguera, and M. Abadias. 2011. Microbiological and physicochemical quality of fresh-cut apple enriched with the probiotic strain Lactobacillus rhamnosus GG. Food Microbiol. 28: 59-66.

Al-Holy, M.A., M. Lin, H.M. Al-Qadiri, and B.A. Rasco. 2008. A comparative study between overlay method and selective-differential media for recovery of stressed Enterobacter sakazakii cells from infant formula. Food Microbiol. 25: 22-28.

Allende, A., B. Martínez, V. Selma, M.I. Gil, J.E. Suárez, and A. Rodríguez. 2007. Growth and bacteriocin production by Lactic Acid Bacteria in vegetable broth and their effectiveness at reducing Listeria monocytogenes in vitro and in fresh-cut lettuce. Food Microbiol. 24(7-8): 759-766.

Alvindia, D.G., and K.T. Natsuaki. 2009. Biocontrol activities of Bacillus amyloliquefaciens DGA14 isolated from banana fruit surface against banana crown rot-causing pathogens. Crop Prot. 28(3): 236-242.

Arguelles-Arias, A., M. Ongena, B. Halimi, Y. Lara, A. Brans, B. Joris, and P. Fickers. 2009. Bacillus amyloliquefaciens GA1 as a source of potent antibiotics and other secondary metabolites for biocontrol of plant pathogens. Microb. Cell Fact. 8: 63.

Arrebola, E., R. Jacobs, and L. Korsten. 2010. Iturin A is the principal inhibitor in the biocontrol activity of Bacillus amyloliquefaciens PPCB004 against postharvest fungal pathogens. J. Appl. Microbiol. 108(2): 386-395. 
Barrette, W.C., D.M. Hannum, W.D. Wheeler, and J.K. Hurst. 1989. General mechanism for the bacterial toxicity of hypochlorous acid: abolition of ATP production. Biochemistry 28(23): 9172-9178.

Bastos, M.D.S.R., N. de Fátima Ferreira Soares, N. José de Andrade, A. Cristina Arruda, and R. Elesbão Alves. 2005. The effect of the association of sanitizers and surfactant in the microbiota of the Cantaloupe (Cucumis melo L.) melon surface. Food Control 16(4): 369-373.

Bayer CropScience LP. 2013a. Serenade Optimum. (130205). Available at http://www.agrian.com/pdfs/Serenade_OPTIMUM_Label.pdf. Accessed 20 July 2014.

Bayer CropScience LP. 2013b. Sonata. Prescrire Int. 17(98). Available at http://www.agrian.com/pdfs/Serenade_OPTIMUM_Label.pdf. Accessed 20 July 2014.

Behrsing, J., S. Winkler, P. Franz, and R. Premier. 2000. Efficacy of chlorine for inactivation of Escherichia coli on vegetables. Postharvest Biol. Technol. 19: 187192.

Bennik, M.H., W. van Overbeek, E.J. Smid, and L.G. Gorris. 1999. Biopreservation in modified atmosphere stored mungbean sprouts: the use of vegetable-associated bacteriocinogenic lactic acid bacteria to control the growth of Listeria monocytogenes. Lett. Appl. Microbiol. 28(3): 226-232.

Berić, T., S. Stanković, V. Draganić, M. Kojić, J. Lozo, and D. Fira. 2013. Novel antilisterial bacteriocin licheniocin 50.2 from Bacillus licheniformis VPS50.2 isolated from soil sample. J. Appl. Microbiol. 116: 502-510.

Beuchat, L.R., and R.E. Brackets. 1990. Survival and growth of Listeria monocytogenes on lettuce as influenced by shredding, chlorine treatment, modified atmosphere packaging and temperature. J. Food Sci. 55(3): 755-758.

Bhunia, A., M. Johnson, and B. Ray. 1988. Purification, characterization and antimicrobial spectrum of a bacteriocin produced by Pediococccus acidilactici. J. Appl. Bacteriol. 65: 261-268.

Bizani, D., A.S. Motta, J.A.C. Morrissy, R.M.S. Terra, A.A. Souto, and A. Brandelli. 2005. Antibacterial activity of cerein $8 \mathrm{~A}$, a bacteriocin-like peptide produced by Bacillus cereus. Int. Microbiol. 8: 125-131.

Brenner, D.J., N.R. Krieg, J.T. Staley, and G.M. Garrity. 2005a. Bergey's Manual of Systematic Bacteriology Vol. Two Part B. 2nd ed. Springer Science+Business Media LLC, New York, NY. 
Brenner, D.J., N.R. Krieg, J.T. Staley, and G.M. Garrity. 2005b. Bergey's Manual of Systematic Bacteriology Vol. Two Part C. 2nd ed. Springer Science+Business Media LLC, New York, NY.

Bressan, W., and J.E.F. Figueiredo. 2010. Chitinolytic Bacillus spp. isolates antagonistic to Fusarium moniliforme in maize. J. Plant Pathol. 92(2): 343-347.

Brötz, H., G. Bierbaum, A. Markus, E. Molitor, and H.-G. Sahl. 1995. Mode of action of the lantibiotic mersacidin: inhibition of peptidoglycan biosynthesis via a novel mechanism? Antimicrob. Agents Chemother. 39(3): 714-719.

Brown, A.L., J.C. Brooks, E. Karunasena, A. Echeverry, A. Laury, and M.M. Brashears. 2011. Inhibition of Escherichia coli O157:H7 and Clostridium sporogenes in spinach packaged in modified atmospheres after treatment combined with chlorine and lactic acid bacteria. J. Food Sci. 76(6): M427-32.

Brown, T.L., H.E. LeMay, B.E. Bursten, C.J. Murphy, and P. Woodward. 2009. Chemistry: The Central Science. 11th ed. Pearson Education, Inc., Upper Saddle River, NJ.

Brul, S., and P. Coote. 1999. Preservative agents in foods: mode of action and microbial resistance mechanisms. Int. J. Food Microbiol. 50: 1-17.

California Food Emergency Response Team. 2007. Investigation of an Escherichia coli O157:H7 outbreak associated with Dole pre-packaged spinach. Sacramento, CA. Available at http://www.marlerclark.com/2006_Spinach_Report_Final_01.pdf. Accessed 25 July 2014.

Cálix-Lara, T.F., M. Rajendran, S.T. Talcott, S.B. Smith, R.K. Miller, A. Castillo, J.M. Sturino, and T.M. Taylor. 2014. Inhibition of Escherichia coli O157:H7 and Salmonella enterica on spinach and identification of antimicrobial substances produced by a commercial Lactic Acid Bacteria food safety intervention. Food Microbiol. 38: 192-200.

Centers for Disease Control and Prevention. 2006. Update on multi-state outbreak of $E$. coli O157:H7 infections from fresh spinach, October 6, 2006. Available at http://www.cdc.gov/ecoli/2006/september/updates/100606.htm. Accessed 20 July 2014.

Centers for Disease Control and Prevention. 2011a. Multistate outbreak of human Salmonella Agona infections linked to whole, fresh imported papayas. Available at http://www.cdc.gov/salmonella/agona-papayas/index.html. Accessed 20 July 2014.

Centers for Disease Control and Prevention. 2011b. Investigation update: outbreak of Shiga toxin-producing E. coli O104 (STEC O104:H4) infections associated with 
travel to Germany. Available at http://www.cdc.gov/ecoli/2011/ecolio104/. Accessed 20 July 2014.

Centers for Disease Control and Prevention. 2012a. Multistate outbreak of listeriosis linked to whole cantaloupes from Jensen Farms, Colorado. Available at http://www.cdc.gov/listeria/outbreaks/cantaloupes-jensen-farms/082712/index.html. Accessed 20 July 2014.

Centers for Disease Control and Prevention. 2012b. Salmonella. Available at http://www.cdc.gov/salmonella/general/index.html. Accessed 21 July 2014.

Centers for Disease Control and Prevention. 2012c. Multistate outbreak of Salmonella Braenderup infections associated with mangoes (final update). Available at http://www.cdc.gov/salmonella/braenderup-08-12/index.html. Accessed 20 July 2014.

Centers for Disease Control and Prevention. 2012d. Multistate outbreak of Salmonella Typhimurium and Salmonella Newport infections linked to cantaloupe (final update). Available at http://www.cdc.gov/salmonella/typhimurium-cantaloupe-0812/index.html. Accessed 20 July 2014.

Centers for Disease Control and Prevention. 2012e. Multistate outbreak of Escherichia coli O157:H7 infections linked to romaine lettuce. Available at http://www.cdc. gov/ecoli/2011/ecoliO157/romainelettuce/032312/index.html. Accessed 20 July 2014.

Centers for Disease Control and Prevention. 2013a. Multistate outbreak of Salmonella Saintpaul infections linked to imported cucumbers (final update). Available at http://www.cdc.gov/salmonella/saintpaul-04-13/index.html. Accessed 20 July 2014.

Centers for Disease Control and Prevention. 2013b. Multistate outbreak of Shiga toxinproducing Escherichia coli O157:H7 infections linked to ready-to-eat salads (final update). Available at http://www.cdc.gov/ecoli/2013/O157H7-11-13/index.html. Accessed 20 July 2014.

Centers for Disease Control and Prevention. 2014. Multistate outbreak of Shiga-toxin producing Escherichia coli O121 infections linked to raw clover sprouts (final update). Available at http://www.cdc.gov/ecoli/2014/O121-05-14/index.html. Accessed 5 April 2015.

Centers for Disease Control and Prevention. 2015. Multistate outbreak of listeriosis linked to commercially produced, prepackaged caramel apples made from Bidart Bros. Apples (final report). Available at http://www.cdc.gov/listeria/outbreaks/ caramel-apples-12-14/. Accessed 4 April 2015. 
Certis USA LLC. 2012. DoubleNickel LC Biofungicide. Available at http://www.certisusa.com/pdf-labels/DoubleNickel_LC_label.pdf. Accessed 3 August 2014.

Chaiharn, M., S. Chunhaleuchanon, and S. Lumyong. 2009. Screening siderophore producing bacteria as potential biological control agent for fungal rice pathogens in Thailand. World J. Microbiol. Biotechnol. 25(11): 1919-1928.

Chakraborty, U., B.N. Chakraborty, M. Basnet, and a P. Chakraborty. 2009. Evaluation of Ochrobactrum anthropi TRS-2 and its talc based formulation for enhancement of growth of tea plants and management of brown root rot disease. J. Appl. Microbiol. 107(2): 625-634.

Chakraborty, S., and A.C. Newton. 2011. Climate change, plant diseases and food security: an overview. Plant Pathol. 60(1): 2-14.

Chen, D., X. Liu, C. Li, W. Tian, Q. Shen, and B. Shen. 2014. Isolation of Bacillus amyloliquefaciens S20 and its application in control of eggplant bacterial wilt. J. Environ. Manage. 137: 120-127.

Chen, X.H., R. Scholz, M. Borriss, H. Junge, G. Mögel, S. Kunz, and R. Borriss. 2009. Difficidin and bacilysin produced by plant-associated Bacillus amyloliquefaciens are efficient in controlling fire blight disease. J. Biotechnol. 140: 38-44.

Chen, X.-H., J. Vater, J. Piel, P. Franke, R. Scholz, K. Schneider, A. Koumoutsi, G. Hitzeroth, N. Grammel, A.W. Strittmatter, G. Gottschalk, R.D. Süssmuth, and R. Borriss. 2006. Structural and functional characterization of three polyketide synthase gene clusters in Bacillus amyloliquefaciens FZB 42. J. Bacteriol. 188(11): 40244036.

Chowdappa, P., S.P. Mohan Kumar, M. Jyothi Lakshmi, and K.K. Upreti. 2013. Growth stimulation and induction of systemic resistance in tomato against early and late blight by Bacillus subtilis OTPB1 or Trichoderma harzianum OTPB3. Biol. Control 65(1): 109-117.

Christie, W.W. 2014. Microbial lipopeptides: structure, occurrence, and biology. AOCS Lipid Libr.Available at http://lipidlibrary.aocs.org/Lipids/lipopep/index.htm. Accessed 15 July 2014.

Cobo Molinos, A., H. Abriouel, R.L. López, E. Valdivia, N. Ben Omar, and A. Gálvez. 2008. Combined physico-chemical treatments based on enterocin AS-48 for inactivation of Gram-negative bacteria in soybean sprouts. Food Chem. Toxicol. 46(8): 2912-2921.

Compaoré, C.S., D.S. Nielsen, H. Sawadogo-Lingani, T.S. Berner, K.F. Nielsen, D.B. Adimpong, B. Diawara, G.A. Ouédraogo, M. Jakobsen, and L. Thorsen. 2013. 
Bacillus amyloliquefaciens ssp. plantarum strains as potential protective starter cultures for the production of Bikalga, an alkaline fermented food. J. Appl. Microbiol. 115(1): 133-146.

Cortés-Zavaleta, O., A. López-Malo, A. Hernández-Mendoza, and H.S. García. 2014. Antifungal activity of lactobacilli and its relationship with 3-phenyllactic acid production. Int. J. Food Microbiol. 173: 30-35.

Crowley, S., J. Mahony, and D. van Sinderen. 2013. Broad-spectrum antifungalproducing lactic acid bacteria and their application in fruit models. Folia Microbiol. (Praha). 58(4): 291-299.

D’Mello, J.P.F., C.M. Placinta, and A.M.C. Macdonald. 1999. Fusarium mycotoxins: a review of global implications for animal health, welfare and productivity. Anim. Feed Sci. Technol. 80(3-4): 183-205.

Dalie, D.K.D., A.M. Deschamps, V. Atanasova-Penichon, and F. Richard-Forget. 2010. Potential of Pediococcus pentosaceus (L006) isolated from maize leaf to suppress fumonisin-producing fungal growth. J. Food Prot. 73(6): 1129-1137.

De Vos, P., G.M. Garrity, D. Jones, N.R. Krieg, W. Ludwig, F.A. Rainey, K.-H. Schlelfer, and W.B. Whitman. 2009. Bergey's Manual of Systematic Bacteriology Vol. Three. 2nd ed. Springer Science+Business Media LLC, New York, NY.

Delves-Broughton, J. 2005. Nisin as a food preservative. Food Aust. 57: 525-527.

Deravel, J., S. Lemière, F. Coutte, F. Krier, N. Van Hese, M. Béchet, N. Sourdeau, M. Höfte, A. Leprêtre, and P. Jacques. 2014. Mycosubtilin and surfactin are efficient, low ecotoxicity molecules for the biocontrol of lettuce downy mildew. Appl. Microbiol. Biotechnol. 98(14): 6255-6264.

Díaz Arias, M.M., L.F. Leandro, and G.P. Munkvold. 2013. Aggressiveness of Fusarium species and impact of root infection on growth and yield of soybeans. Phytopathology 103(8): 822-832.

Diep, D.B., L. Godager, D. Brede, and I.F. Nes. 2006. Data mining and characterization of a novel pediocin-like bacteriocin system from the genome of Pediococcus pentosaceus ATCC 25745. Microbiology 152(Pt 6): 1649-1659.

Donmez, M.F., A. Esitken, H. Yildiz, and S. Ercisli. 2011. Biocontrol of Botrytis cinerea on strawberry fruit by plant growth promoting bacteria. J. Anim. Plant Sci. 21(4): $758-763$.

Dow, A., C. Alvarado, and M. Brashears. 2011. Reduction of inoculated Salmonella cocktail in ground turkey and turkey breasts using Lactobacillus-based intervention. Poult. Sci. 90(4): 876-879. 
Echeverry, A., J.C. Brooks, M.F. Miller, J.A. Collins, G.H. Loneragan, and M.M. Brashears. 2010. Validation of lactic acid bacteria, lactic acid, and acidified sodium chlorite as decontaminating interventions to control Escherichia coli $\mathrm{O} 157: \mathrm{H} 7$ and Salmonella Typhimurium DT 104 in mechanically tenderized and brine-enhanced (nonintact) beef at the purveyor. J. Food Prot. 73(12): 2169-2179.

Elmer, P.A.G., and T. Reglinski. 2006. Biosuppression of Botrytis cinerea in grapes. Plant Pathol. 55(2): 155-177.

Favret, M.E., and A.A. Yousten. 1989. Thuricin: the bacteriocin produced by Bacillus thuringiensis. J. Invertebr. Pathol. 53: 206-216.

Fratianni, F., A. Sada, L. Cipriano, A. Masucci, and F. Nazzaro. 2007. Biochemical characteristics, antimicrobial and mutagenic activity in organically and conventionally produced Malus domestica, Annurca. Open Food Sci. J. 1(1): 10-16.

Gerez, C.L., M.J. Torres, G. Font de Valdez, and G. Rollán. 2013. Control of spoilage fungi by lactic acid bacteria. Biol. Control 64(3): 231-237.

Gomaa, E.Z. 2012. Chitinase production by Bacillus thuringiensis and Bacillus licheniformis: their potential in antifungal biocontrol. J. Microbiol. 50(1): 103-111.

Gomaa, E.Z. 2013a. Antimicrobial and anti-adhesive properties of biosurfactant produced by lactobacilli isolates, biofilm formation and aggregation ability. J. Gen. Appl. Microbiol. 59: 425-436.

Gomaa, E.Z. 2013b. Antimicrobial activity of a biosurfactant produced by Bacillus licheniformis strain m104 grown on whey. Brazilian Arch. Biol. Technol. 56(2): 259-268.

Gould, L.H., E.A. Mungai, S.D. Johnson, L.C. Richardson, I.T. Williams, P.M. Griffin, and D.J. Cole. 2013a. Surveillance for foodborne disease outbreaks--United States, 2009-2010. Atlanta, GA. Available at http://www.ncbi.nlm.nih.gov/pubmed/ 23344696. Accessed 28 June 2014.

Gould, L.H., K. Walsh, A.R. Vieira, K. Herman, I.T. Williams, A.J. Hall, and D. Cole. 2013b. Surveillance for foodborne disease outbreaks--United States, 1998-2008. Atlanta, GA. Available at http://www.ncbi.nlm.nih.gov/pubmed/23804024. Accessed 28 June 2014.

Gould, M., L.M. Nelson, D. Waterer, and R.K. Hynes. 2008. Biocontrol of Fusarium sambucinum, dry rot of potato, by Serratia plymuthica 506. Biocontrol Sci. Technol. 18: 1005-1016. 
Gragg, S.E., and M.M. Brashears. 2010. Reduction of Escherichia coli O157:H7 in fresh spinach, using Lactic Acid Bacteria and chlorine as a multihurdle intervention. J. Food Prot. 73(2): 358-361.

Gray, E.J., K.D. Lee, A.M. Souleimanov, M.R. Di Falco, X. Zhou, A. Ly, T.C. Charles, B.T. Driscoll, and D.L. Smith. 2006. A novel bacteriocin, thuricin 17, produced by plant growth promoting rhizobacteria strain Bacillus thuringiensis NEB17: isolation and classification. J. Appl. Microbiol. 100(3): 545-554.

Gudiña, E.J., J.A. Teixeira, and L.R. Rodrigues. 2011. Biosurfactant-producing lactobacilli: screening, production profiles, and effect of medium composition. Appl. Environ. Soil Sci. 2011: 1-9.

Hamed, H.A., Y.A. Moustafa, and S.M. Abdel-Aziz. 2011. In vivo efficacy of Lactic Acid Bacteria in biological control against Fusarium oxysporum for protection of tomato plant. Life Sci. J. 8(4): 462-468.

Hathout, Y., Y. Ho, V. Ryzhov, P. Demirev, and C. Fenselau. 2000. Kurstakins: a new class of lipopeptides isolated from Bacillus thuringiensis. J. Nat. Prod. 63: 14921496.

Haydu, J.J., and D.E. Legard. 2003. An economic analysis of preharvest fungicide applications to control Botrytis Fruit Rot in annual strawberries in Florida. HortScience 38(1): 124-127.

Huang, X., Z. Lu, H. Zhao, X. Bie, F. Lü, and S. Yang. 2006. Antiviral activity of antimicrobial lipopeptide from Bacillus subtilis fmbj against Pseudorabies Virus, Porcine Parvovirus, Newcastle Disease Virus and Infectious Bursal Disease Virus in vitro. Int. J. Pept. Res. Ther. 12(4): 373-377.

Huang, W., J. Suo, and Y. Cui. 2011. Optimization of antimicrobial activity of surfactin and polylysine against Salmonella enteritidis in milk evaluated by a response surface methodology. Foodborne Pathog. Dis. 8(3): 439-443.

Hussain, M., and C. Dawson. 2013. Economic impact of food safety outbreaks on food businesses. Foods 2(4): 585-589.

Huszcza, E., and B. Burczyk. 2006. Surfactin isoforms from Bacillus coagulans. Zeitschrift fur Naturforsch. C 61: 727-733.

Hyronimus, B., C. Le Marrec, and M.C. Urdaci. 1998. Coagulin, a bacteriocin-like inhibitory substance produced by Bacillus coagulans I4. J. Appl. Microbiol. 85: 4250 . 
Ilhan, K., and O.A. Karabulut. 2013. Efficacy and population monitoring of bacterial antagonists for gray mold (Botrytis cinerea Pers. ex. Fr.) infecting strawberries. BioControl 58(4): 457-470.

Jadhav, V.V., A. Yadav, Y.S. Shouche, S. Aphale, A. Moghe, S. Pillai, A. Arora, and R.K. Bhadekar. 2013. Studies on biosurfactant from Oceanobacillus sp. BRI 10 isolated from Antarctic Sea water. Desalination 318: 64-71.

Jungk, J., J. Baumbach, M. Landen, L.K. Gaul, L. Alaniz, T. Dang, E.A. Miller, J. Weiss, K. Smith, E. Hedican, F. Grant, T. Beuregard, D. Bergmire-Sweat, D. Griffin, J. Engel, S. Gossack, A. Roanhorse, H. Shorty, J. Cheek, J. Redd, and I. Vigil. 2008. Outbreak of Salmonella serotype Saintpaul infections associated with multiple raw produce items—United States, 2008. Morb. Mortal. Wkly. Rep. 57(34): 929-934.

Kalinovskaya, N.I., T.A. Kuznetsova, E.P. Ivanova, L.A. Romanenko, V.G. Voinov, F. Huth, and H. Laatsch. 2002. Characterization of surfactin-like cyclic depsipeptides synthesized by Bacillus pumilus from Ascidian Halocynthia aurantium. Mar. Biotechnol. 4: 179-188.

Kamensky, M., M. Ovadis, I. Chet, and L. Chernin. 2003. Soil-borne strain IC14 of Serratia plymuthica with multiple mechanisms of antifungal activity provides biocontrol of Botrytis cinerea and Sclerotinia sclerotiorum diseases. Soil Biol. Biochem. 35: 323-331.

Kamoun, F., I. Ben Fguira, N.B. Ben Hassen, H. Mejdoub, D. Lereclus, and S. Jaoua. 2011. Purification and characterization of a new Bacillus thuringiensis bacteriocin active against Listeria monocytogenes, Bacillus cereus and Agrobacterium tumefaciens. Appl. Biochem. Biotechnol. 165(1): 300-314.

Karaca, H., and Y.S. Velioglu. 2014. Effects of ozone treatments on microbial quality and some chemical properties of lettuce, spinach, and parsley. Postharvest Biol. Technol. 88: 46-53.

Keskinen, L.A., and B.A. Annous. 2011. Efficacy of adding detergents to sanitizer solutions for inactivation of Escherichia coli O157:H7 on Romaine lettuce. Int. J. Food Microbiol. 147(3): 157-161.

Keskinen, L.A., A. Burke, and B.A. Annous. 2009. Efficacy of chlorine, acidic electrolyzed water and aqueous chlorine dioxide solutions to decontaminate Escherichia coli O157:H7 from lettuce leaves. Int. J. Food Microbiol. 132(2-3): 134-140.

Kim, P.I., H. Bai, D. Bai, H. Chae, S. Chung, Y. Kim, R. Park, and Y.-T. Chi. 2004. Purification and characterization of a lipopeptide produced by Bacillus thuringiensis CMB26. J. Appl. Microbiol. 97(5): 942-949. 
Koenning, S.R., and J.A. Wrather. 2010. Suppression of soybean yield potential in the continental United States by plant diseases from 2006 to 2009. Plant Heal. Prog.: doi: 10.1094/PHP-2010-1122-01-RS.

Koo, O.-K., M. Eggleton, C. a O’Bryan, P.G. Crandall, and S.C. Ricke. 2012. Antimicrobial activity of lactic acid bacteria against Listeria monocytogenes on frankfurters formulated with and without lactate/diacetate. Meat Sci. 92(4): 533537.

Kracht, M., H. Rokos, M. Ozel, M. Kowall, G. Pauli, and J. Vatera. 1999. Antiviral and hemolytic activities of surfactin isoforms and their methyl ester derivatives. J. Antibiot. (Tokyo). 52(7): 613-619.

Le Marrec, C., B. Hyronimus, P. Bressollier, B. Verneuil, and M.C. Urdaci. 2000. Biochemical and genetic characterization of coagulin, a new antilisterial bacteriocin in the pediocin family of bacteriocins, produced by Bacillus coagulans I4. Appl. Environ. Microbiol. 66(12): 5213-5220.

Lee, H., and H.-Y. Kim. 2011. Lantibiotics, Class I bacteriocins from the genus Bacillus. J. Microbiol. Biotechnol. 21(3): 229-235.

Levenfors, J.J., R. Hedman, C. Thaning, B. Gerhardson, and C.J. Welch. 2004. Broadspectrum antifungal metabolites produced by the soil bacterium Serratia plymuthica A 153. Soil Biol. Biochem. 36(4): 677-685.

Liao, C.-H. 2009. Control of foodborne pathogens and soft-rot bacteria on bell pepper by three strains of bacterial antagonists. J. Food Prot. 72(1): 85-92.

Lisboa, M.P., D. Bonatto, D. Bizani, J.A.P. Henriques, and A. Brandelli. 2006.

Characterization of a bacteriocin-like substance produced by Bacillus amyloliquefaciens isolated from the Brazilian Atlantic forest. Int. Microbiol. 9: 111118.

Lu, H.J., F. Breidt, I.M. Pérez-Díaz, and J.A. Osborne. 2011. Antimicrobial effects of weak acids on the survival of Escherichia coli O157:H7 under anaerobic conditions. J. Food Prot. 74(6): 893-898.

Maarten van Dijl, J., and M. Hecker. 2013. Bacillus subtilis: from soil bacterium to super-secreting cell factory. Microb. Cell Fact. 12(3): 1-6.

Magan, N., and D. Aldred. 2007. Post-harvest control strategies: minimizing mycotoxins in the food chain. Int. J. Food Microbiol. 119: 131-139.

Magnusson, J., K. Strom, S. Roos, J. Sjogren, and J. Schnurer. 2003. Broad and complex antifungal activity among environmental isolates of lactic acid bacteria. FEMS Microbiol. Lett. 219(1): 129-135. 
Makovitzki, A., and Y. Shai. 2005. pH-dependent antifungal lipopeptides and their plausible mode of action. Biochemistry 44(28): 9775-9784.

Mandal, V., S.K. Sen, and N.C. Mandal. 2008. Optimized culture conditions for bacteriocin production by Pediococcus acidilactici LAB 5 and its characterization. Indian J. Biochem. Biophys. 45: 106-110.

Mari, M., M. Guizzardi, M. Brunelli, and A. Folchi. 1996a. Postharvest biological control of grey mould (Botrytis cinerea Pers.: Fr.) on fresh-market tomatoes with Bacillus amyloliquefaciens. Crop Prot. 15(8): 699-705.

Mari, M., M. Guizzardi, and G.C. Pratella. 1996b. Biological control of Gray Mold in pears by antagonistic bacteria. Biol. Control 7: 30-37.

Martirani, L., M. Varcamonti, G. Naclerio, and M. De Felice. 2002. Purification and partial characterization of bacillocin 490, a novel bacteriocin produced by a thermophilic strain of Bacillus licheniformis. Microb. Cell Fact. 5: 1-5.

McDonnell, G., and A.D. Russell. 1999. Antiseptics and disinfectants: activity, action, and resistance. Clin. Microbiol. Rev. 12(1): 147-179.

Miller, S.A., R.C. Rowe, and R.M. Riedel. 1996. Extension FactSheet: Fusarium and Verticillium wilts of tomato, potato, pepper, and eggplant. Columbus, $\mathrm{OH}$. Available at http://ohioline.osu.edu/hyg-fact/3000/pdf/3122.pdf. Accessed 15 April 2015.

Mills, S., L.M. Serrano, C. Griffin, P.M. O’Connor, G. Schaad, C. Bruining, C. Hill, R.P. Ross, and W.C. Meijer. 2011. Inhibitory activity of Lactobacillus plantarum LMG P-26358 against Listeria innocua when used as an adjunct starter in the manufacture of cheese. Microb. Cell Fact. 10 Suppl 1(Suppl 1): S7.

Mongkolthanaruk, W. 2012. Classification of Bacillus beneficial substances related to plants, humans and animals. J. Microbiol. Biotechnol. 22(12): 1597-1604.

Moorman, G. 2015. Botrytis or Gray Mold. Available at http://extension.psu.edu/pests/ plant-diseases/all-fact-sheets/botrytis-or-gray-mold. Accessed 26 April 2014.

Moyne, A., R. Shelby, T.E. Cleveland, and S. Tuzun. 2001. Bacillomycin D: an iturin with antifungal activity against Aspergillus flavus. J. Appl. Microbiol. 90: 622-629.

Mu, W., S. Yu, L. Zhu, J. Bo, and T. Zhang. 2012. Production of 3-phenyllactic acid and 4-hydroxyphenyllactic acid by Pediococcus acidilactici DSM 20284 fermentation. Eur. Food Res. Technol. 235(3): 581-585.

Neal, J.A., M. Marquez-Gonzalez, E. Cabrera-Diaz, L.M. Lucia, C.A. O’Bryan, P.G. Crandall, S.C. Ricke, and A. Castillo. 2012. Comparison of multiple chemical 
sanitizers for reducing Salmonella and Escherichia coli $\mathrm{O} 157: \mathrm{H} 7$ on spinach (Spinacia oleracea) leaves. Food Res. Int. 45(2): 1123-1128.

Nutrition Physiology Company. 2012. GRAS notification for the use of Lactic Acid Bacteria to control pathogenic bacteria in meat and poultry products. (463). Available at http://www.fda.gov/ucm/groups/fdagov-public/@fdagov-foodsgen/documents/document/ucm349355.pdf. Accessed 14 July 2014.

O’Sullivan, L., R.P. Ross, and C. Hill. 2002. Potential of bacteriocin-producing Lactic Acid Bacteria for improvements in food safety and quality. Biochimie 84: 593-604.

Oerke, E.-C. 2005. Crop losses to pests. J. Agric. Sci. 144: 31-43.

Ölmez, H., and U. Kretzschmar. 2009. Potential alternative disinfection methods for organic fresh-cut industry for minimizing water consumption and environmental impact. LWT - Food Sci. Technol. 42(3): 686-693.

Pakpitcharoen, A., K. Potivejkul, P. Kanjanavas, and S. Areekit. 2008. Biodiversity of thermotolerant Bacillus sp. producing biosurfactants, biocatalysts, and antimicrobial agents. ScienceAsia 34: 424-431.

Parisot, J., S. Carey, E. Breukink, W.C. Chan, A. Narbad, and B. Bonev. 2008. Molecular mechanism of target recognition by subtilin, a Class I lanthionine antibiotic. Antimicrob. Agents Chemother. 52(2): 612-618.

Peraica, M., B. Radic, A. Lucic, and M. Pavlovic. 1999. Toxic effects of mycotoxins in humans. Bull. World Health Organ. 77(9): 754-766.

Płaza, G.A., A. Turek, E. Król, and R. Szczygłowska. 2013. Antifungal and antibacterial properties of surfactin isolated from Bacillus subtilis growing on molasses. African J. Microbiol. Res. 7(25): 3165-3170.

Prabhukarthikeyan, R., D. Saravanakumar, and T. Raguchander. 2014. Combination of endophytic Bacillus and Beauveria for the management of Fusarium wilt and fruit borer in tomato. Pest Manag. Sci. 70(11): 1742-1750.

Predmore, A., and J. Li. 2011. Enhanced removal of a human norovirus surrogate from fresh vegetables and fruits by a combination of surfactants and sanitizers. Appl. Environ. Microbiol. 77(14): 4829-4838.

Prütz, W.A. 1996. Hypochlorous acid interactions with thiols, nucleotides, DNA, and other biological substrates. Arch. Biochem. Biophys. 332(1): 110-120.

Randazzo, C.L., I. Pitino, G.O. Scifò, and C. Caggia. 2009. Biopreservation of minimally processed Iceberg lettuces using a bacteriocin produced by Lactococcus lactis wild strain. Food Control 20(8): 756-763. 
Rice, R.G. 2011. Ozone. Facts sheet for agri-food processors. World Food Sci.Available at http://worldfoodscience.com/cms/index.html@pid=1006025.html. Accessed 14 July 2014.

Rodríguez, E., J. Calzada, J.L. Arqués, J.M. Rodríguez, M. Nuñez, and M. Medina. 2005. Antimicrobial activity of pediocin-producing Lactococcus lactis on Listeria monocytogenes, Staphylococcus aureus and Escherichia coli O157:H7 in cheese. Int. Dairy J. 15(1): 51-57.

Romano, A., D. Vitullo, M. Senatore, G. Lima, and V. Lanzotti. 2013. Antifungal cyclic lipopeptides from Bacillus amyloliquefaciens strain BO5A. J. Nat. Prod. 76: 20192025.

Romero, D., A. De Vicente, R.H. Rakotoaly, S.E. Dufour, J. Veening, E. Arrebola, F.M. Cazorla, O.P. Kuipers, M. Paquot, and A. Pérez-garcía. 2007. The iturin and fengycin families of lipopeptides are key factors in antagonism of Bacillus subtilis toward Podosphaera fusca. Mol. Plant-Microbe Interact. 20(4): 430-440.

Roy, A., D. Mahata, D. Paul, S. Korpole, O.L. Franco, and S.M. Mandal. 2013. Purification, biochemical characterization and self-assembled structure of a fengycin-like antifungal peptide from Bacillus thuringiensis strain SM1. Front. Microbiol. 4: 1-11.

Ryan, L.A.M., E. Zannini, F. Dal Bello, A. Pawlowska, P. Koehler, and E.K. Arendt. 2011. Lactobacillus amylovorus DSM 19280 as a novel food-grade antifungal agent for bakery products. Int. J. Food Microbiol. 146(3): 276-283.

Ryu, E.H., E.J. Yang, E.R. Woo, and H.C. Chang. 2014. Purification and characterization of antifungal compounds from Lactobacillus plantarum HD1 isolated from kimchi. Food Microbiol. 41: 19-26.

Sabaté, D.C., and M.C. Audisio. 2013. Inhibitory activity of surfactin, produced by different Bacillus subtilis subsp. subtilis strains, against Listeria monocytogenes sensitive and bacteriocin-resistant strains. Microbiol. Res. 168(3): 125-129.

Saidi, N., S. Kouki, F.M. Hiri, M.R. Hajlaoui, M. Mahrouk, H. Ou-Zari, N. Jedidi, and A. Hassen. 2009. Characterization and selection of Bacillus sp. strains, effective biocontrol agents against Fusarium oxysporum f. sp. radicis-lycopersici, the causal agent of Fusarium crown and root rot in tomato. Ann. Microbiol. 59(2): 191-198.

Sansinenea, E., and A. Ortiz. 2011. Secondary metabolites of soil Bacillus spp. Biotechnol. Lett. 33(8): 1523-1538.

Sathe, S.J., N.N. Nawani, P.K. Dhakephalkar, and B.P. Kapadnis. 2007. Antifungal lactic acid bacteria with potential to prolong shelf-life of fresh vegetables. J. Appl. Microbiol. 103(6): 2622-2628. 
Savary, S., A. Ficke, J.-N. Aubertot, and C. Hollier. 2012. Crop losses due to diseases and their implications for global food production losses and food security. Food Secur. 4(4): 519-537.

Schneider, K., X.H. Chen, J. Vater, P. Franke, G. Nicholson, R. Borriss, and R.D. Süssmuth. 2007. Macrolactin is the polyketide biosynthesis product of the pks2 cluster of Bacillus amyloliquefaciens FZB42. J. Nat. Prod. 70: 1417-1423.

Schnürer, J., and J. Magnusson. 2005. Antifungal lactic acid bacteria as biopreservatives. Trends Food Sci. Technol. 16(1-3): 70-78.

Shih, I.L., C.Y. Kuo, F.C. Hsieh, S.S. Kao, and C. Hsieh. 2008. Use of surface response methodology to optimize culture condtions for iturin A production by Bacillus subtilis in solid-state fermentation. J. Chinese Inst. Chem. Eng. 39: 635-643.

Silk, B.J., B.E. Mahon, P.M. Griffin, L.H. Gould, R. V. Tauxe, S.M. Crim, K.A. Jackson, and O.L. Henao. 2013. Vital signs: Listeria illness, deaths, and outbreaks--United States, 2009-2011. Atlanta, GA. Available at http://www.ncbi.nlm.nih.gov/pubmed/ 23739336. Accessed 5 June 2014.

Singh, P.K., and D. Vyas. 2009. Biocontrol of plant diseases and sustainable agriculture. Proc. Natl. Acad. Sci. India 79: 110-128.

Smilanick, J., P. Hartsell, D. Henson, D. Fouse, M. Assemi, and C. Harris. 1990. Inhibitory activity of sulfur dioxide on the germination of spores of Botrytis cinerea. Phytopathology 80: 217-220.

Sohn, M.-J., C.-J. Zheng, and W.-G. Kim. 2008. Macrolactin S, a new antibacterial agent with FabG-inhibitory activity from Bacillus sp. AT28. J. Antibiot. (Tokyo). 61(11): 687-691.

Sowndhararajan, K., S. Marimuthu, and S. Manian. 2013. Biocontrol potential of phylloplane bacterium Ochrobactrum anthropi BMO-111 against blister blight disease of tea. J. Appl. Microbiol. 114(1): 209-218.

Stiles, M.E., and W.H. Holzapfel. 1997. Lactic acid bacteria of foods and their current taxonomy. Int. J. Food Microbiol. 36(1): 1-29.

Strom, K., J. Sjogren, A. Broberg, and J. Schnurer. 2002. Lactobacillus plantarum MiLAB 393 produces the antifungal cyclic dipeptides cyclo (L-Phe-L-Pro) and cyclo(L-Phe-trans-4-OH-L-Pro) and 3-phenyllactic acid. Appl. Environ. Microbiol. 68(9): 4322-4327.

Suproniene, S., R. Semaskiene, G. Juodeikiene, A. Mankeviciene, D. Cizeikiene, D. Vidmantiene, L. Basinskiene, and S. Sakalauskas. 2014. Seed treatment with lactic 
acid bacteria against seed-borne pathogens of spring wheat. Biocontrol Sci. Technol. 25(2): 144-154.

Suslow, T. 1997. Postharvest chlorination: basic properties and key points for effective disinfection. Davis, CA. Available at http://anrcatalog.ucdavis.edu/pdf/8003.pdf. Accessed 25 July 2014.

Swartzberg, D., B. Kirshner, D. Rav-David, Y. Elad, and D. Granot. 2007. Botrytis cinerea induces senescence and is inhibited by autoregulated expression of the IPT gene. Eur. J. Plant Pathol. 120(3): 289-297.

Tan, Z., B. Lin, and R. Zhang. 2013. A novel antifungal protein of Bacillus subtilis B25. Springerplus 2: 543.

Tang, Q., X. Bie, Z. Lu, F. Lv, Y. Tao, and X. Qu. 2014. Effects of fengycin from Bacillus subtilis fmbJ on apoptosis and necrosis in Rhizopus stolonifer. J. Microbiol. 52(8): 675-680.

Tao, Y., X. Bie, F. Lv, H. Zhao, and Z. Lu. 2011. Antifungal activity and mechanism of fengycin in the presence and absence of commercial surfactin against Rhizopus stolonifer. J. Microbiol. 49(1): 146-150.

Tendulkar, S.R., Y.K. Saikumari, V. Patel, S. Raghotama, T.K. Munshi, P. Balaram, and B.B. Chattoo. 2007. Isolation, purification and characterization of an antifungal molecule produced by Bacillus licheniformis BC98, and its effect on phytopathogen Magnaporthe grisea. J. Appl. Microbiol. 103(6): 2331-2339.

The Center for Food Security \& Public Health. 2005. Listeriosis. Ames, IA. Available at http://www.cfsph.iastate.edu/Factsheets/pdfs/listeriosis.pdf. Accessed 25 July 2014.

Trias, R., L. Bañeras, E. Badosa, and E. Montesinos. 2008a. Bioprotection of Golden Delicious apples and Iceberg lettuce against foodborne bacterial pathogens by Lactic Acid Bacteria. Int. J. Food Microbiol. 123: 50-60.

Trias, R., L. Bañeras, E. Montesinos, and E. Badosa. 2008b. Lactic acid bacteria from fresh fruit and vegetables as biocontrol agents of phytopathogenic bacteria and fungi. Int. Microbiol. 11(4): 231-236.

Troyano Pueyo, M., C. Bloch, A.M. Carmona-Ribeiro, and P. di Mascio. 2009. Lipopeptides produced by a soil Bacillus megaterium strain. Microb. Ecol. 57(2): 367-378.

Turgrul, T., and E. Cansunar. 2005. Detecting surfactant-producing miccroorganisms by the drop-collapse test. World J. Microbiol. Biotechnol. 21: 851-853. 
U.S. Environmental Protection Agency. 2002. Reregistration Eligibility Decision (RED) Thiabendazole. Regist. Eligibility Decis.: 1-18. Available at http://www.epa.gov/ pesticides/reregistration/REDs/thiabendazole_red.pdf Accessed 20 February 2015.

U.S. Environmental Protection Agency. 2004. Reregistration Eligibility Decision (RED) Captan. Regist. Eligibility Decis.: 1-281. Available at http://www.epa.gov/ pesticides/reregistration/REDs/2325red_imazalil.pdf Accessed 20 February 2015.

U.S. Food and Drug Administration. 2011a. Environmental assessment: factors potentially contributing to the contamination of fresh whole cantaloupe implicated in multi-state outbreak of listeriosis. Available at http://www.fda.gov/Food/ RecallsOutbreaksEmergencies/Outbreaks/ucm276247.htm. Accessed 6 July 2014.

U.S. Food and Drug Administration. 2011b. Fish and Fishery Products Hazards and Controls Guidance. (April). Available at http://www.fda.gov/downloads/food/ guidanceregulation/ucm251970.pdf. Accessed 20 July 2014.

U.S. Food and Drug Administration. 2012. Bad Bug Book: Foodborne Pathogenic Microorganisms and Natural Toxins Handbook. 2nd ed. U.S. Food and Drug Administration, Silver Spring, MD. Available at http://www.fda.gov/downloads/ Food/FoodborneIllnessContaminants/UCM297627.pdf. Accessed 11 June 2014.

U.S. Food and Drug Administration. 2013a. Food Code 2013 Recommendations of the United States Public Health Service Food and Drug Administration. U.S. Department of Commerce, Alexandria, VA. Available at http://www.fda.gov/ downloads/Food/GuidanceRegulation/RetailFoodProtection/FoodCode/UCM374510 .pdf. Accessed 2 August 2014.

U.S. Food and Drug Administration. 2013b. Methods to reduce/eliminate pathogens from produce and fresh-cut produce. Safe Pract. Food Process.: 1-23. Available at http://www.fda.gov/food/foodscienceresearch/safepracticesforfoodprocesses/ucm09 1363.htm. Accessed 6 July 2014.

U.S. Food and Drug Administration. 2014a. 21CFR173.315. CFR--Code Fed. Regul. Title 21Available at http://www.accessdata.fda.gov/scripts/cdrh/cfdocs/cfcfr/ cfrsearch.cfm?fr=173.315. Accessed 3 January 2015.

U.S. Food and Drug Administration. 2014b. Food irradiation: what you need to know. Food Facts (November)Available at http://www.fda.gov/Food/ResourcesForYou/ Consumers/ucm261680.htm. Accessed 10 February 2015.

Ugras, S., K. Sezen, H. Kati, and Z. Demirbag. 2013. Purification and characterization of the bacteriocin Thuricin Bn1 produced by Bacillus thuringiensis subsp. kurstaki Bn1 isolated from a hazelnut pest. J. Microbiol. Biotechnol. 23(2): 167-176. 
Ukuku, D.O. 2006. Effect of sanitizing treatments on removal of bacteria from cantaloupe surface, and re-contamination with Salmonella. Food Microbiol. 23(3): 289-293.

United Fresh Produce Association. 2013. FreshFacts on Retail; Whole and fresh cut produce trends: Q3 2013. Washington, DC. Available at http://www.unitedfresh.org/ assets/UnitedFresh ReportQ32013.pdf. Accessed 25 July 2014.

University of California Integrated Pest Management. 2014a. UC IPM UC Management Guidelines for Fusarium Wilt on Strawberry. Available at http://www.ipm.ucdavis. edu/PMG/r734101411.html. Accessed 27 August 2014.

University of California Integrated Pest Management. 2014b. UC IPM UC Management Guidelines for Gray Mold on Floriculture and Ornamental Nurseries. Available at http://www.ipm.ucdavis.edu/PMG/r280100511.html. Accessed 11 August 2014.

University of California Integrated Pest Management. 2014c. Agricultural Pests. 204(4957). Available at http://www.ipm.ucdavis.edu/PMG/crops-agriculture.html. Acessed 11 August 2014.

University of Georgia. 2011. Peroxyacetic acid as disinfectant. A Systems Approach for Produce Safety. Available at http://www.ugacfs.org/producesafety/Pages/Basics/ Peroxyaceticacid.html. Accessed 23 June 2014.

USDA-National Agricultural Statistics Service. 2014. Crop Values 2013 Summary. Washington, DC. Available at http://usda.mannlib.cornell.edu/usda/nass/ CropValuSu//2010s/2014/CropValuSu-02-14-2014.pdf. Accessed 11 June 2014.

Vanittanakom, N., and W. Leoffler. 1986. Fengycin--a novel antifungal lipopeptide antibiotic produced by Bacillus subtilis F-29-3. J. Antibiot. (Tokyo). 39(7): 888901.

Velraeds, M.M., H.C. Van Der Mei, G. Reid, and H.J. Busscher. 1996. Inhibition of initial adhesion of uropathogenic Enterococcus faecalis by biosurfactants from Lactobacillus isolates. Appl. Environ. Microbiol. 62(6): 1958-1963.

Virto, R., P. Manas, I. Alvarez, S. Condon, and J. Raso. 2005. Membrane damage and microbial inactivation by chlorine in the absence and presence of a chlorinedemanding substrate. Appl. Environ. Microbiol. 71(9): 5022-5028.

Voulgari, K., M. Hatzikamari, A. Delepoglou, P. Georgakopoulos, E. LitopoulouTzanetaki, and N. Tzanetakis. 2010. Antifungal activity of non-starter lactic acid bacteria isolates from dairy products. Food Control 21(2): 136-142. 
Wang, Z., Y. Wang, L. Zheng, X. Yang, H. Liu, and J. Guo. 2014. Isolation and characterization of an antifungal protein from Bacillus licheniformis HS10. Biochem. Biophys. Res. Commun. 454(1): 48-52.

Weissinger, W.R., W. Chantarapanont, and L.R. Beuchat. 2000. Survival and growth of Salmonella Baildon in shredded lettuce and diced tomatoes, and effectiveness of chlorinated water as a sanitizer. Int. J. Food Microbiol. 62: 123-131.

Westers, L., H. Westers, and W.J. Quax. 2004. Bacillus subtilis as cell factory for pharmaceutical proteins: a biotechnological approach to optimize the host organism. Biochim. Biophys. Acta 1694(1-3): 299-310.

Williamson, B., B. Tudzynski, P. Tudzynski, and J.A.L. Van Kan. 2007. Botrytis cinerea: the cause of grey mould disease. Mol. Plant Pathol. 8(5): 561-580.

World Health Organization. 2011. Outbreaks of E. coli O104:H4 infection: update 30. Available at http://www.euro.who.int/en/health-topics/emergencies/internationalhealth-regulations/news/news/2011/07/outbreaks-of-e.-coli-o104h4-infectionupdate-30. Accessed 24 July 2014.

Xiao, D., R. Ye, P.M. Davidson, D.G. Hayes, D.A. Golden, and Q. Zhong. 2011. Sucrose monolaurate improves the efficacy of sodium hypochlorite against Escherichia coli O157:H7 on spinach. Int. J. Food Microbiol. 145(1): 64-68.

Xie, Y., H. An, Y. Hao, Q. Qin, Y. Huang, Y. Luo, and L. Zhang. 2011. Characterization of an anti-Listeria bacteriocin produced by Lactobacillus plantarum LB-B1 isolated from koumiss, a traditionally fermented dairy product from China. Food Control 22(7): 1027-1031.

Yuan, J., B. Li, N. Zhang, R. Waseem, Q. Shen, and Q. Huang. 2012. Production of bacillomycin- and macrolactin-type antibiotics by Bacillus amyloliquefaciens NJN-6 for suppressing soilborne plant pathogens. J. Agric. Food Chem. 60(12): 2976-2981.

Zeng, W., K. Vorst, W. Brown, B.P. Marks, S. Jeong, F. Pérez-Rodríguez, and E.T. Ryser. 2014. Growth of Escherichia coli O157:H7 and Listeria monocytogenes in packaged fresh-cut romaine mix at fluctuating temperatures during commercial transport, retail storage, and display. J. Food Prot. 77(2): 197-206.

Zhang, S., and J.M. Farber. 1996. The effects of various disinfectants against Listeria monocytogenes on fresh-cut vegetables. Food Microbiol. 13: 311-321.

Zhao, P., C. Quan, Y. Wang, J. Wang, and S. Fan. 2014. Bacillus amyloliquefaciens Q426 as a potential biocontrol agent against Fusarium oxysporum f. sp. spinaciae. J. Basic Microbiol. 54(5): 448-456. 
Zimmerman, S.B., C.D. Schwartz, R.L. Monaghan, B.A. Pelak, B. Weissberger, E.C. Gilfillan, S. Mochales, S. Hernandez, S.A. Currie, E. Tejera, and E.O. Stapley. 1987. Difficidin and oxydifficidin: novel broad spectrum antibacterial antibiotics produced by Bacillus subtilis. J. Antibiot. (Tokyo). 40(12): 1677-1681.

Zinedine, A., J.M. Soriano, J.C. Moltó, and J. Mañes. 2007. Review on the toxicity, occurrence, metabolism, detoxification, regulations and intake of zearalenone: an oestrogenic mycotoxin. Food Chem. Toxicol. 45(1): 1-18. 
APPENDICES 


\section{APPENDIX A. ANTIFUNGAL SCREENING TEMPLATE, RAW DATA, AND \\ PICTURES}

A.1 Antifungal Screening Inoculation Template

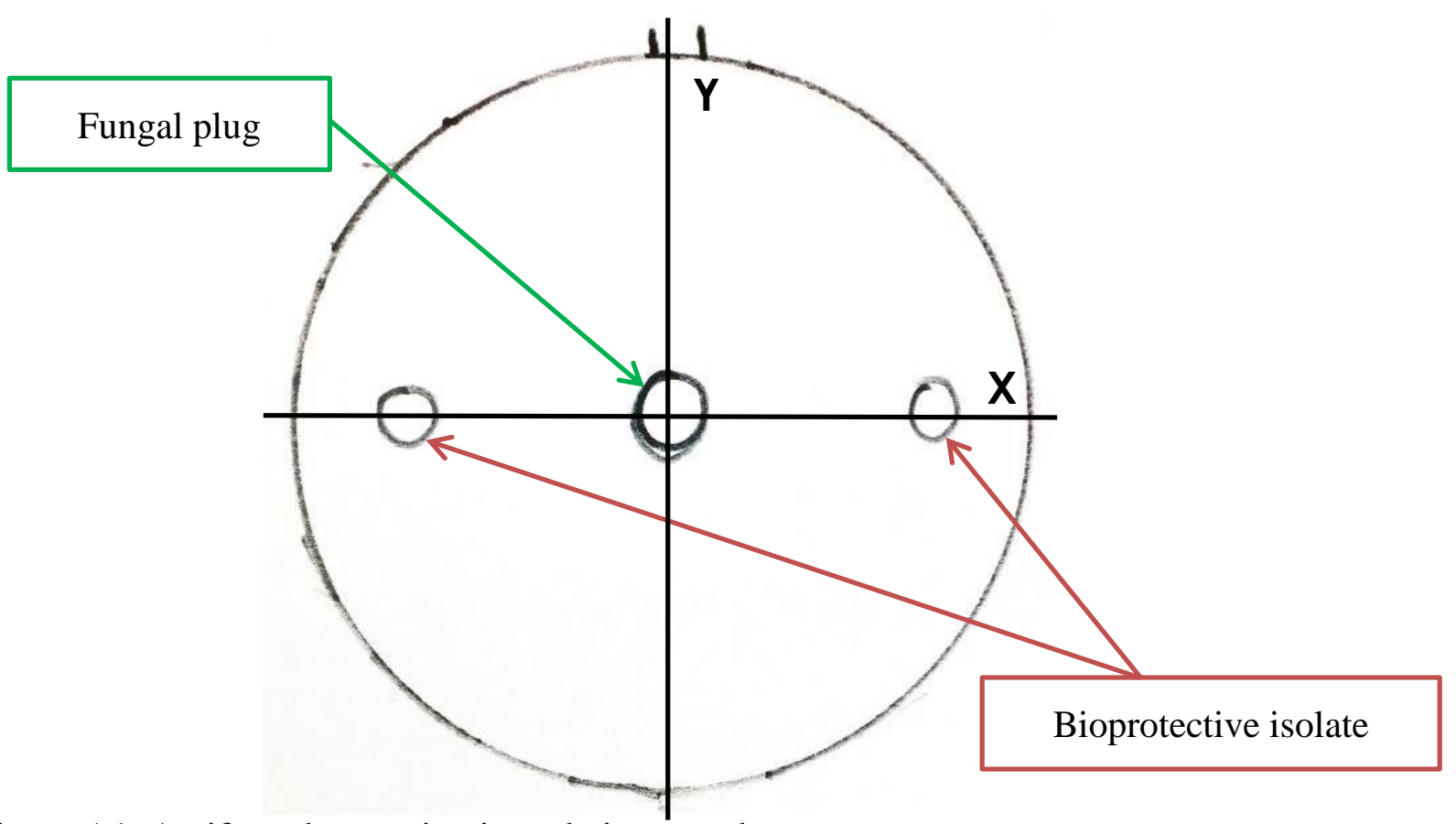

Figure A1. Antifungal screening inoculation template. 
A.2 Average Diameters of Botrytis cinerea, Fusarium pallidoroseum, and Fusarium moniliforme Colonies in the Presence of

Bioprotective Isolates

Table A1. Average diameters (in mm) of Botrytis cinerea, Fusarium pallidoroseum, or Fusarium moniliforme colonies in the presence of bioprotective isolates ( $\mathrm{X}$ axis/Y axis)

\begin{tabular}{|c|c|c|c|c|c|c|c|c|}
\hline \multirow{2}{*}{ Isolate } & \multicolumn{8}{|c|}{ Day } \\
\hline & 3 & 4 & 5 & 6 & 7 & 8 & 9 & 10 \\
\hline \multicolumn{9}{|c|}{ B. amyloliquefaciens BA1 } \\
\hline Bot. cinerea & $40.4 / 68.1$ & $40.4 / 84.3$ & $40.4 / 84.3$ & $40.4 / 84.3$ & $40.4 / 84.3$ & $40.4 / 84.3$ & $40.4 / 84.3$ & $40.4 / 84.3$ \\
\hline F. pallidoroseum & $30.2 / 34.0$ & $31.5 / 42.1$ & $32.2 / 52.7$ & $32.2 / 62.9$ & $32.2 / 72.9$ & $32.2 / 77.5$ & $32.2 / 84.3$ & $32.2 / 84.3$ \\
\hline F. moniliforme & $37.4 / 30.8$ & $39.4 / 41.1$ & $39.4 / 52.5$ & $39.4 / 63.7$ & $39.4 / 75.5$ & $39.4 / 83.0$ & $39.4 / 84.3$ & $39.4 / 84.3$ \\
\hline \multicolumn{9}{|c|}{ B. amyloliquefaciens BA2 } \\
\hline Bot. cinerea & $35.9 / 69.3$ & $35.9 / 84.3$ & $35.9 / 84.3$ & $37.3 / 84.3$ & $37.3 / 84.3$ & $37.3 / 84.3$ & $37.3 / 84.3$ & $37.3 / 84.3$ \\
\hline F. pallidoroseum & $30.4 / 32.4$ & $30.9 / 41.9$ & $31.4 / 52.5$ & $31.4 / 62.0$ & $31.4 / 71.7$ & $31.4 / 78.8$ & $31.4 / 84.3$ & $31.4 / 84.3$ \\
\hline F. moniliforme & $32.0 / 31.7$ & $32.9 / 42.7$ & $32.9 / 50.8$ & $33.9 / 64.3$ & $33.9 / 75.6$ & $33.9 / 84.3$ & $33.9 / 84.3$ & $33.9 / 84.3$ \\
\hline \multicolumn{9}{|c|}{ B. amyloliquefaciens BA3 } \\
\hline Bot. cinerea & $31.1 / 66.8$ & $31.1 / 84.3$ & $31.1 / 84.3$ & $35.8 / 84.3$ & $35.8 / 84.3$ & $35.8 / 84.3$ & $35.8 / 84.3$ & $35.8 / 84.3$ \\
\hline F. pallidoroseum & $26.5 / 35.1$ & $27.6 / 45.8$ & $28.2 / 56.2$ & $28.2 / 67.4$ & $28.2 / 78.8$ & $28.2 / 83.4$ & $28.2 / 83.4$ & $28.2 / 83.4$ \\
\hline F. moniliforme & $29.8 / 30.2$ & 32.041 .9 & $32.0 / 52.5$ & $32.9 / 66.5$ & $32.9 / 74.2$ & $32.9 / 79.5$ & $32.9 / 84.3$ & $32.9 / 84.3$ \\
\hline \multicolumn{9}{|c|}{ B. amyloliquefaciens BA4 } \\
\hline Bot. cinerea & $33.3 / 70.6$ & $33.3 / 84.3$ & $33.3 / 84.3$ & $33.3 / 84.3$ & $33.3 / 84.3$ & $33.3 / 84.3$ & $33.3 / 84.3$ & $33.3 / 84.3$ \\
\hline F. pallidoroseum & $27.6 / 34.5$ & $27.6 / 44.9$ & $27.6 / 56.2$ & $27.6 / 67.9$ & $27.6 / 80.6$ & $27.6 / 84.3$ & $27.6 / 84.3$ & $27.6 / 84.3$ \\
\hline F. moniliforme & $31.4 / 31.1$ & $32.7 / 42.0$ & $32.7 / 50.9$ & $33.4 / 62.6$ & $33.4 / 72.8$ & $33.4 / 83.3$ & $33.4 / 84.3$ & $33.4 / 84.3$ \\
\hline \multicolumn{9}{|c|}{ B. amyloliquefaciens BA5 } \\
\hline Bot. cinerea & $33.2 / 84.3$ & $31.4 / 67.5$ & $31.4 / 84.3$ & $31.4 / 84.3$ & $33.2 / 84.3$ & $33.2 / 84.3$ & $33.2 / 84.3$ & $33.2 / 84.3$ \\
\hline F. pallidoroseum & $24.8 / 32.2$ & $24.8 / 39.3$ & $24.8 / 45.7$ & $26.1 / 55.7$ & $26.1 / 62.6$ & $26.1 / 69.4$ & $26.1 / 74.9$ & $26.1 / 76.8$ \\
\hline F. moniliforme & $30.5 / 33.2$ & $32.6 / 42.6$ & $32.6 / 52.0$ & $32.6 / 65.3$ & $32.6 / 75.6$ & $32.6 / 82.4$ & $32.6 / 84.3$ & $32.6 / 84.3$ \\
\hline
\end{tabular}


Table A1 continued...

\begin{tabular}{|c|c|c|c|c|c|c|c|c|}
\hline \multirow{2}{*}{ Isolate } & \multicolumn{8}{|c|}{ Day } \\
\hline & 3 & 4 & 5 & 6 & 7 & 8 & 9 & 10 \\
\hline \multicolumn{9}{|l|}{ B. clausii } \\
\hline Bot. cinerea & $45.6 / 48.4$ & $50.7 / 60.0$ & $55.2 / 74.1$ & $58.8 / 84.3$ & $58.8 / 84.3$ & $58.8 / 84.3$ & $58.8 / 81.8$ & $58.8 / 76.8$ \\
\hline F. pallidoroseum & $45.8 / 47.7$ & $52.4 / 57.9$ & $69.5 / 72.4$ & $71.6 / 79.9$ & $79.8 / 84.3$ & $84.3 / 84.3$ & $84.3 / 84.3$ & $84.3 / 84.3$ \\
\hline F. moniliforme & $40.2 / 40.0$ & $48.9 / 54.4$ & $48.9 / 76.0$ & $48.9 / 83.5$ & $58.5 / 84.3$ & $65.8 / 84.3$ & $70.9 / 84.3$ & $70.9 / 84.3$ \\
\hline \multicolumn{9}{|l|}{ B. coagulans } \\
\hline Bot. cinerea & $32.4 / 66.0$ & $32.4 / 84.3$ & $32.4 / 84.3$ & $32.4 / 84.3$ & $32.4 / 84.3$ & $32.4 / 84.3$ & $32.4 / 84.3$ & $32.4 / 84.3$ \\
\hline F. pallidoroseum & $25.7 / 31.5$ & $27.3 / 36.0$ & $27.3 / 39.1$ & $27.3 / 45.1$ & $28.5 / 51.5$ & $28.5 / 58.4$ & $28.5 / 64.3$ & $28.5 / 67.8$ \\
\hline F. moniliforme & $31.0 / 33.9$ & $32.3 / 43.7$ & $32.3 / 52.7$ & $32.3 / 67.0$ & $32.3 / 75.7$ & $32.3 / 84.3$ & $33.3 / 84.3$ & $34.6 / 84.3$ \\
\hline \multicolumn{9}{|l|}{ B. firmus } \\
\hline Bot. cinerea & $39.9 / 50.2$ & $42.8 / 61.6$ & $42.8 / 79.2$ & $42.8 / 84.3$ & $42.8 / 84.3$ & $42.8 / 84.3$ & $42.8 / 82.9$ & $42.8 / 81.9$ \\
\hline F. pallidoroseum & $47.5 / 51.6$ & $52.3 / 59.6$ & $57.8 / 72.2$ & $62.0 / 80.6$ & $65.0 / 80.6$ & $65.0 / 80.6$ & $65.0 / 80.6$ & $65.0 / 80.6$ \\
\hline F. moniliforme & $43.8 / 45.3$ & $46.8 / 55.4$ & $46.8 / 68.3$ & $46.8 / 78.1$ & $51.8 / 81.5$ & $51.8 / 84.3$ & $51.8 / 84.3$ & $51.8 / 84.3$ \\
\hline \multicolumn{9}{|l|}{ B. licheniformis } \\
\hline Bot. cinerea & $65.8 / 64.3$ & $74.8 / 81.8$ & $84.3 / 84.3$ & $84.3 / 84.3$ & $84.3 / 84.3$ & $84.3 / 84.3$ & $84.3 / 84.3$ & $84.3 / 84.3$ \\
\hline F. pallidoroseum & $33.5 / 33.0$ & $45.6 / 43.8$ & $51.9 / 55.8$ & $54.7 / 65.9$ & $58.7 / 81.3$ & $70.4 / 84.3$ & $78.8 / 84.3$ & $80.1 / 84.3$ \\
\hline F. moniliforme & $29.3 / 37.9$ & $38.9 / 47.8$ & $48.4 / 57.0$ & $54.5 / 64.4$ & $58.7 / 72.0$ & $64.4 / 79.9$ & $68.3 / 84.3$ & $70.4 / 84.3$ \\
\hline \multicolumn{9}{|l|}{ B. megaterium } \\
\hline Bot. cinerea & $32.1 / 66.8$ & $32.1 / 84.3$ & $32.1 / 84.3$ & $32.1 / 84.3$ & $32.1 / 84.3$ & $32.1 / 84.3$ & $32.1 / 84.3$ & $32.1 / 84.3$ \\
\hline F. pallidoroseum & $26.5 / 34.2$ & $27.1 / 43.3$ & $27.1 / 52.7$ & $27.1 / 63.8$ & $27.1 / 74.2$ & $27.1 / 83.2$ & $27.1 / 84.3$ & $27.1 / 84.3$ \\
\hline F. moniliforme & $30.0 / 30.6$ & $31.6 / 40.7$ & $31.6 / 50.5$ & $32.5 / 62.3$ & $32.5 / 74.1$ & $32.5 / 84.3$ & $32.5 / 84.3$ & $32.5 / 84.3$ \\
\hline \multicolumn{9}{|l|}{ B. pumilus } \\
\hline Bot. cinerea & $58.1 / 63.1$ & $70.8 / 77.8$ & $79.5 / 84.3$ & $84.3 / 84.3$ & $84.3 / 84.3$ & $84.3 / 84.3$ & $84.3 / 84.3$ & $84.3 / 84.3$ \\
\hline F. pallidoroseum & $33.0 / 32.5$ & $44.0 / 42.8$ & $51.7 / 51.2$ & $56.4 / 62.6$ & $63.3 / 71.2$ & $81.8 / 84.3$ & $83.5 / 84.3$ & $84.3 / 84.3$ \\
\hline F. moniliforme & $32.3 / 29.0$ & $41.7 / 38.8$ & $50.7 / 51.6$ & $54.4 / 63.8$ & $69.7 / 74.0$ & $83.2 / 81.2$ & $84.3 / 84.3$ & $84.3 / 84.3$ \\
\hline \multicolumn{9}{|l|}{ B. sphaericus } \\
\hline Bot. cinerea & $60.2 / 62.1$ & $84.3 / 84.3$ & $84.3 / 84.3$ & $84.3 / 84.3$ & $84.3 / 84.3$ & $84.3 / 84.3$ & $84.3 / 84.3$ & $84.3 / 84.3$ \\
\hline F. pallidoroseum & $28.7 / 27.6$ & $40.2 / 40.7$ & $52.6 / 53.8$ & $61.8 / 59.4$ & $75.6 / 66.8$ & $84.3 / 79.9$ & $84.3 / 84.3$ & $84.3 / 84.3$ \\
\hline F. moniliforme & $27.6 / 28.7$ & $40.7 / 40.2$ & $53.8 / 52.6$ & $59.4 / 61.8$ & $66.8 / 75.6$ & $79.9 / 84.3$ & $84.3 / 84.3$ & $84.3 / 84.3$ \\
\hline
\end{tabular}


Table A1 continued...

\begin{tabular}{|c|c|c|c|c|c|c|c|c|}
\hline \multirow{2}{*}{ Isolate } & \multicolumn{8}{|c|}{ Day } \\
\hline & 3 & 4 & 5 & 6 & 7 & 8 & 9 & 10 \\
\hline \multicolumn{9}{|l|}{ B. thiaminolyticus } \\
\hline Bot. cinerea & $34.1 / 37.7$ & $39.0 / 51.1$ & $41.8 / 69.6$ & $42.5 / 78.3$ & $42.5 / 78.3$ & $42.5 / 78.3$ & $42.5 / 76.9$ & $42.5 / 74.3$ \\
\hline F. pallidoroseum & $40.7 / 40.1$ & $51.8 / 58.1$ & $57.6 / 73.9$ & $59.5 / 80.9$ & $59.5 / 84.3$ & $68.3 / 84.3$ & $72.4 / 84.3$ & $72.4 / 84.3$ \\
\hline F. moniliforme & $38.8 / 40.3$ & $47.8 / 55.6$ & $52.7 / 76.4$ & $54.7 / 83.7$ & $65.6 / 84.3$ & $73.7 / 84.3$ & $84.3 / 84.3$ & $84.3 / 84.3$ \\
\hline \multicolumn{9}{|l|}{ B. thuringiensis $\mathrm{BT} 1$} \\
\hline Bot. cinerea & 65.9/67.4 & $79.2 / 81.9$ & $84.3 / 84.3$ & $84.3 / 84.3$ & $84.3 / 84.3$ & $84.3 / 84.3$ & $84.3 / 84.3$ & $84.3 / 84.3$ \\
\hline F. pallidoroseum & $32.7 / 33.6$ & $43.0 / 43.1$ & $49.7 / 54.3$ & $59.1 / 66.0$ & $68.4 / 76.8$ & $79.4 / 84.3$ & $81.0 / 84.3$ & $84.3 / 84.3$ \\
\hline F. moniliforme & $32.5 / 31.5$ & $42.0 / 41.7$ & $51.5 / 51.1$ & $61.6 / 61.7$ & $70.5 / 70.1$ & $78.1 / 79.3$ & $84.3 / 84.1$ & $84.3 / 84.3$ \\
\hline \multicolumn{9}{|l|}{ B. thuringiensis BT2 } \\
\hline Bot. cinerea & $31.1 / 61.5$ & $32.2 / 84.3$ & $32.2 / 84.3$ & $37.0 / 84.3$ & $37.0 / 84.3$ & $37.0 / 84.3$ & $37.0 / 84.3$ & $37.0 / 84.3$ \\
\hline F. pallidoroseum & $26.8 / 32.8$ & $27.2 / 43.1$ & $27.2 / 53.2$ & $27.2 / 65.5$ & $27.2 / 75.6$ & $27.2 / 84.3$ & $27.2 / 84.3$ & $27.2 / 84.3$ \\
\hline F. moniliforme & $32.9 / 30.8$ & $34.3 / 40.6$ & $35.3 / 50.0$ & $35.3 / 59.8$ & $35.3 / 70.1$ & $35.3 / 78.4$ & $35.3 / 84.3$ & $35.3 / 84.3$ \\
\hline \multicolumn{9}{|l|}{ Lb. amylovorus } \\
\hline Bot. cinerea & $36.1 / 39.5$ & $45.8 / 50.7$ & $49.4 / 58.9$ & $52.9 / 84.3$ & $52.9 / 84.3$ & $52.9 / 84.3$ & $50.8 / 84.3$ & $49.4 / 70.1$ \\
\hline F. pallidoroseum & $36.3 / 35.8$ & $48.1 / 49.3$ & $56.2 / 58.7$ & $63.0 / 70.5$ & $71.5 / 79.7$ & 79.7/84.1 & $84.3 / 84.3$ & $84.3 / 84.3$ \\
\hline F. moniliforme & $32.0 / 32.5$ & $42.3 / 43.3$ & $51.6 / 53.9$ & $59.7 / 65.9$ & $66.5 / 77.7$ & $73.0 / 84.3$ & $77.4 / 84.3$ & $80.1 / 84.3$ \\
\hline \multicolumn{9}{|l|}{ Lb. plantarum } \\
\hline Bot. cinerea & $30.2 / 36.0$ & $36.1 / 48.5$ & $39.1 / 59.5$ & $53.7 / 84.3$ & $50.0 / 84.3$ & $48.0 / 84.3$ & $45.3 / 83.6$ & $42.5 / 69.6$ \\
\hline F. pallidoroseum & $31.6 / 31.8$ & $40.6 / 44.4$ & $48.1 / 53.2$ & $54.5 / 60.5$ & $58.7 / 73.5$ & $69.0 / 80.9$ & $75.5 / 84.3$ & $79.6 / 84.3$ \\
\hline F. moniliforme & $27.7 / 31.6$ & $32.5 / 41.0$ & $36.8 / 49.3$ & $44.0 / 60.7$ & $48.6 / 68.7$ & $61.5 / 80.4$ & $68.9 / 84.3$ & $73.7 / 84.3$ \\
\hline \multicolumn{9}{|l|}{ O. sojae } \\
\hline Bot. cinerea & $43.3 / 43.1$ & $51.5 / 50.5$ & $52.2 / 60.2$ & $84.3 / 84.3$ & $84.3 / 84.3$ & $82.3 / 83.8$ & $77.4 / 77.4$ & $63.5 / 67.2$ \\
\hline F. pallidoroseum & $45.4 / 46.3$ & $50.5 / 61.3$ & $62.6 / 78.1$ & $65.2 / 83.1$ & $70.1 / 84.2$ & $73.0 / 84.3$ & $73.0 / 84.3$ & $73.0 / 84.3$ \\
\hline F. moniliforme & $41.1 / 40.6$ & $52.7 / 55.0$ & $65.3 / 75.0$ & $67.0 / 82.1$ & $84.3 / 84.3$ & $84.3 / 84.3$ & $84.3 / 84.3$ & $84.3 / 84.3$ \\
\hline \multicolumn{9}{|l|}{ O. anthropi } \\
\hline Bot. cinerea & $56.4 / 68.2$ & $72.1 / 84.3$ & $79.9 / 84.3$ & $84.3 / 84.3$ & $84.3 / 84.3$ & $84.3 / 84.3$ & $84.3 / 84.3$ & $84.3 / 84.3$ \\
\hline F. pallidoroseum & $32.3 / 36.0$ & $43.3 / 45.7$ & $49.8 / 54.7$ & $49.8 / 62.3$ & $49.8 / 73.4$ & $49.8 / 77.5$ & $56.4 / 80.1$ & $56.4 / 80.1$ \\
\hline F. moniliforme & $31.5 / 40.6$ & $42.0 / 55.0$ & $48.0 / 75.0$ & $62.2 / 82.1$ & $76.3 / 84.3$ & $82.1 / 84.3$ & $84.3 / 84.3$ & $84.3 / 84.3$ \\
\hline
\end{tabular}


Table A1 continued...

\begin{tabular}{|c|c|c|c|c|c|c|c|c|}
\hline \multirow{2}{*}{ Isolate } & \multicolumn{8}{|c|}{ Day } \\
\hline & 3 & 4 & 5 & 6 & 7 & 8 & 9 & 10 \\
\hline \multicolumn{9}{|l|}{ P. acidilactici } \\
\hline Bot. cinerea & $25.4 / 26.5$ & $29.8 / 37.4$ & $31.6 / 47.3$ & $37.3 / 84.3$ & $37.3 / 79.7$ & $35.7 / 72.3$ & $34.5 / 62.2$ & $34.1 / 56.2$ \\
\hline F. pallidoroseum & $31.6 / 32.8$ & $40.9 / 43.4$ & $49.6 / 52.6$ & $60.7 / 63.8$ & $67.4 / 66.9$ & $73.7 / 74.5$ & $80.4 / 79.1$ & $83.1 / 83.4$ \\
\hline F. moniliforme & $32.3 / 33.4$ & $40.2 / 44.6$ & $47.5 / 56.2$ & $56.4 / 69.5$ & $62.0 / 80.1$ & $72.1 / 84.3$ & $78.6 / 84.3$ & $83.9 / 84.3$ \\
\hline \multicolumn{9}{|l|}{ P. pentosaceus } \\
\hline Bot. cinerea & $27.2 / 30.9$ & $30.5 / 43.1$ & $33.5 / 48.3$ & $45.6 / 84.3$ & $44.1 / 79.3$ & $41.4 / 75.7$ & $38.0 / 66.9$ & $37.0 / 58.7$ \\
\hline F. pallidoroseum & $29.8 / 32.2$ & $35.5 / 39.2$ & $39.4 / 45.2$ & $45.5 / 52.1$ & $48.6 / 55.6$ & $49.5 / 55.6$ & $49.5 / 55.6$ & $49.5 / 55.6$ \\
\hline F. moniliforme & $30.7 / 34.7$ & $37.5 / 48.0$ & $45.5 / 59.2$ & $54.9 / 72.1$ & $65.4 / 82.2$ & $73.6 / 84.3$ & $79.2 / 84.3$ & $84.3 / 84.3$ \\
\hline \multicolumn{9}{|l|}{ S. plymuthica } \\
\hline Bot. cinerea & $40.5 / 56.4$ & $41.1 / 79.9$ & $41.1 / 84.3$ & $41.1 / 84.3$ & $41.1 / 84.3$ & $41.1 / 84.3$ & $41.1 / 84.3$ & $41.1 / 84.3$ \\
\hline F. pallidoroseum & $20.8 / 21.7$ & $30.5 / 32.8$ & $33.1 / 44.4$ & $34.0 / 53.9$ & $34.0 / 66.3$ & $34.0 / 76.2$ & $34.0 / 84.3$ & $34.0 / 84.3$ \\
\hline F. moniliforme & $31.5 / 29.4$ & $39.3 / 40.8$ & $44.7 / 55.2$ & $49.9 / 67.4$ & $50.5 / 79.2$ & $50.5 / 84.3$ & $50.5 / 84.3$ & $50.5 / 84.3$ \\
\hline \multicolumn{9}{|l|}{ PDA } \\
\hline Bot. cinerea & $59.4 / 61.2$ & 75.9/77.7 & $84.3 / 83.7$ & $84.3 / 84.3$ & $84.3 / 84.3$ & $84.3 / 84.3$ & $84.3 / 84.3$ & $84.3 / 84.3$ \\
\hline F. pallidoroseum & $24.0 / 24.3$ & $34.5 / 34.9$ & $45.4 / 46.5$ & $55.6 / 55.4$ & $69.5 / 68.7$ & 79.0/77.6 & $84.3 / 84.3$ & $84.3 / 84.3$ \\
\hline F. moniliforme & $31.7 / 30.4$ & $41.8 / 42.2$ & $54.3 / 54.8$ & $65.1 / 66.0$ & $84.3 / 78.0$ & $84.3 / 84.3$ & $84.3 / 84.3$ & $84.3 / 84.3$ \\
\hline \multicolumn{9}{|l|}{ TSA } \\
\hline Bot. cinerea & $40.5 / 40.3$ & $60.2 / 61.5$ & $80.7 / 80.2$ & $84.3 / 84.3$ & $84.3 / 84.3$ & $84.3 / 84.3$ & $84.3 / 84.3$ & $84.3 / 84.3$ \\
\hline F. pallidoroseum & $47.1 / 45.7$ & $62.6 / 59.8$ & $77.3 / 75.3$ & $82.2 / 79.7$ & $84.3 / 82.1$ & $84.3 / 82.1$ & $84.3 / 82.1$ & $84.3 / 82.1$ \\
\hline F. moniliforme & $42.5 / 42.9$ & $55.1 / 56.7$ & $73.5 / 74.0$ & $83.4 / 82.3$ & $84.3 / 84.3$ & $84.3 / 84.3$ & $84.3 / 84.3$ & $84.3 / 84.3$ \\
\hline \multicolumn{9}{|l|}{ MRS } \\
\hline Bot. cinerea & $37.0 / 36.1$ & $54.6 / 54.1$ & $62.5 / 62.1$ & $74.7 / 84.3$ & $81.5 / 84.3$ & $84.3 / 84.3$ & $84.3 / 84.3$ & $84.3 / 84.3$ \\
\hline F. pallidoroseum & $25.4 / 27.3$ & $34.2 / 36.4$ & $40.2 / 42.5$ & $45.3 / 47.1$ & $49.5 / 52.2$ & $57.2 / 58.6$ & $67.9 / 67.9$ & $77.8 / 78.6$ \\
\hline F. moniliforme & $25.4 / 27.3$ & $34.2 / 36.4$ & $40.2 / 42.5$ & $45.3 / 47.1$ & $49.5 / 52.2$ & $57.2 / 58.6$ & $67.9 / 67.9$ & $77.8 / 78.6$ \\
\hline
\end{tabular}




\section{APPENDIX B. PICTURES OF THE ANTIFUNGAL SCREENING OF BIOPROTECTIVE ISOLATES AGAINST BOTRYTIS CINEREA, FUSARIUM PALLIDOROSEUM, AND FUSARIUM MONILIFORME}

This appendix contains the pictures from the antifungal screening of the bioprotective isolates against Botrytis cinerea, Fusarium pallidoroseum, and Fusarium moniliforme. Pictures were taken of control plates and the plates of those isolates that demonstrated fungal inhibition only; pictures were not taken of bioprotective isolate plates that showed no inhibition. Each isolate was screened twice in duplicate; the pictures included in this appendix most clearly illustrate the results of the screenings.

The rings drawn on the plates indicate the boarder of the fungal colony and the number corresponds with the numbers of days the plate had been incubated when the ring was drawn. On some plates, Day 2 is marked, but all measurements began on Day 3.

The vertical and horizontal lines drawn on some of the plates represent the $\mathrm{X}$ and $\mathrm{Y}$ axes on which measurements were taken (see Figure 1A for antifungal screening inoculation template). Some plates do not have the $\mathrm{X}$ and $\mathrm{Y}$ axes because the picture was taken before they were drawn. 


\section{B.1 Control Plates}

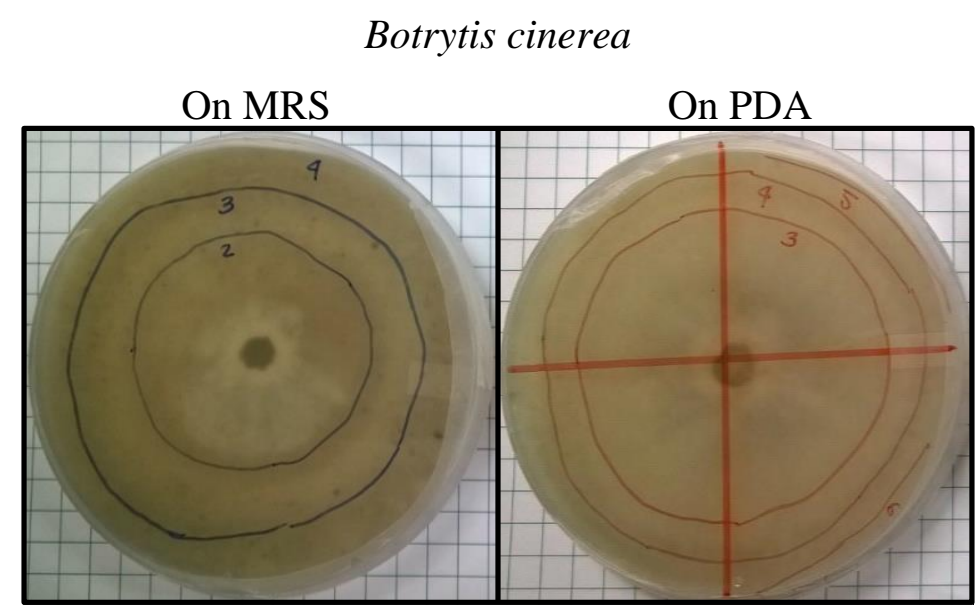

Fusarium pallidoroseum

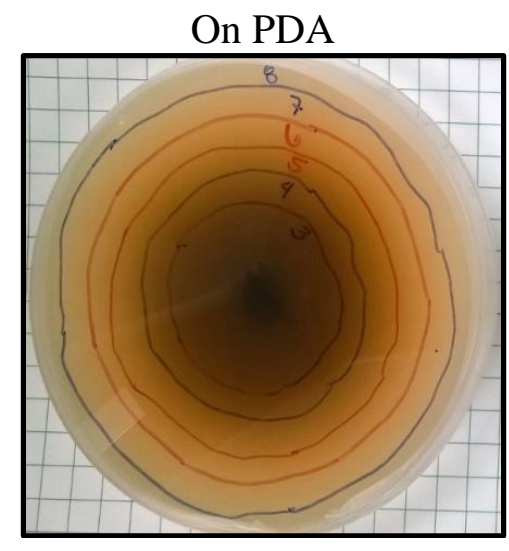

Fusarium moniliforme

On PDA

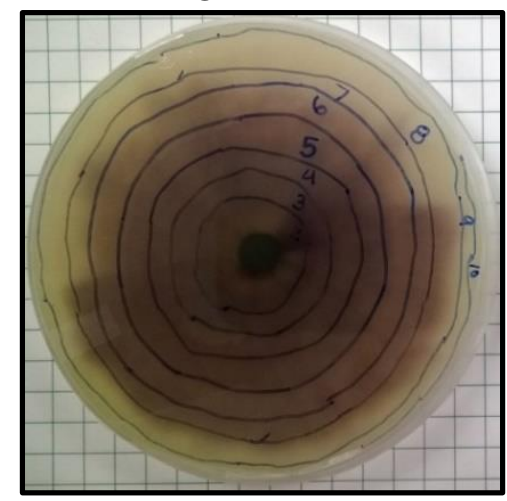


B.2 Botrytis cinerea, Fusarium pallidoroseum, or Fusarium moniliforme Grown in the

Presence of Bioprotective Isolates

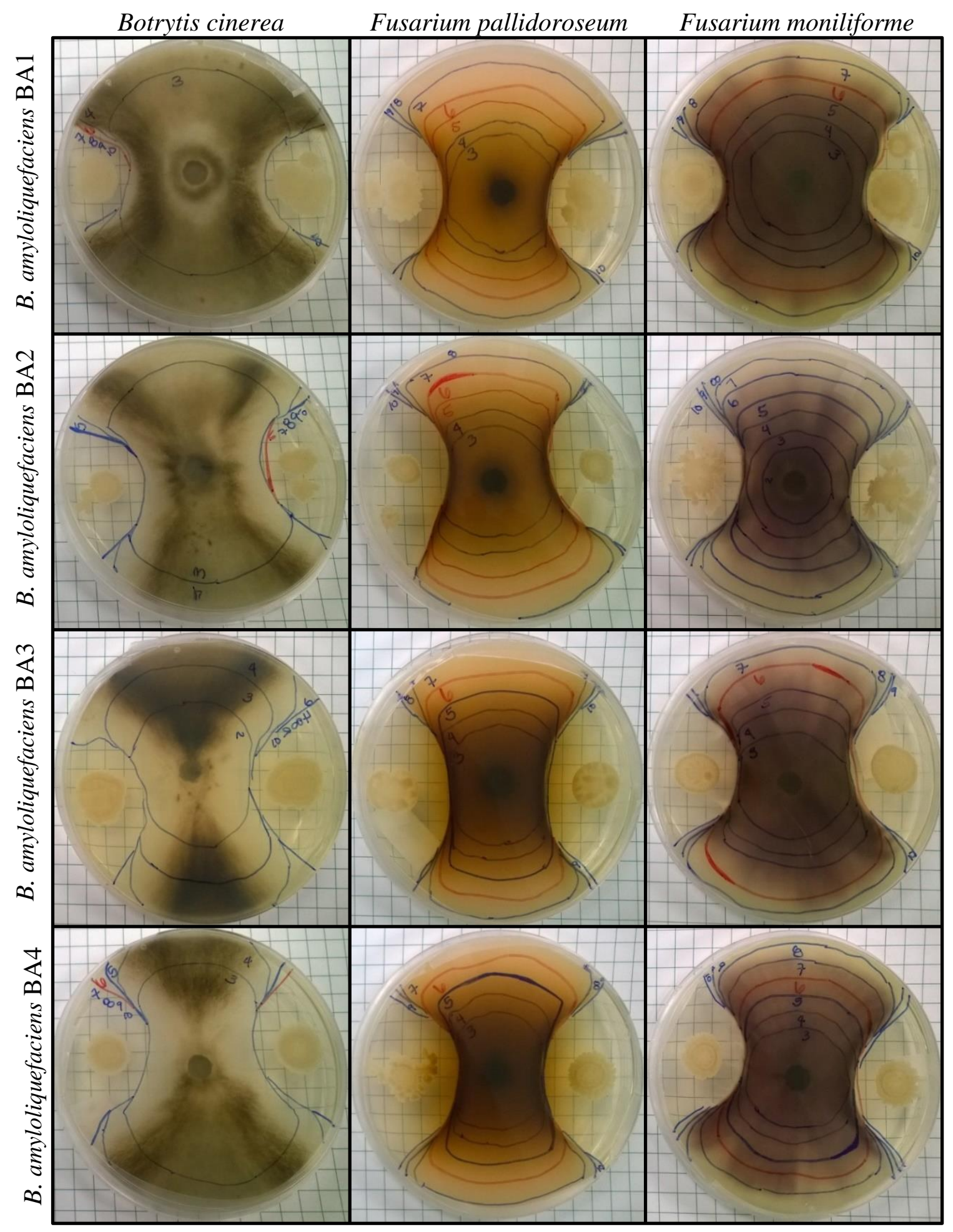




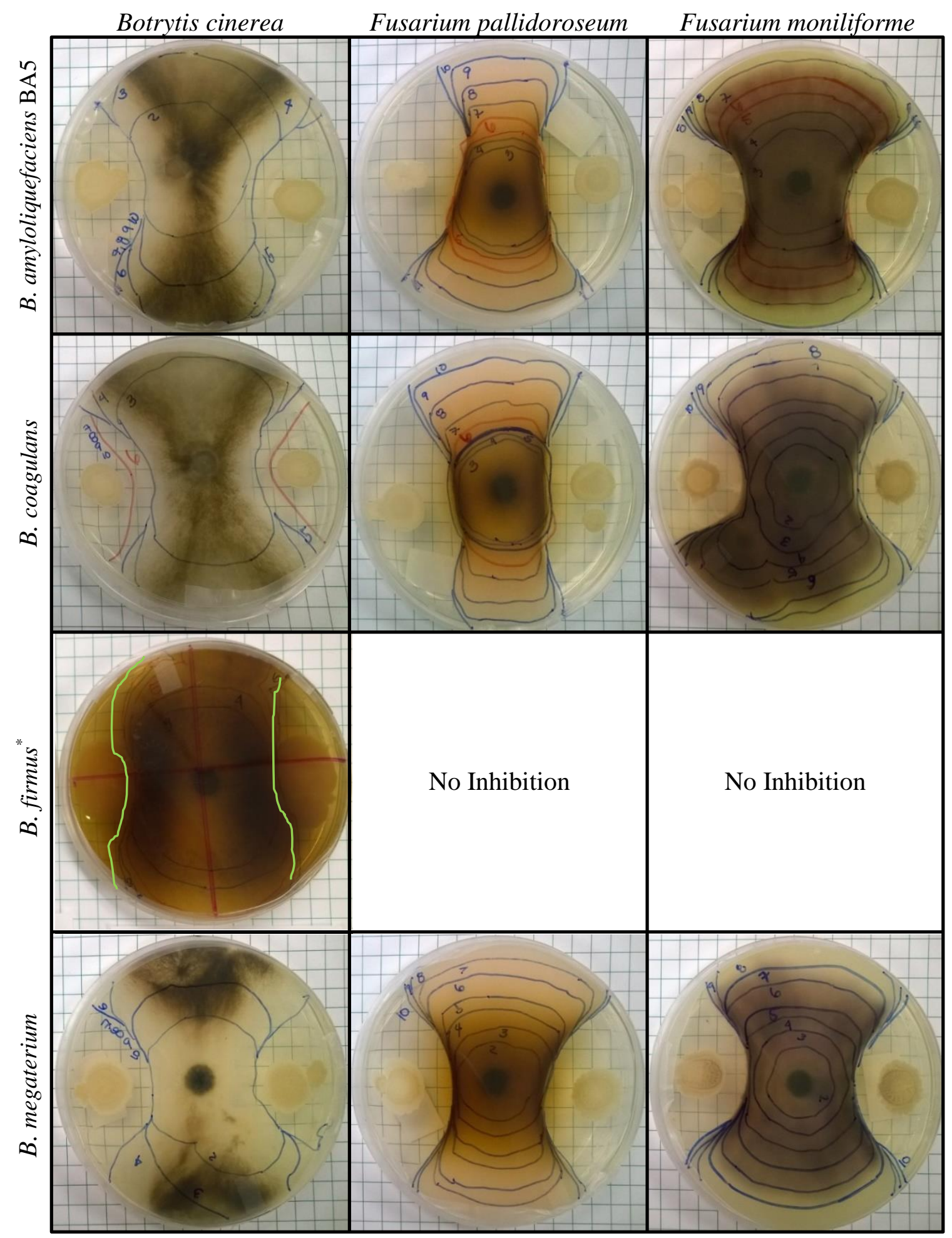

*Fungal colony border after $10 \mathrm{~d}$ incubation was added to the picture because the marks on the petri dish were difficult to see 


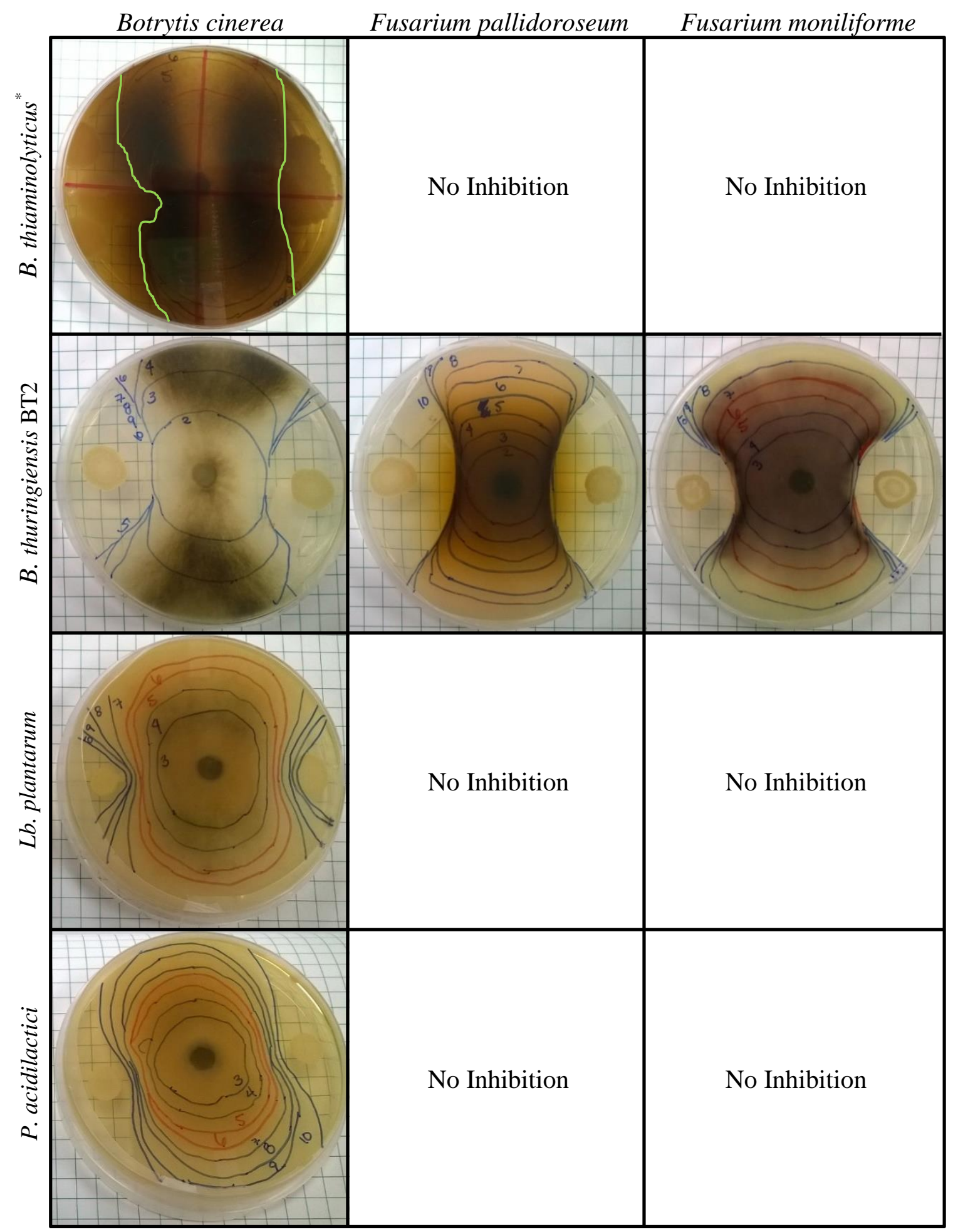

*Fungal colony border after $10 \mathrm{~d}$ incubation was added to the picture because the marks on the petri dish were difficult to see 


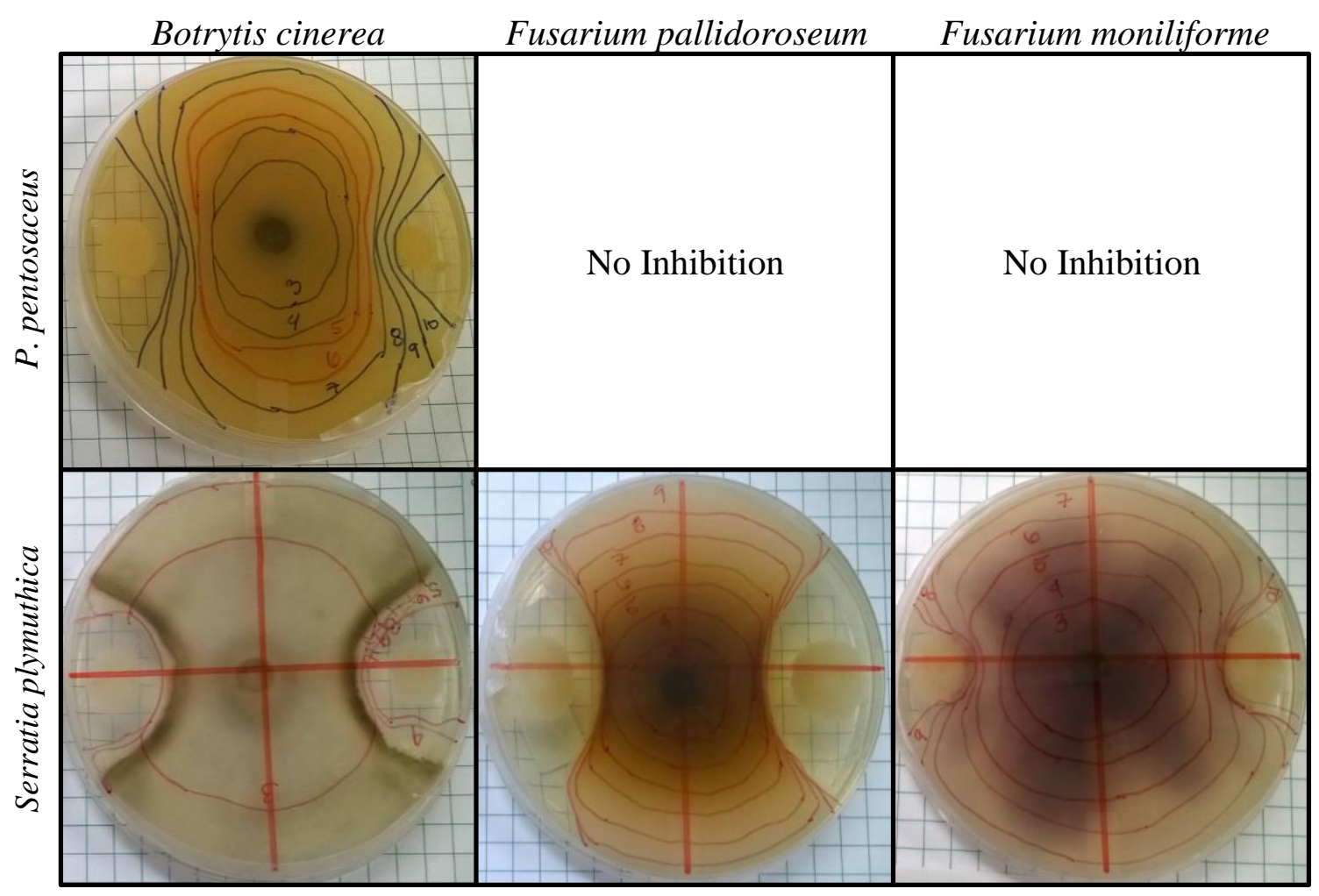




\section{APPENDIX C. ANTIMICROBIAL SCREENING PICTURES}

This appendix contains the pictures from the antimicrobial screening of the bioprotective isolates, Lactic Acid Bacteria cocktails, and B. subtilis fermentate against $L$. monocytogenes, Salmonella, and E. coli O157:H7. Pictures were taken those isolates that demonstrated bacterial inhibition only; pictures were not taken of bioprotective isolate plates that showed no inhibition. Each isolate was screened twice in triplicate; the pictures included in this appendix most clearly illustrate the results of the screenings. The handwritten numbers in the pictures indicate the size of the zone of inhibition in $\mathrm{mm}$. 
C.1 Screening of Lactic Acid Bacteria Isolates and Cocktails Against Listeria monocytogenes, Salmonella, and Escherichia coli O157:H7

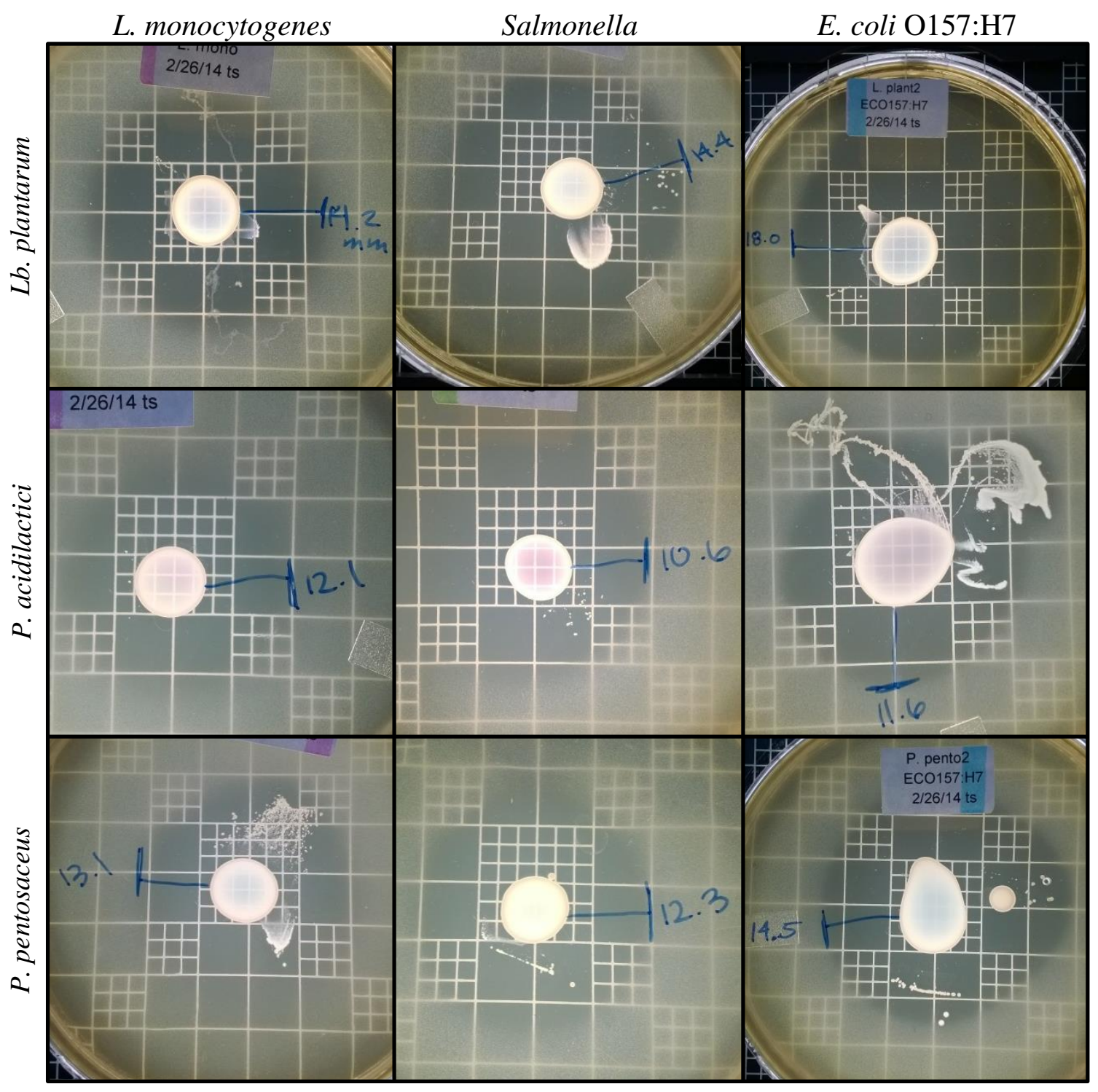




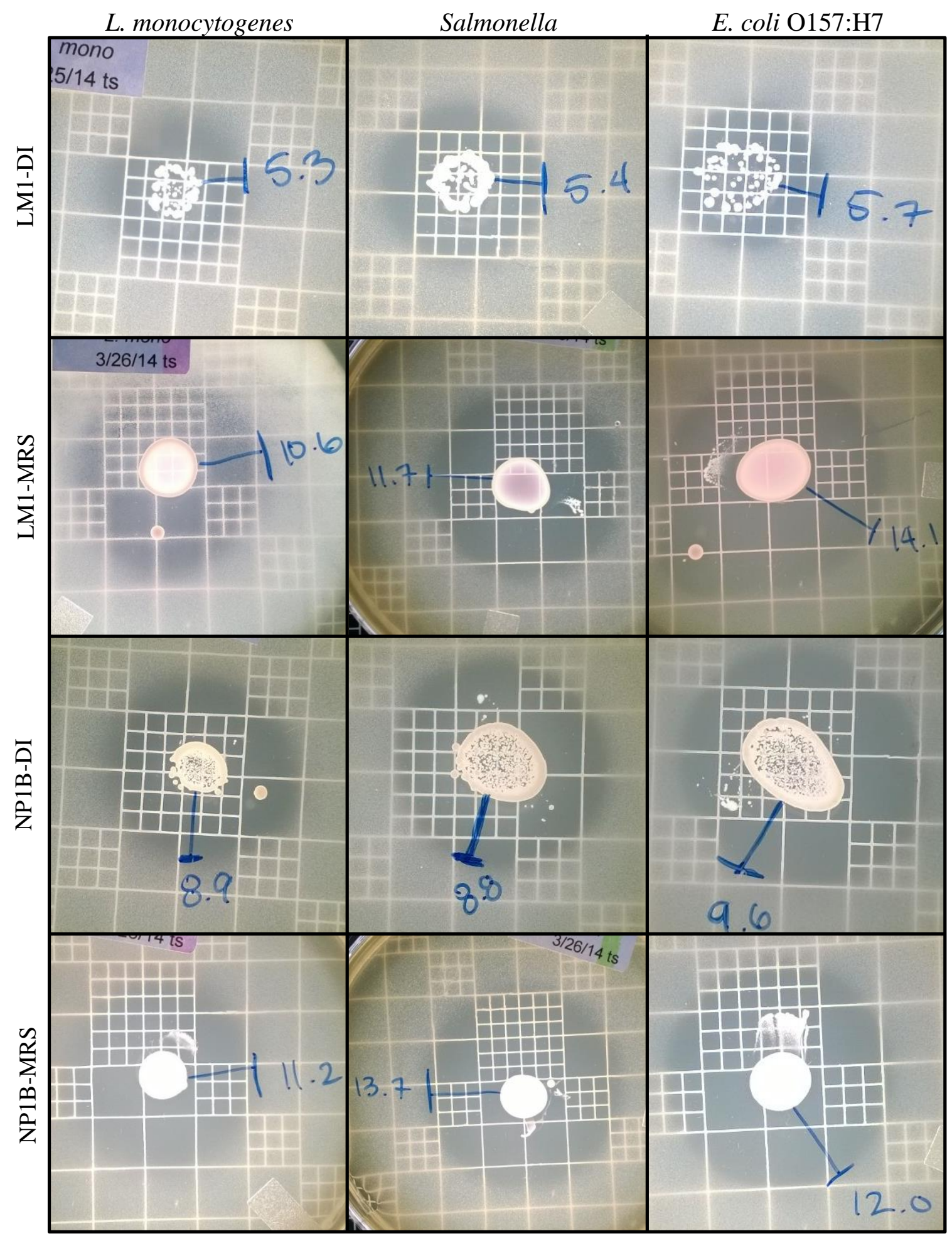




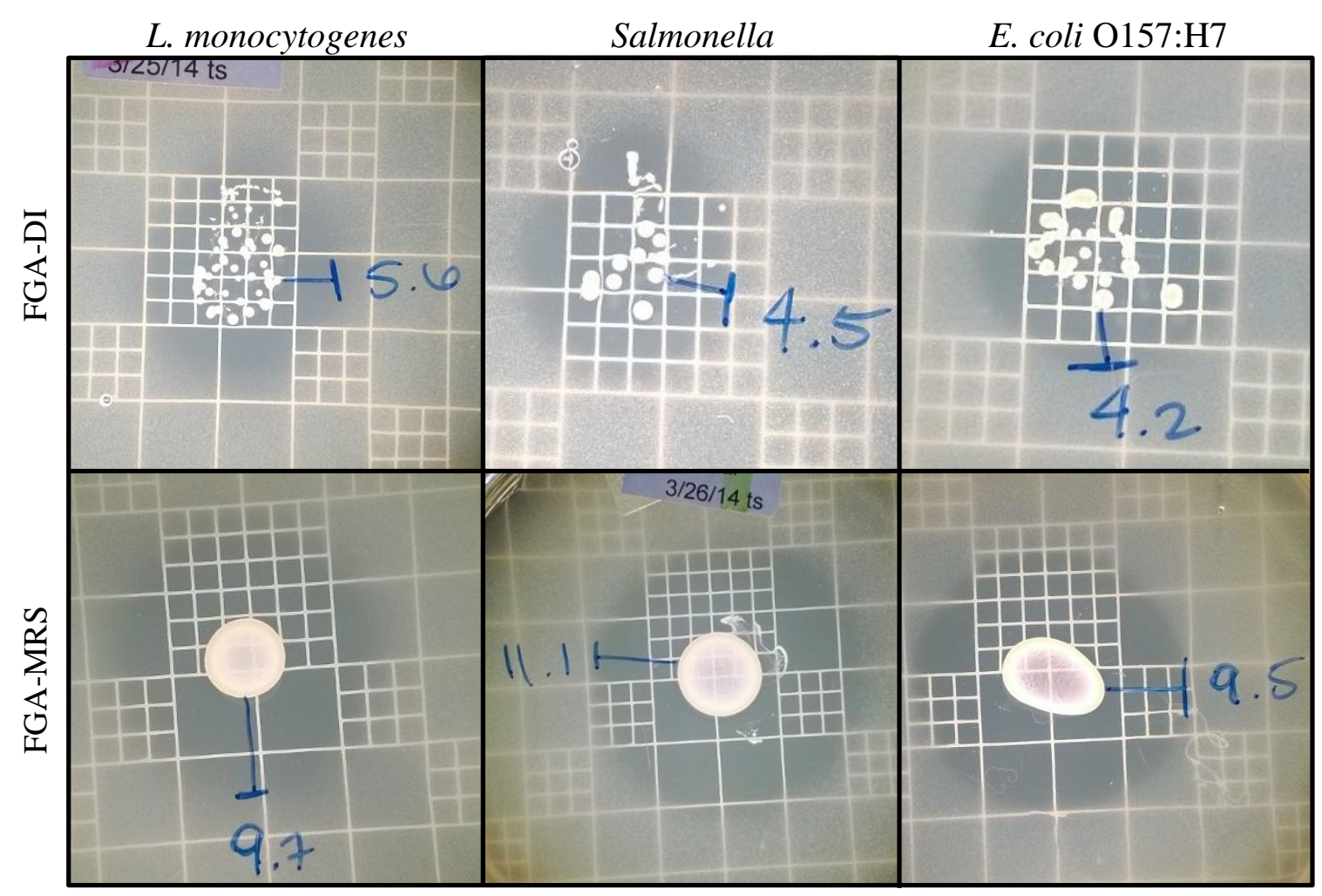


C.2 Screening of Non-Lactic Acid Bacteria Isolates and Bacillus subtilis Fermentate Against Listeria monocytogenes, Salmonella, and Escherichia coli O157:H7

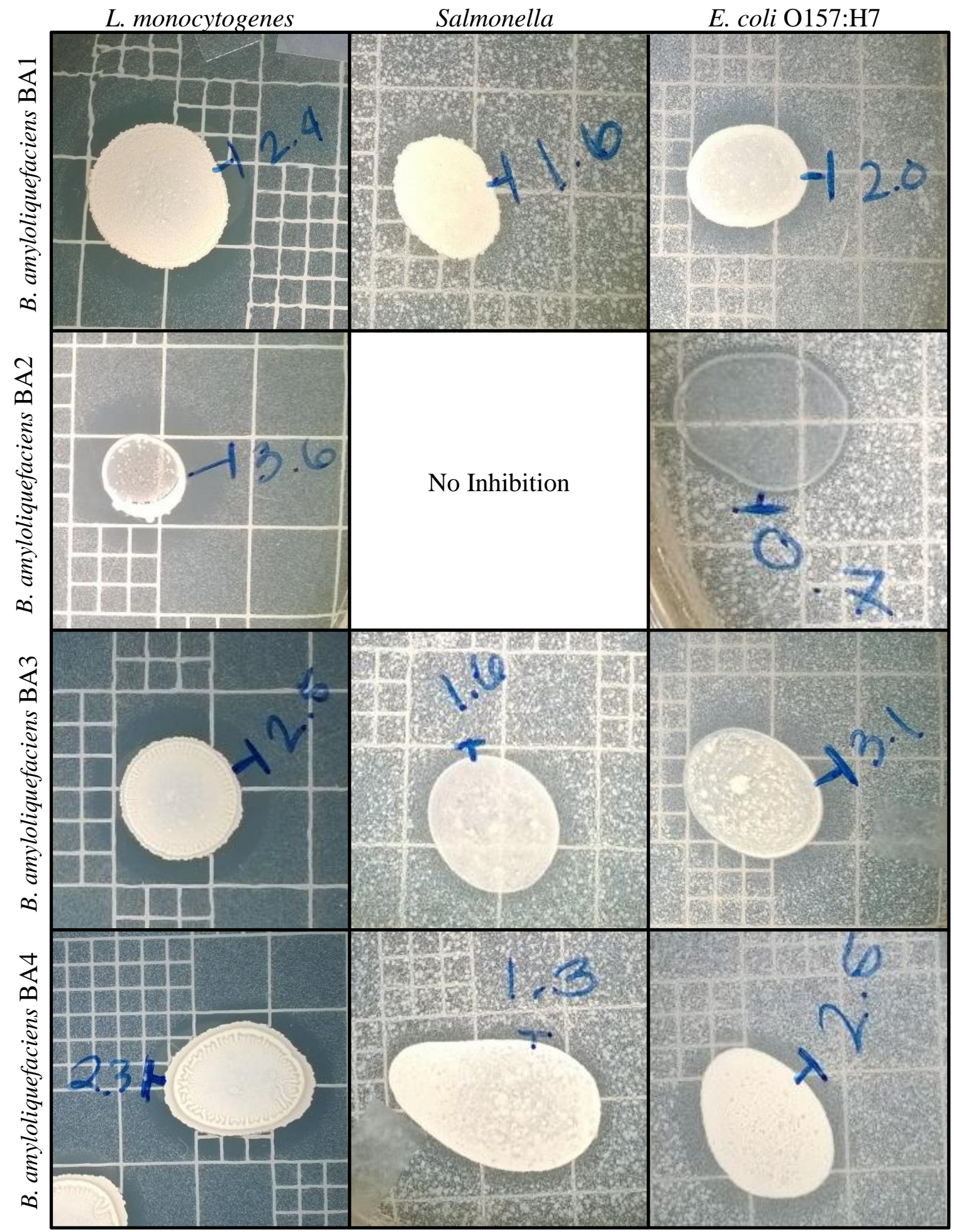




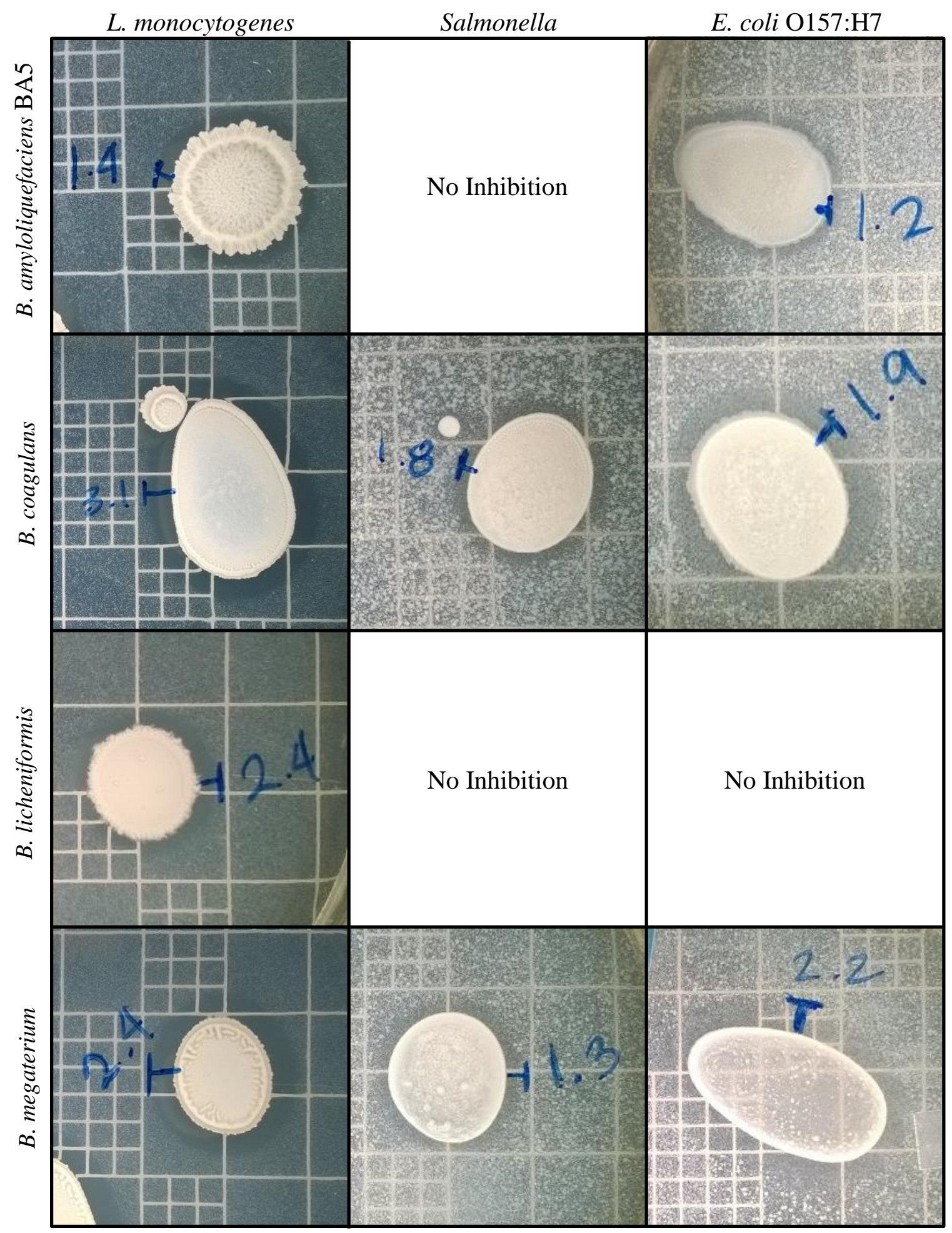




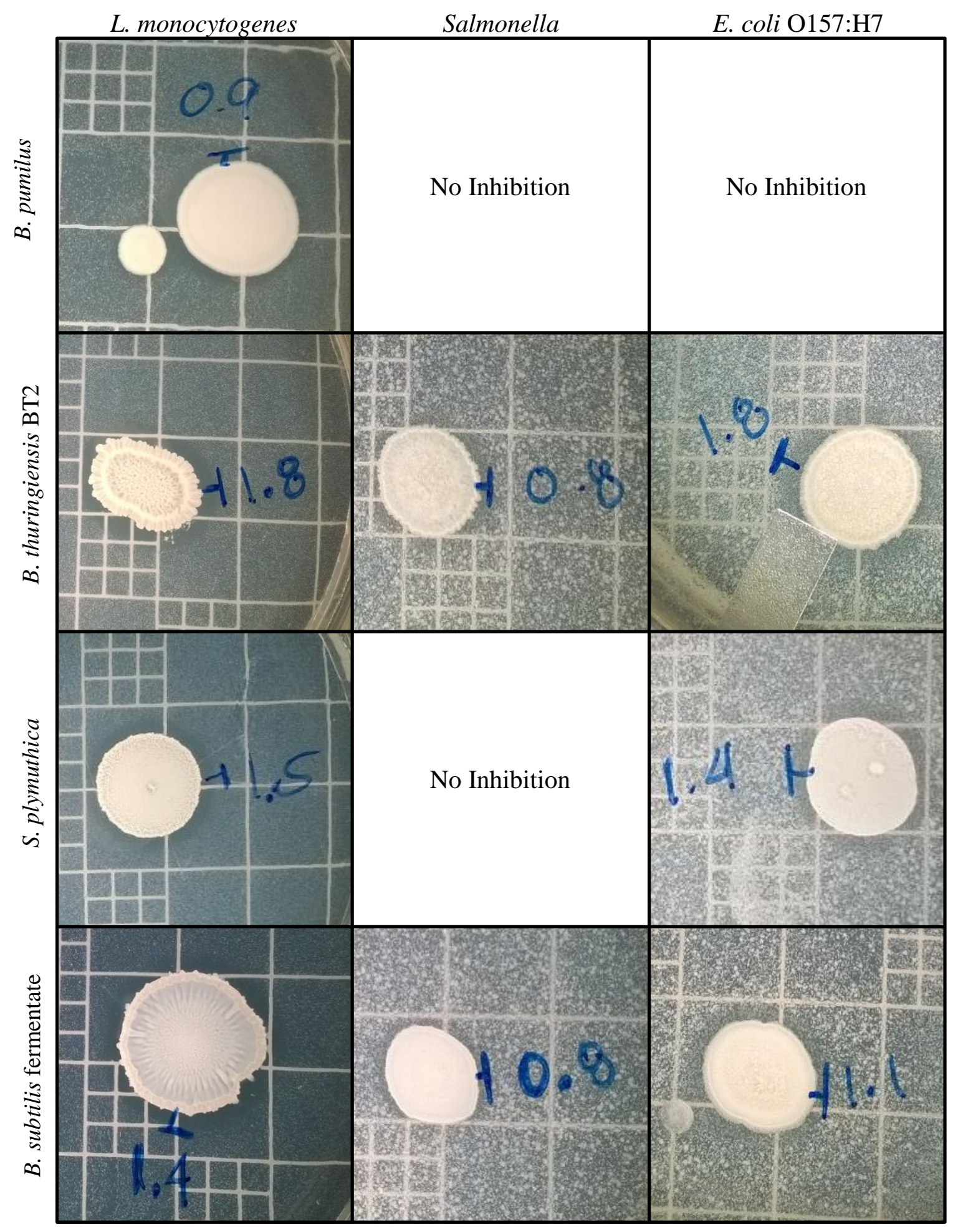


Table D1. Optical densities of Listeria monocytogenes, Salmonella, and Escherichia coli O157:H7 grown in the presence of the CFS and NCFS of Lactic Acid Bacteria isolates after $48 \mathrm{~h}^{1}$

\begin{tabular}{lccc}
\hline Treatment & OD $_{600}$ & \\
\cline { 2 - 4 } Lb. plantarum & Trial 1 & Trial 2 & Trial 3 \\
CFS/LM & & & \\
NCFS/LM & 0.125 & 0.108 & 0.108 \\
LM control & 0.412 & 0.379 & 0.376 \\
CFS/SAL & 0.547 & 0.546 & 0.555 \\
NCFS/SAL & 0.126 & 0.108 & 0.110 \\
SAL control & 1.193 & 1.117 & 0.905 \\
CFS/EC & 1.250 & 0.703 & 0.741 \\
NCFS/EC & 0.130 & 0.108 & 0.107 \\
EC control & 1.241 & 1.148 & 0.927 \\
$\boldsymbol{P .}$ acidilactici & 1.380 & 0.815 & 0.846 \\
CFS/LM & & & \\
NCFS/LM & 0.134 & 0.110 & 0.110 \\
LM control & 0.516 & 0.548 & 0.629 \\
CFS/SAL & 0.547 & 0.563 & 0.536 \\
NCFS/SAL & 0.124 & 0.110 & 0.109 \\
SAL control & 0.758 & 0.717 & 0.734 \\
CFS/EC & 1.250 & 0.706 & 0.697 \\
NCFS/EC & 0.134 & 0.108 & 0.106 \\
EC control & 0.843 & 0.780 & 0.823 \\
$\boldsymbol{P .}$ pentosaceus & 1.380 & 0.819 & 0.852 \\
CFS/LM & & & \\
NCFS/LM & 0.121 & 0.115 & 0.298 \\
LM control & 0.522 & 1.152 & 1.179 \\
CFS/SAL & 0.547 & 0.791 & 0.846 \\
NCFS/SAL & 0.124 & 0.118 & 0.273 \\
SAL control & 0.797 & 1.572 & 1.609 \\
CFS/EC & 1.250 & 1.338 & 1.345 \\
NCFS/EC & 0.124 & 0.120 & 0.250 \\
EC control & 0.929 & 1.694 & 1.512 \\
\hline S & 1.380 & 1.616 & \\
\hline
\end{tabular}

${ }^{1}$ Shaded rows indicate data sets not used in final statistical analysis.

${ }^{2}$ CFS: cell-free supernatant; NCFS: neutralized cell-free supernatant; LM: Listeria monocytogenes; SAL: Salmonella; EC: Escherichia coli O157:H7.c 